TRABALHO DE GRADUAÇÃO

\title{
PROCEDIMENTO COMPUTACIONAL PARA AVALIAÇÃO DO PROBLEMA DE COLAPSO DE TENSÃO EM SISTEMAS DE POTÊNCIA
}

Izumi Renata Santos Takada

Brasília, Dezembro de 2006

UNIVERSIDADE DE BRASÍLIA

FACULDADE DE TECNOLOGIA

DEPARTAMENTO DE ENGENHARIA ELÉTRICA 
UNIVERSIDADE DE BRASILIA

Faculdade de Tecnologia

\section{TRABALHO DE GRADUAÇÃO \\ PROCEDIMENTO COMPUTACIONAL PARA AVALIAÇÃO DO PROBLEMA \\ DE COLAPSO DE TENSÃO \\ EM SISTEMAS DE POTÊNCIA}

Izumi Renata Santos Takada

Relatório submetido como requisito parcial para obtenção do grau de Engenheiro Eletricista

Banca Examinadora

Prof. Francisco Damasceno Freitas,Dr.

UnB/ENE (Orientador)

Prof. Mauro Moura Severino, Mestre. UnB/

ENE (Examinador Interno)

Prof. Alcides Leandro da Silva, Mestre. UnB/

ENE (Examinador Interno) 
FICHA CATALOGRÁFICA

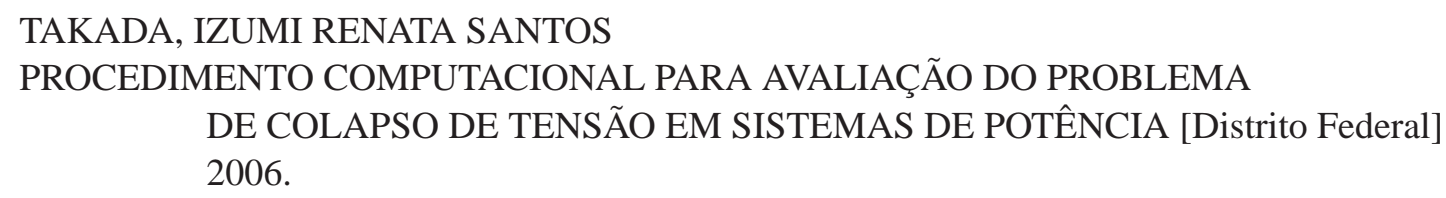

viii, 64p.(ENE/FT/UnB, Engenheiro Eletricista,2006). Monografia de Graduação -

Universidade de Brasília.Faculdade de Tecnologia.

Departamento de Engenharia Elétrica
1. Colapso de Tensão
2. Fluxo de Potência Continuado
3. Vetor Tangente
4. Fluxo de Carga
I. ENE/FT/UnB
II. Título (série)

\section{REFERÊNCIA BIBLIOGRÁFICA}

TAKADA, I. R. S.(2006). Procedimento Computacional para Avaliação do Problema de Colapso de Tensão em Sistemas de Potência. Monografia de Graduação, Publicação ENE 12/2006, Departamento de Engenharia Elétrica, Universidade de Brasília, Brasília, DF, 64p.

\section{CESSÃO DE DIREITOS}

NOME DO AUTOR: Izumi Renata Santos Takada.

TÍTULO: Procedimento Computacional para Avaliação do Problema de Colapso de Tensão em Sistemas de Potência.

GRAU / ANO:Engenheiro Eletricista / 2006

É concedida à Universidade de Brasília permissão para reproduzir cópias desta monografia de graduação e para emprestar ou vender tais cópias somente para propósitos acadêmicos e científicos. O autor reserva outros direitos de publicação e nenhuma parte desta monografia de graduação pode ser reproduzida sem a autorização por escrito do autor.

Izumi Renata Santos Takada

QI 4 Bloco E apartamento 313 - Guará 1

71010-052 Brasília - DF - Brasil. 


\section{Dedicatória}

À minha querida família, meus pais Maria Regina e Mário, e a minha irmã Sayuri.

Izumi Renata Santos Takada 


\section{Agradecimentos}

Agradeço a Deus pela fé, força e perseverança que nunca me abandonaram até aqui.

A minha preciosa família pelo amor, carinho, apoio e paciência sem limites de todos os dias, sem exceção.

Aos mestres por todos ensinamentos e lições de vida, em especial ao Professor Dr. Francisco Damasceno Freitas pela atenciosa orientação.

A todos meus amigos da Engenharia Elétrica, principalmente Marcello Sasaki, Francisco, Luíz Bianchi, Fernanda, Otávio, Samuel, Ana Ravena, Ewerton, Marcos, Thompson, Maria Clara, Luíza, Cícero, Guilherme, Renan, Rogério, Arthur e Danilo pela amizade, companhia, horas de estudo, momentos de descontração e por toda ajuda durante os últimos anos.

E também ao Edson Mintsu e ao Tiago Alves, sempre dispostos a sanarem minhas dúvidas com muita disposição.

Izumi Renata Santos Takada 
O colapso de tensão é um fenômeno preocupante nos sistemas de potência, pois sua ocorrência significa falta de energia nos centros consumidores. Este problema é caracterizado pela perda do controle da tensão em uma ou mais barras, espalhando-se pelos pontos vizinhos, de forma que a amplitude das tensões apresentam valores fora dos limites aceitáveis de operação. Na literatura, existem diferentes métodos para sua análise, com objetivo de evitá-lo. Neste trabalho, as técnicas utilizadas para o estudo do Colapso de Tensão são o Fluxo de Potência Continuado e o Método do Vetor Tangente. O resultado é uma ferramenta computacional capaz de simular o aumento de carga nos sistemas até que o ponto de colapso seja atingido, além de identificar a barra crítica e traçar curvas PV.

ABSTRACT

Voltage collapse is a worrying phenomenon in power systems, as it means a power shortage at the consumers. This problem is characterized by a voltage control loss in one of the buses, spreading through the neighbors points causing voltage to reach values out of the acceptable operational limits. There are several methods to analyse this problem in order to avoid it. In this work the techniques used to study the voltage collapse are the Continued Power Flow and the Tangent Vector Method. The result is a computational tool capable to simulatate the load increase in the system until it reaches the collapse point, identify the critic bus and trace PV curves. 


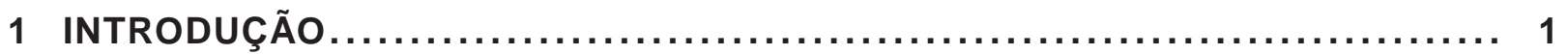

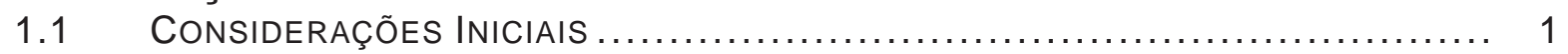

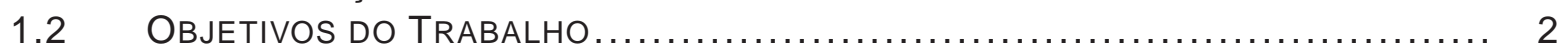

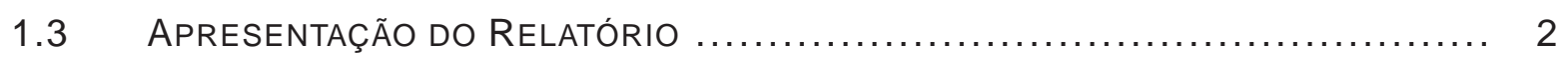

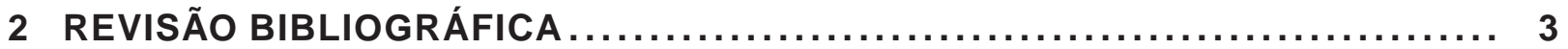

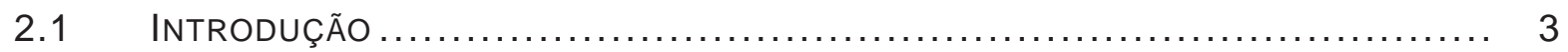

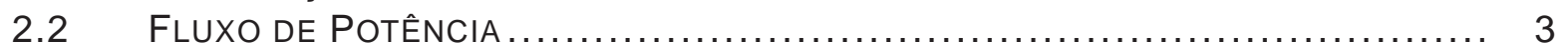

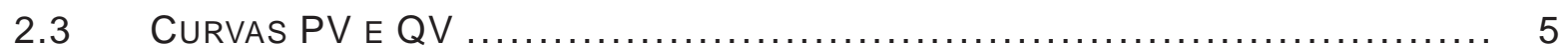

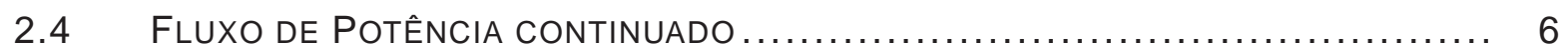

2.4.1 Passo Preditor e Passo Corretor do Fluxo de CARGa CONTINUAdo .... 7

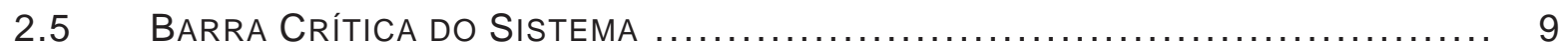

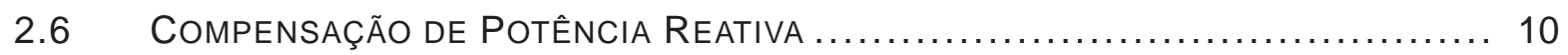

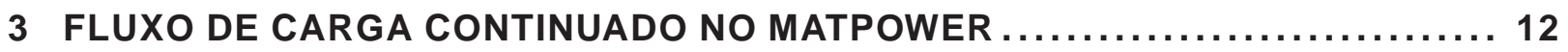

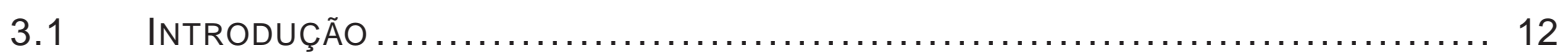

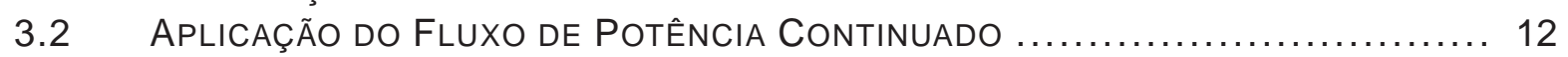

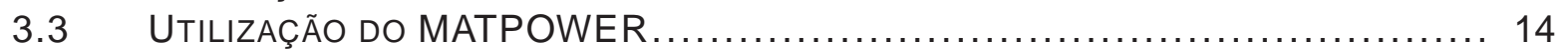

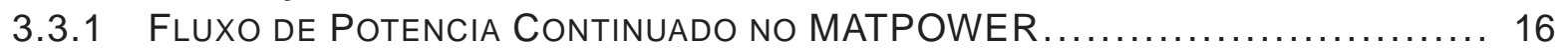

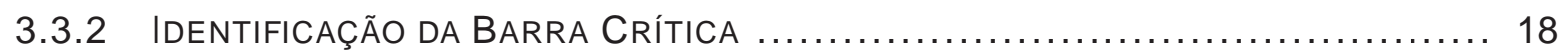

4 RESULTADOS DAS SIMULAÇÕES E TESTES COMPUTACIONAIS DO FLUXO

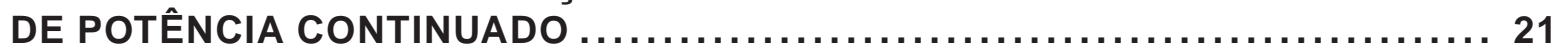

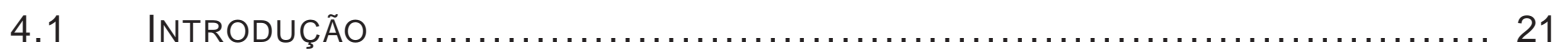

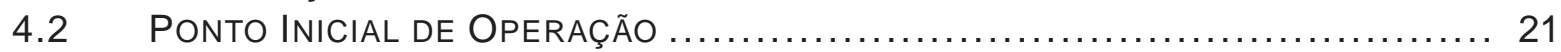

4.3 Resultado do Fluxo de PotênCIA CONTINUAdo.......................... 24

4.3.1 RESUltado do FluXo de POTÊnCIA CONTINUAdO dO Sistema 09 BARRAS.... 24

4.3.2 REsultado do FluXo de POTÊnCIA CONTINUAdO dO SISTEMA 14 BARRAS.... 26

4.3.3 Resultado do Fluxo de Potência Continuado do Sistema 57 barRas.... 29

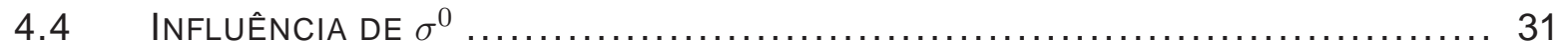

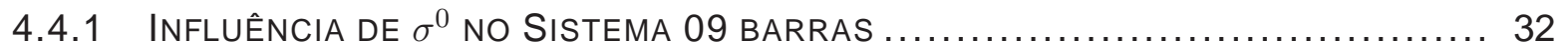

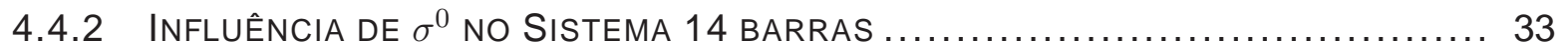

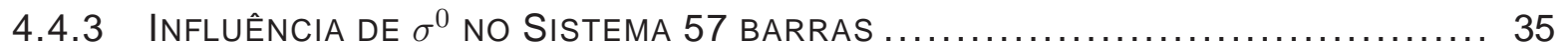

4.5 COMPENSAÇÃo de POTÊnCIA REATIVA nas BARRAS CRÍTICAS $\ldots \ldots \ldots \ldots \ldots \ldots . . \ldots$

4.5.1 Compensação de Potência Reativa na BarRas Crítica do Sistema 09

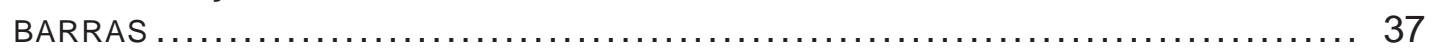

4.5.2 Compensação de PotênCia Reativa na BarRas Crítica do Sistema 14

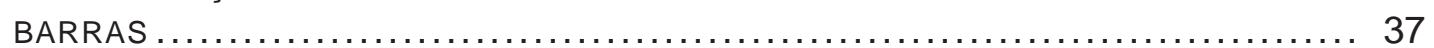

4.5.3 Compensação de Potência Reativa na BarRas Crítica do Sistema 57

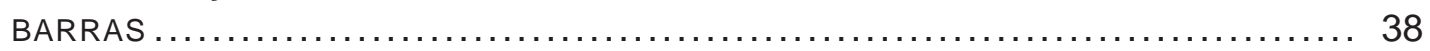

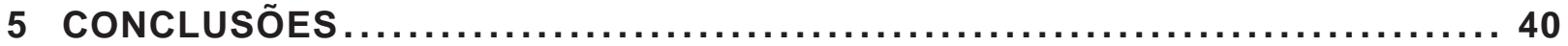

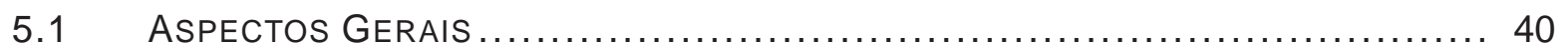

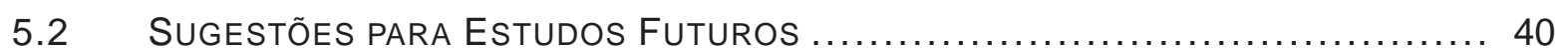

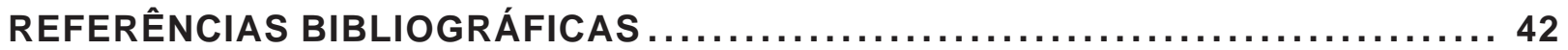


ANEXOS

I DADOS DE ENTRADA DOS SISTEMAS 09,14 E 57 BARRAS . ............... 45

I.1 DADOS DE ENTRADA DOS SISTEMAS 09 BARRAS ........................... 45

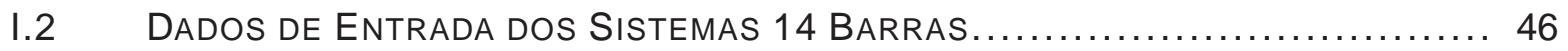

I.3 DAdOS DE ENTRADA DOS SISTEMAS 57 BARRAS ......................... 48

II PRINCIPAIS CÓDIGOS ADAPTADOS DO MATPOWER $\ldots \ldots \ldots \ldots \ldots \ldots \ldots \ldots \ldots$

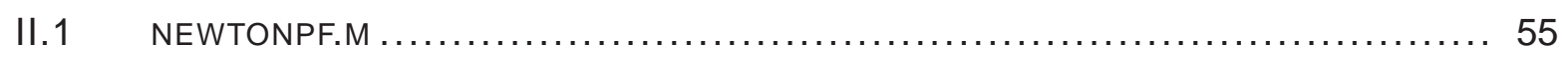

II.2 NEWTONCONTINUADO.M............................................ 59 


\section{LISTA DE FIGURAS}

2.1 Curva PV para Fator de Potência Constante .................................................... 5

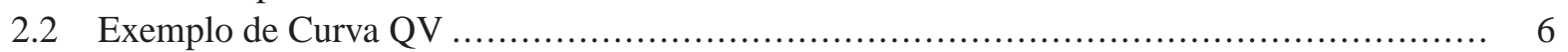

2.3 Fluxo de Potência Continuado - Passo Preditor e Corretor........................................ 9

2.4 Banco de Capacitores da Subestação São João do Piauí ........................................ 11

3.1 Diagrama de Blocos de Fluxo de Carga Continuado....................................... 12

3.2 Fluxograma do Fluxo Continuado.............................................................. 13

4.1 Curva PV do Sistema de 09 barras Após o Fluxo Continuado de Potência...................... 25

4.2 Decaimento Exponencial de $\Delta \lambda$ no Fluxo de Potência Continuado do Sistema de 09 barras. 26

4.3 Curva PV do Sistema de 14 barras Após o Fluxo Continuado de Potência...................... 28

4.4 Decaimento Exponencial de $\Delta \lambda$ no Fluxo de Potência Continuado do Sistema de 14 barras. 28

4.5 Curva PV do Sistema de 57 barras Após o Fluxo Continuado de Potência..................... 30

4.6 Decaimento Exponencial de $\Delta \lambda$ no Fluxo de Potência Continuado do Sistema de 57 barras. 31

4.7 Curva PV do Sistema de 09 barras pós o Fluxo Continuado com $\sigma^{0}=\mathbf{0 . 0 0 0 2}$. ................ 32

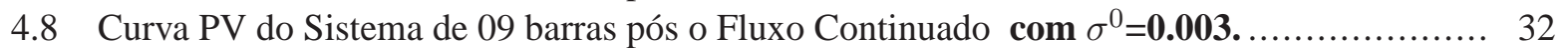

4.9 Curva PV do Sistema de 09 barras pós o Fluxo Continuado com $\sigma^{0}=\mathbf{0 . 0 0 5} \ldots \ldots \ldots \ldots \ldots \ldots \ldots \ldots$

4.10 Curva PV do Sistema de 14 barras pós o Fluxo Continuado com $\sigma^{0}=\mathbf{0 . 0 0 2 5}$................ 33

4.11 Curva PV do Sistema de 14 barras pós o Fluxo Continuado com $\sigma^{0}=\mathbf{0 . 0 1 7 5}$................ 34

4.12 Curva PV do Sistema de 14 barras pós o Fluxo Continuado com $\sigma^{0}=\mathbf{0 . 0 2} \ldots \ldots \ldots \ldots \ldots \ldots \ldots . . . \ldots \ldots$

4.13 Curva PV do Sistema de 57 barras pós o Fluxo Continuado $\operatorname{com} \sigma^{0}=\mathbf{0 . 0 0 4}$.................. 35

4.14 Curva PV do Sistema de 57 barras pós o Fluxo Continuado com $\sigma^{0}=\mathbf{0 . 0 2 5} \ldots \ldots \ldots \ldots \ldots \ldots \ldots . \ldots \ldots$

4.15 Curva PV do Sistema de 57 barras pós o Fluxo Continuado $\operatorname{com} \sigma^{0}=\mathbf{0 . 0 2 7 5}$. ............... 36

4.16 Curva PV do Sistema de 09 barras com Banco de Capacitores na Barra Crítica................ 37

4.17 Curva PV do Sistema de 14 barras com Banco de Capacitores na Barra Crítica................ 38

4.18 Curva PV do Sistema de 57 barras com Banco de Capacitores na Barra Crítica................ 39 


\section{LISTA DE TABELAS}

3.1 Resultado do Fluxo de Carga Continuado do Sistema 30 Barras.

15

3.2 Resultado do Fluxo de Carga Continuado do Sistema 30 Barras - Continuação. ............... 16

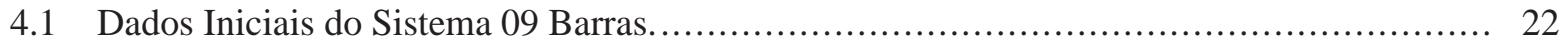

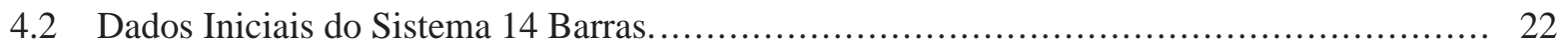

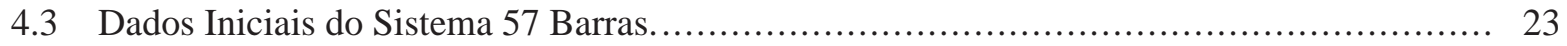

4.4 Resultado do Fluxo de Potência Continuado - Sistema 09 Barras................................ 24

4.5 Resultado do Fluxo de Potência Continuado - Sistema 14 Barras................................ 27

4.6 Resultado do Fluxo de Potência Continuado - Sistema 57 Barras............................... 29 


\section{LISTA DE SÍMBOLOS}

\section{Símbolos Latinos}

\begin{tabular}{|c|c|}
\hline Barra PQ & Barra de Carga \\
\hline Barra PV & Barra de Geração \\
\hline$B_{k m}$ & Susceptância entre a Barra k e a Barra m \\
\hline$B s$ & Susceptância Shunt \\
\hline Curva QV & Curva Potência Reativa vs Tensão \\
\hline Curva PV & Curva Potência Ativa vs Tensão \\
\hline$d$ & Operador Derivada \\
\hline$e_{k}$ & Parâmetro da Continuação \\
\hline$G_{k m}$ & Condutância entre a Barra k e a Barra m \\
\hline$G(V, \theta, \lambda)$ & Função que Representa um Conjunto de Equações em função de $V, \theta$ e $\lambda$ \\
\hline$G_{\theta}$ & Derivada Parcial de $\mathrm{G}$ em relação a $\theta$ \\
\hline$G_{V}$ & Derivada Parcial de G em relação a V \\
\hline$G_{\lambda}$ & Derivada Parcial de $\mathrm{G}$ em relação a $\lambda$ \\
\hline$H$ & Sensibilidade das Potências Ativas em relação as Fases das Barras \\
\hline$[J]$ & Matriz Jacobiana do Sistema \\
\hline$L$ & Sensibilidade das Potências Reativas em relação as Tensões das Barras \\
\hline$M$ & Sensibilidade das Potências Reativas em relação as Fases das Barras \\
\hline$M_{p}$ & Margem de Potência \\
\hline$N$ & Sensibilidade das Potências Ativas em relação as Tensões das Barras \\
\hline NB & Número de Barras do Sistema \\
\hline$P_{k}$ & Potência Ativa da Barra k \\
\hline$P_{k}^{e s p}$ & Potência Ativa Especificada na Barra k \\
\hline$P_{G k}$ & Potência Ativa Gerada na Barra k \\
\hline$P_{C k}$ & Potência Ativa da Carga na Barra k \\
\hline$Q_{k}$ & Potência Reativa da Barra k \\
\hline$Q_{k}^{e s p}$ & Potência Reativa Especificada na Barra k \\
\hline$Q_{G k}$ & Potência Reativa Gerada na Barra k \\
\hline$Q_{C k}$ & Potência Reativa da Carga na Barra k \\
\hline$S^{\max }$ & Potência Aparente co Ponto Máximo de Carregamento \\
\hline$S^{i}$ & Potência de determinado ponto de operação \\
\hline$t$ & Vetor Tangente \\
\hline$V_{k}$ & Módulo da Tensão na Barra k \\
\hline$V_{m}$ & Módulo da Tensão na Barra m \\
\hline$V^{e}$ & Tensão Estimada para Próxima Solução \\
\hline$V^{i}$ & Tensão da Solução Atual \\
\hline$Y_{\text {bus }}$ & Matriz de Admitância de Barras da Rede \\
\hline$Y_{k m}$ & Elemento da matriz de Admitância \\
\hline$Y_{i i}$ & Somatório da Admitância de Todos Rlementos Ligados a Barra k \\
\hline$Y_{i j}$ & Admitância entre a Barra k e a Barra m \\
\hline
\end{tabular}




\section{Símbolos Gregos}

d Operador Derivada Parcial

$\Delta P \quad$ Incremento de Potência Ativa

$\Delta Q \quad$ Incremento de Potência Reativa

$\Delta \theta \quad$ Desvio do Ângulo da Tensão

$\Delta V \quad$ Desvio da Magnitude da Tensão

$\Delta \lambda \quad$ Incremento do Fator de Carregamento

$\lambda \quad$ Fator de Carregamento

$\lambda_{0} \quad$ Fator de Carregamento Inicial

$\lambda^{e} \quad$ Fator de Carregamento Estimado para Próxima Solução

$\lambda^{i} \quad$ Fator de Carregamento da Solução Atual

$\sigma \quad$ Tamanho do Passo Preditor

$\sigma^{0} \quad$ Tamanho do Passo Preditor Inicial

$\theta_{k} \quad$ Ângulo da Tensão da Barra k

$\theta_{m} \quad$ Ângulo da Tensão da Barra $m$

$\theta_{k m} \quad$ Diferença de Fase Entre as Barras k e m

$\theta^{e} \quad$ Ângulo Estimado para Próxima Solução

$\theta^{i} \quad$ Ângulo da Solução Atual

$\theta p v_{i} \quad$ Variável que representa os Ângulos das Barras de Geração

$\theta p q_{i} \quad$ Variável que representa os Ângulos das Barras de Carga

\section{Variáveis}

AchaMais Rotina que identifica o elemento que ocorre mais vezes em um vetor aclamb Acumula os valores da variável $\lambda$

$b c$ İndice da Barra crítica

dlamb Variável $\Delta \lambda$

ElmtoMax Vetor que guarda a posição dos elementos máximos do vetor tangente

ENFORCE_Q_LIMS Opção do MATPOWER ${ }^{\circledR}$ Para considerar os limites de Geração reativa lamb Variável $\lambda$

$n p q \quad$ Número de Barras de Carga

npv Número de Barras de Geração

Sbus Matriz de injeção de Potência Aparente especificada nas Barras

$V a \quad$ Variável Ângulo das tensões nas Barras

$V m \quad$ Variável módulo das tensões nas Barras

$V a(p v) \quad$ Variável que representa os Ângulos das Barras de Geração

$V a(p q) \quad$ Variável que representa os Ângulos das Barras de Carga

$V m(p q) \quad$ Variável que representa a Magnitude das tensões nas Barras de Geração

$V p q_{i}$

VBarraCritica Tensão da Barra crítica

VBarraMinimo Tensão da Barra com Tensão mais baixa

VBarraMeio Tensão de um Barra de Carga aleatória 


\section{Siglas}

FACTS

FC

IEEE

MATLAB ${ }^{\circledR}$

MATPOWER ${ }^{\circledR}$

PMC

SEPs

SIN

TVI
Flexible AC Transmisson Systems

Fluxo de Carga

Instituto de Engenheiros Eletricistas e Eletrônicos

MATrix LABoratory - Software de alta performance voltado para o cálculo numérico.

Pacote de arquivos . m do MATLAB ${ }^{\circledR}$ para simulação do Fluxo de Potência

Ponto Máximo de Carregamento

Sistemas Elétricos de Potência

Sistema Interligado Nacional

Índice do Vetor Tangente 


\section{INTRODUÇÃO}

Este capítulo apresenta a principal motivação deste trabalho de graduação, bem como seus objetivos e também a seqüência em que os tópicos serão abordados.

\subsection{CONSIDERAÇÕES INICIAIS}

Atualmente, os Sistemas Elétricos de Potência (SEP), em especial o Sistema Interligado Nacional (SIN), tendem a funcionar nos limites de operação. Isso ocorre devido à expansão contínua de carga nos centros consumidores, associada às restrições ambientais e econômicas para construção de novas usinas geradoras de energia elétrica e à expansão de linhas de transmissão. Conseqüentemente, as redes de transmissão e distribuição vêm enfrentando problemas críticos de instabilidade de tensão, principalmente o afundamento e o colapso de tensão, que podem culminar na interrupção do fornecimento de energia.

O colapso de tensão é caracterizado pelo declínio na tensão de uma ou mais barras seguido da perda de controle da tensão monitorada. Trata-se de um fenômeno local que se espalha pelas barras vizinhas, podendo ser iniciado pela falta de uma linha de transmissão ou de um gerador, ou então através de sucessivas pertubações [1].

Inúmeros são os trabalhos a respeito da estabilidade de tensão e do colapso de tensão, apresentando sempre o mesmo foco: a qualidade da tensão de suprimento, porém com técnicas diferentes em sua abordagem. Entre estas técnicas, os principais temas escolhidos aqui foram o fluxo de carga continuado e o Método do Vetor Tangente.

Os métodos convencionais de fluxo de carga são considerados inapropriados para se obter o Ponto Máximo de Carregamento (PMC) por causa da singularidade da Matriz Jacobiana nas proximidades do ponto de colapso. Neste caso, o fluxo de carga continuado apresenta-se como uma ferramenta eficiente, pois permite a obtenção de todas as soluções reais do fluxo de Potência e a margem de carga do sistema, utilizando técnicas iterativas de parametrização que evitam a singularidade da Matriz Jacobiana. Além disso, ao atingir o PMC é possível encontrar as margens de estabilidade, traçar as curvas PV e QV, e obter informações para determinação de medidas efetivas de reforço, prevenindo problemas futuros [2, 3]. Complementarmente, durante o fluxo continuado, o método do vetor tangente identifica a barra crítica do sistema, determinando a localização exata dos pontos que necessitam atenção especial. 


\subsection{OBJETIVOS DO TRABALHO}

O presente trabalho oferece uma pequena contribuição para o estudo do problema de colapso de tensão. O estudo será baseado na análise estática de instabilidade de tensão, explorando o fluxo de potência continuado, o vetor tangente, a barra crítica do sistema, curvas PV e a compensação de potência reativa.

\subsection{APRESENTAÇÃO DO RELATÓRIO}

No capítulo 2, são revistos os principais conceitos sobre a avaliação do comportamento da magnitude das tensões em um SEP quando é submetido a um aumento progressivo de carga. Em seguida, o capítulo 3 descreve a metodologia para o desenvolvimento de um algoritmo que realiza os procedimentos e cálculos necessários para execução do fluxo de carga continuado, a partir do programa MATPOWER. Os resultados das simulações computacionais da rotina criada no capítulo3 são apresentados no capítulo 4, seguido das conclusões e sugestões para estudos futuros no capítulo 5. Os anexos contém o material complementar necessário. 


\section{REVISÃO BIBLIOGRÁFICA}

Conceitos básicos sobre o Fluxo de Potência, Curvas PV e QV, Fluxo de Potência Continuado, Barra Crítica do Sistema e Compensação de Potência Reativa serão apresentados aqui.

\subsection{INTRODUÇÃO}

Uma maneira de analisar um SEP é variar progressivamente sua carga, monitorando-se a tensão em cada barra e o fluxo de potência nos ramos do circuito. Para isso pode-se aplicar o Fluxo de Potência continuado. O entendimento e o sucesso do método da continuação associado ao fluxo de carga necessitam de alguns conceitos simples e conhecidos, como a formulação do fluxo de potência, as curvas PV e QV e o vetor tangente, que serão apresentados neste capítulo. Além disso, serão mostradas algumas considerações sobre a barra crítica do sistema e a idéia básica sobre a compensação de potência reativa, exemplificando a utilidade do fluxo de potência continuado.

\subsection{FLUXO DE POTÊNCIA}

A solução do fluxo de potência, ou Fluxo de Carga (FC) de um sistema elétrico de potência é fundamental para sua operação, pois fornece o perfil de tensões e ângulos em toda rede, ajuste de tap dos transformadores, carregamento dos equipamentos e interligações, perdas do sistema e também a potência reativa fornecida ou absorvida pelos geradores.

A injeção de potência em determinada barra do sistema (barra k) depende da magnitude das tensões e da diferença entre as fases desta barra e aquelas que estão conectadas à ela. Além disso, em cada barra pode haver geração ou absorção de energia (carga), de forma que a potência injetada, ou potência especificada, na barra é a diferença entre a potência (ativa ou reativa) gerada e a potência absorvida, ou seja:

$$
\begin{gathered}
P_{k}^{e s p}=P_{G k}-P_{C k} \\
Q_{k}^{e s p}=Q_{G k}-Q_{C k}
\end{gathered}
$$

$P_{G k}$ e $Q_{G k}$ são as potências ativa e reativa geradas, enquanto que $P_{C k}$ e $Q_{C k}$ são as potências ativa e reativa da carga, respectivamente. 
As equações básicas do FC são [4]:

$$
\begin{aligned}
& P_{k}^{e s p}=V_{k} \sum_{m=1}^{N B} V_{m}\left[G_{k m} \cos \theta_{k m}+B_{k m} \operatorname{sen} \theta_{k m}\right]=P_{k}(V, \theta) \\
& Q_{k}^{e s p}=V_{k} \sum_{m=1}^{N B} V_{m}\left[G_{k m} \operatorname{sen} \theta_{k m}-B_{k m} \cos \theta_{k m}\right]=Q_{k}(V, \theta)
\end{aligned}
$$

Onde:

NB é o número de barras do sistema.

$\theta_{k m}$ é a diferença de fase entre as barras $\mathrm{k}$ e $\mathrm{m}$.

$G_{k m}$ e $B_{k m}$ são a condutância e a susceptância, respectivamente, do elemento $Y_{k m}$ da matriz de admitância de barras da rede $Y_{b u s}$, que é igual à:

$$
Y_{\text {bus }}=\left\{\begin{array}{l}
Y_{i i}=\sum Y_{k m} \rightarrow \text { Somatório de todos elementos ligados a barra } k \\
Y_{i j}=-Y_{k m} \rightarrow \text { Admitância entre a barra } k \text { e a barra } m
\end{array}\right.
$$

O número de equações e icógnitas do FC depende da caracterização das barras do sistema, pois barras de carga fornecem duas equações $\left(P_{k}\right.$ e $\left.Q_{k}\right)$, barras de geração fornecem uma equação $\left(P_{k}\right)$ e a barra swing (ou barra de referência) não fornece equações.

O conjunto de equações 2.3 e 2.4 é escrito da seguinte maneira:

$$
\begin{aligned}
& 0=-P_{k}^{e s p}+V_{k} \sum_{m=1}^{N B} V_{m}\left[G_{k m} \cos \theta_{k m}+B_{k m} \operatorname{sen} \theta_{k m}\right]=\Delta P_{k}(V, \theta) \\
& 0=-Q_{k}^{e s p}+V_{k} \sum_{m=1}^{N B} V_{m}\left[G_{k m} \operatorname{sen} \theta_{k m}-B_{k m} \cos \theta_{k m}\right]=\Delta Q_{k}(V, \theta)
\end{aligned}
$$

Para calcular os estados, ou seja as fases $\theta_{i}$ e tensões $V_{i}$, do sistema de equações não-lineares acima, é necessária a aplicação do método de Newton-Raphson. Neste método, uma determinada função é expandida em uma série de Taylor no ponto de operação escolhido considerando apenas a parte linear da série, ou seja, os termos de ordem superior são desconsiderados. Com um processo iterativo, as raízes são determinadas calculando-se seus incrementos a cada iteração a partir de um ponto inicial arbitrário, até que se alcance o resultado dentro da tolerância estabelecida.

Quando o Método de Newton-Raphson é aplicado ao problema do fluxo de potência, devem-se calcular os desvios $\Delta \theta$ e $\Delta V$, da seguinte forma:

$$
\left[\begin{array}{c}
\Delta P \\
\Delta Q
\end{array}\right]=-[J]\left[\begin{array}{c}
\Delta \theta \\
\Delta V
\end{array}\right]
$$




$$
\left[\begin{array}{c}
\Delta \theta \\
\Delta V
\end{array}\right]=-[J]^{-1}\left[\begin{array}{c}
\Delta P \\
\Delta Q
\end{array}\right]
$$

A matriz Jacobiana do sistema $[J]$ é igual à:

$$
[J]=\left[\begin{array}{ll}
\frac{\partial P(\theta, V)}{\partial \theta} & \frac{\partial P(\theta, V)}{\partial V} \\
\frac{\partial Q(\theta, V)}{\partial \theta} & \frac{\partial Q(\theta, V)}{\partial V}
\end{array}\right]=\left[\begin{array}{cc}
H & N \\
M & L
\end{array}\right]
$$

Em que:

$H$ é a sensibilidade das potências ativas em relação aos ângulos das barras

$N$ é a sensibilidade das potências ativas em relação às tensões das barras

$M$ é a sensibilidade das potências reativas em relação aos ângulos das barras

$L$ é a sensibilidade das potências reativas em relação às tensões das barras [4].

\subsection{CURVAS PV E QV}

Duas ferramentas bastante utilizadas para caracterizar um SEP, principalmente tratando-se do estudo de estabilidade de tensão, são as curvas PV e QV devido à sua confiabilidade e facilidade de aquisição. Ambas as curvas determinam a capacidade de carga do sistema em relação à tensão, indicando as regiões estáveis ou instáveis de operação, e a robustez do sistema. Por isso, com auxílio de tais curvas é possível determinar os locais sujeitos ao problema de instabilidade de tensão, além de ações corretivas e preventivas para fortalecer os pontos que necessitam de algum tipo de reforço.

Para traçar uma curva PV, apelidada de "curva do nariz", aumenta-se o carregamento do sistema com fator de potência constante, calculando o valor de tensão na mesma barra até que o ponto máximo de carregamento seja atingido, que representa o limite máximo de transmissão (ponto de colapso). A região da curva acima do ponto de colapso indica os pontos de operação satisfatória, enquanto que os pontos abaixo estão na região instável de operação, ou solução falsa. Assim, existem dois valores possível de tensão para cada carga.

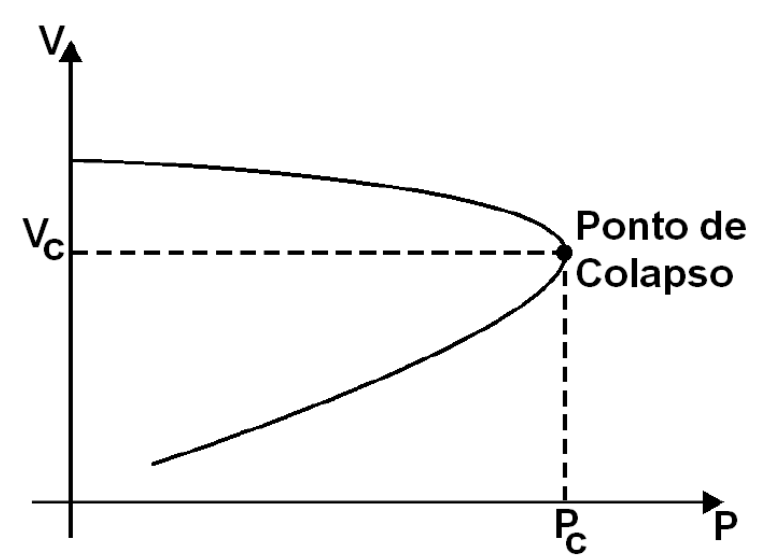

Figura 2.1: Curva PV para Fator de Potência Constante [5]. 
A curva QV é usada com frequiência na análise de sensibilidade de tensão para uma dada potência injetada, ou seja, mostra as variações da tensão em relação a uma mudança na potência reativa gerada na barra, além de ser fundamental para o cálculo de compensação de potência reativa.

Dada uma curva $Q V$, a região estável de operação encontra-se à direita do ponto crítico $\left(\frac{\partial Q}{\partial V}>0\right)$, enquanto que a região instável, à esquerda do mesmo ponto $\left(\frac{\partial Q}{\partial V}<0\right)$. Por exemplo, na figura a seguir, o ponto $A$ está na região estável, pois um aumento em $Q$ resultará em uma tensão mais alta. Já o ponto $B$ é instável, pois ao incrementar $Q$ a tensão será mais baixa.

A curva QV também informa a Margem de Potência Reativa do sistema, que é a distância entre um determinado ponto de operação e o ponto de mínimo da curva [1].

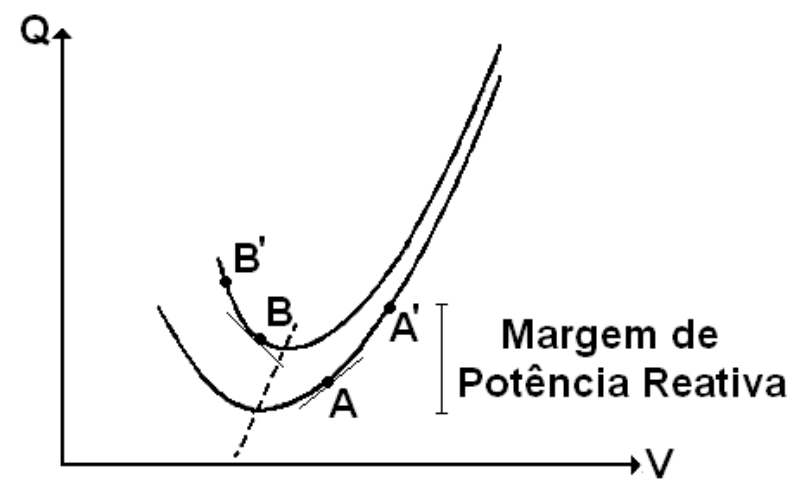

Figura 2.2: Exemplo de Curva QV

\subsection{FLUXO DE POTÊNCIA CONTINUADO}

O cálculo do fluxo de potência convencional apresentado anteriormente não é interessante na análise estática de instabilidade de tensão, pois para traçar as curvas PV e QV é necessário executar um número grande de fluxos de potência, o que pode consumir bastante tempo e também não indica as verdadeiras causas do problema da instabilidade. Além disso, neste procedimento, o carregamento ocorre em algumas barras individuais, diferentemente do que ocorre na realidade e ainda, as barras devem ser escolhidas cuidadosamente, traçando-se várias curvas PV e PQ para obter informações completas [6].

No entanto, o principal problema do FC convencional na questão da instabilidade de tensão é a divergência do fluxo no PMC do sistema devido à não singularidade da matriz Jacobiana neste ponto. Por isso, são aplicados métodos de continuação ao problema do fluxo de potência que possibilitam a obtenção completa do perfil das barras, à medida que se varia o carregamento [7].

No fluxo de carga continuado, o fator de carregamento $\lambda$ é responsável por conduzir um SEP de um 
ponto de equilíbrio estável para outro. Este parâmetro é acrescido às equações do fluxo de potência convencional, da seguinte maneira:

$$
\left.\begin{array}{l}
\lambda P^{e s p}-P(\theta, V)=0 \\
\lambda Q^{e s p}-Q(\theta, V)=0
\end{array}\right\}=G(V, \theta, \lambda)=0
$$

A parametrização utilizando $\lambda$ pode representar variáveis com significado físico claro, como por exemplo a tensão $V_{k}$, onde a barra k é a barra crítica do sistema, ou então a perda total de potência ativa e reativa na barra de referência ou nas barras de geração [2]. Neste trabalho, $\lambda$ será considerado um incremento nas potências ativa e reativa das cargas, acompanhado pelo aumento correspondente na geração.

A solução do conjunto de equações 2.11 é alcançada, para diferentes valores de $\lambda$, seguindo o princípio geral do Fluxo de Potência continuado: o esquema preditor-corretor.

\subsubsection{Passo Preditor e Passo Corretor do Fluxo de Carga continuado}

A função do passo preditor é encontrar um ponto aproximado para solução seguinte. Existem diferentes técnicas de previsão encontradas na literatura, entre estas as mais populares estão a do preditor secante, e principalmente a do previsor tangente, que será discutida no presente trabalho. A técnica do vetor tangente consiste em dar um passo de tamanho apropriado na direção tangente do caminho da solução. O vetor tangente $t$ é calculado derivando-se as equações do fluxo de carga continuado [2].

$$
d[G(\theta, V, \lambda)]=G_{\theta} d \theta+G_{V} d V+G_{\lambda} d \lambda=0
$$

ou

$$
\left[\begin{array}{lll}
G_{\theta} & G_{V} & G_{\lambda}
\end{array}\right] \cdot\left[\begin{array}{c}
d \theta \\
d V \\
d \lambda
\end{array}\right]=\left[\begin{array}{ll}
J & G_{\lambda}
\end{array}\right] \cdot t=0
$$

onde:

$$
G_{\theta}=\left[\begin{array}{c}
\frac{\partial P}{\partial \theta} \\
\frac{\partial Q}{\partial \theta}
\end{array}\right] \quad G_{V}=\left[\begin{array}{c}
\frac{\partial P}{\partial V} \\
\frac{\partial Q}{\partial V}
\end{array}\right] \quad G_{\lambda}=\left[\begin{array}{c}
P^{e s p} \\
Q^{e s p}
\end{array}\right]
$$

Uma vez que $\lambda$ foi inserido nas equações do FC, conforme 2.11, o número de icógnitas é maior que o número de equações, por isso é necessário mais uma equação para solucionar o sistema. Neste sentido, uma variável do vetor tangente $t$ deve ser especificada com valor diferente de zero, que é chamada de parâmetro da continuação. Uma nova equação $\left(e_{k} \cdot t=t_{k}= \pm 1\right)$ é acrescida ao conjunto de equações 2.13, 
da seguinte forma:

$$
\left[\begin{array}{ccc}
G_{\theta} & G_{V} & G_{\lambda} \\
& e_{k} &
\end{array}\right] \cdot\left[\begin{array}{c}
d \theta \\
d V \\
d \lambda
\end{array}\right]=\left[J_{a}\right] . t=\left[\begin{array}{c}
0 \\
\pm 1
\end{array}\right]
$$

Em outras palavras, a seguinte equação foi adicionada ao problema:

$$
\lambda=\lambda_{0}+\Delta \lambda
$$

em que:

$$
\frac{\partial \Delta \lambda}{\partial \lambda}=1
$$

Assim, $\lambda$ é incrementado a cada iteração, começando pelo caso base (igual ao fluxo de carga convencional) em que $\lambda_{0}=1$ e $\Delta \lambda=0$.

A matriz Jacobiana aumentada $J_{a}$ é a composição da matriz Jacobiana convencional com os vetores $G_{\lambda}$ e $e_{k}$. O vetor $e_{k}$ é uma linha com todos elementos nulos, exceto o k-ésimo, que é igual à 1 (ou -1, quando o parâmetro representa um variável que diminui). A escolha do índice $\mathrm{k}$ deve ser tal que o vetor $t$ tenha norma diferente de zero, e garanta que $J_{a}$ não seja singular no PMC. Com isso, é possível calcular o vetor $t$ e a estimativa para próxima solução será:

$$
\left[\begin{array}{c}
\theta^{e} \\
V^{e} \\
\lambda^{e}
\end{array}\right]=\left[\begin{array}{c}
\theta^{i} \\
V^{i} \\
\lambda^{i}
\end{array}\right]+\sigma\left[\begin{array}{c}
d \theta \\
d V \\
d \lambda
\end{array}\right]
$$

o sobrescrito $e$ significa estimativa e $i$ é a solução atual [2].

O escalar $\sigma$ define o tamanho do passo preditor de maneira que a solução prevista esteja dentro do raio de convergência do passo corretor. O controle do passo afeta a eficiência computacional do método, pois na condição de carga leve, $\sigma$ pequeno resultará em poucas mudanças no ponto de operação, exigindo um passo $\sigma$ relativamente grande, já na região próxima ao ponto de colapso (carga pesada), $\sigma$ deve ser pequeno para que a estimativa não se encontre fora da solução.

O método de controle do tamanho do passo utilizado aqui é baseado no vetor tangente normalizado, ou seja:

$$
\sigma=\frac{\sigma^{0}}{\|t\|_{2}}
$$

em que $\|t\|_{2}$ é a norma Euclidiana do vetor tangente $t$ e $\sigma^{0}$ é um escalar pré-definido. A eficiência e o resultado do método são dependentes da escolha inicial de $\sigma^{0}$, geralmente bons resultados são atingidos 
com valores pequenos $\sigma^{0}$ que são determinados empiricamente, pois são diferente para cada sistema. E a medida que o sistema torna-se carregado, a magnitude do vetor tangente aumenta e $\sigma$ diminui [2].

Caso $\sigma$ seja fixado em 1, tem-se o chamado "traço normal", se $\sigma>1$ ou $\sigma<1$, o traço é rápido ou lento, respectivamente [8].

Depois que a etapa preditora produziu uma estimação para a solução seguinte $\left[\theta^{e} V^{e} \lambda^{e}\right]^{T}$, é preciso corrigir o erro. Qualquer método numérico pode ser usado como corretor. Usualmente, inclusive neste trabalho, é utilizado o próprio método de Newton-Raphson para solucionar o fluxo de potência que utiliza a estimativa como ponto de partida [9]. A figura a seguir exemplifica o mecanismo do fluxo de potência continuado.

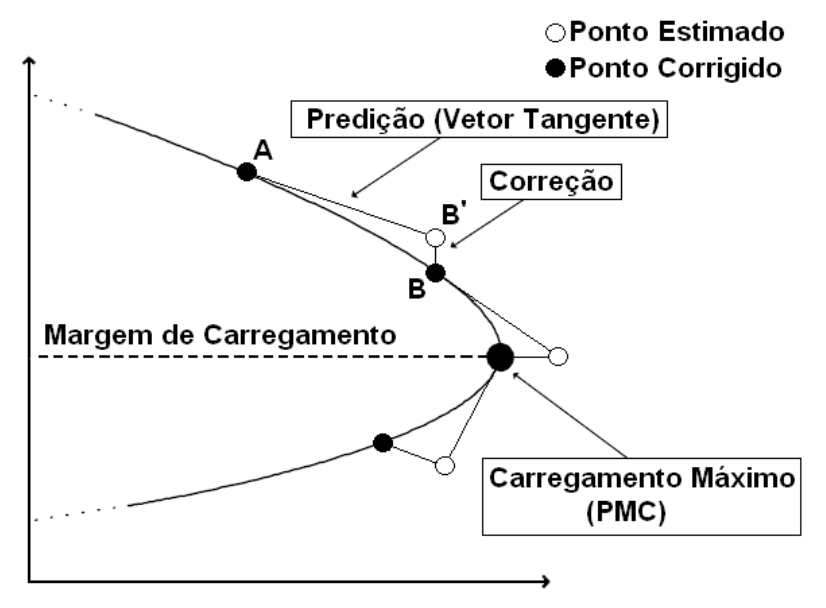

Figura 2.3: Fluxo de Potência Continuado - Passo Preditor e Corretor [7].

\subsection{BARRA CRÍTICA DO SISTEMA}

Do ponto de vista da segurança de tensão, barras críticas são:

i) aquelas para quais a transmissão de potência ativa e reativa se encontra perto do máximo permissível,

ii) aquelas onde ações de controle de tensão podem ter conseqüências opostas ao esperado, e

iii) aquelas que apresentam maior sensibilidade devido à uma perturbação no sistema.

A identificação da barra crítica é fundamental na análise do colapso de tensão, pois uma vez detectada sua existência é recomendada a aplicação de ações de controle para tornar as condições de segurança mais severas, aumentando a distância da carga da barra crítica até o (novo) máximo permitido. Muitas vezes isso 
pode ser conseguido através da alteração do perfil de tensão e, conseqüentemente, da redução de perdas, ou então é necessário o redespacho de potência ativa.

A barra crítica do sistema não significa a barra que apresenta menor tensão, mas sim aquela cuja tensão tem maior variação quando ocorre aumento de carga, decrescendo mais rapidamente. Em outras palavras, é onde a tensão "afunda primeiro". Nos casos mais extremos, representa o ponto inicial de um processo evolutivo de desligamentos de carga em cascata, conhecido por efeito dominó.

Atualmente, na literatura existem alguns índices que indicam a barra crítica e a proximidade do colapso de tensão, como o Índice baseado nos Fluxos de Potência, o Índice que leva em conta a Máxima Transferência de Potência, ou o Índice que considera os Fluxos de Potência Ativa e Reativa [9]. Também é possível utilizar a Margem de Potência, que é a diferença de potência entre o ponto de operação e o PMC $\left(M_{p}=S^{\max }-S^{i}\right)$, identificando o Caminho de Transmissão mais carregado, em seguida o Ramo de Transmissão Crítico e finalmente a barra crítica [5].

Neste trabalho, será utilizado o método do vetor tangente para encontrar a barra crítica do sistema, visto que o vetor $t$ da equação 2.15 contém informações importantes de como as variáveis de estado são afetadas pelo aumento do parâmetro de carga $\lambda$. A vantagem do método do vetor tangente é a identificação precoce da barra crítica, diferentemente dos outros índices de colapso de tensão [8].

Para isso, deve-se considerar apenas os elementos do vetor tangente referentes às tensões nas barras de carga. Aquele que apresentar maior valor em módulo será correspondente a barra crítica [1]. O índice $c$ da barra crítica será:

$$
c \leftarrow \max \left\{\left|\frac{\partial V_{1}}{\partial \lambda}\right|,\left|\frac{\partial V_{2}}{\partial \lambda}\right|, \ldots\left|\frac{\partial V_{n}}{\partial \lambda}\right|\right\}
$$

Outra forma conhecida de identificar a barra crítica do sistema é pelo Índice do Vetor Tangente (TVI) dado por:

$$
T V I_{i}=\left|\frac{d V i}{d \lambda}\right|^{-1}
$$

Para a barra crítica (índice i), o TVI $\rightarrow 0$ no ponto do colapso pois $\left|\frac{d V i}{d \lambda}\right| \rightarrow \infty[10]$.

\subsection{COMPENSAÇÃO DE POTÊNCIA REATIVA}

A compensação de potência reativa em SEPs é uma maneira consagrada e eficiente de aumentar a capacidade de transmissão e a estabilidade de tensão. Trata-se de balancear a potência reativa gerada ou consumida pelas linhas de transmissão, já que capacitâncias em paralelo produzem potência reativa 
proporcional ao quadrado da tensão e aproximadamente constante, enquanto que indutâncias em série consomem potência reativa proporcional ao quadrado da corrente e variável [11]. Além disso, o problema do colapso de tensão está associado a tensões muito baixas, de modo que uma ação de controle que eleva a tensão nas barras como a compensação de reativos ajuda a evitar este tipo de problema, aumentar a capacidade de carga do sistema e reduzir as perdas de potência ativa.

As formas mais comuns de compensação de reativos são bancos de capacitores em série, banco de capacitores ou reatores em paralelo e, mais recentemente, os FACTS (Flexible AC Transmisson Systems) que além da compensação de reativos também controlam o fluxo de potência na linha. Cada forma de compensação possui vantagens e desvantagens em relação a sua complexidade ou simplicidade, desempenho e custo de implantação, operação e manutenção.

Neste trabalho, serão feitos testes simulando a compensação de potência reativa utilizando-se bancos de capacitores em paralelo nas barras críticas dos sistemas analisados, devido à sua simplicidade, baixo custo e bons resultados.

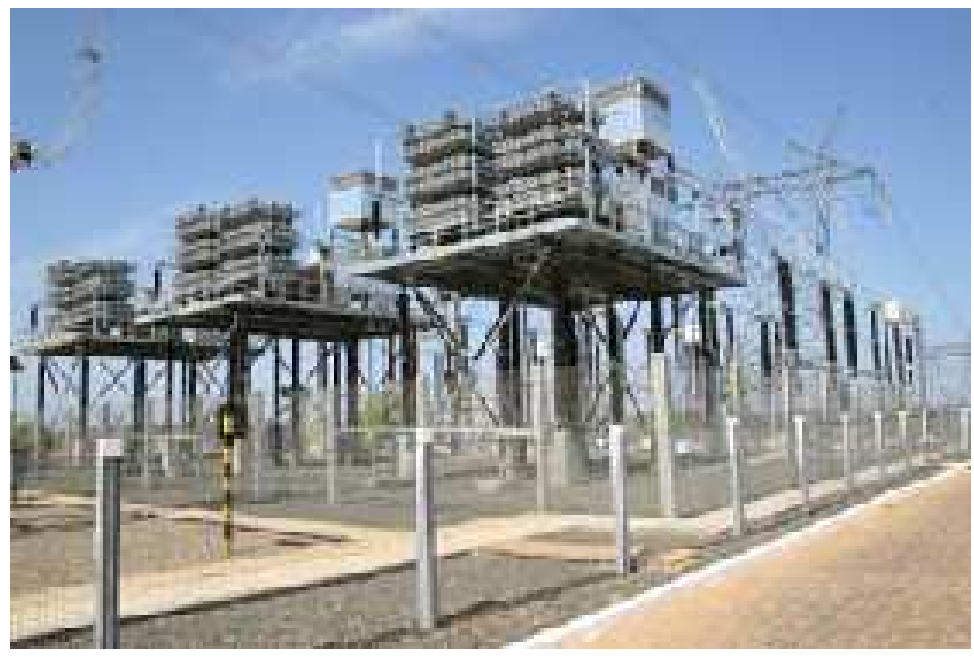

Figura 2.4: Banco de Capacitores da Subestação São João do Piauí [12]. 


\title{
3 FLUXO DE CARGA CONTINUADO NO MATPOWER
}

\author{
O presente capítulo apresenta os procedimentos \\ necessários para o cálculo do fluxo de potência \\ continuado e a identificação da barra crítica.
}

\subsection{INTRODUÇÃO}

Para simular o aumento de carga de um SEP de forma confiável, utiliza-se o método da continuação. Neste procedimento, é necessário acrescentar ao conjunto de equações do FC uma icógnita e uma equação para executar a etapa preditora e corretora, seguindo alguns passos vistos do capítulo anterior. Este capítulo mostra como o fluxo de carga continuado pode ser implementado e como seus conceitos são aplicados, exemplificando seu funcionamento. Além disso, há informações sobre a identificação da barra crítica do sistema pelo método do vetor tangente, e como são traçadas as curvas PV após obter o resultado do fluxo continuado.

\subsection{APLICAÇÃO DO FLUXO DE POTÊNCIA CONTINUADO}

A partir de um código, rotina ou programa que apresente o resultado do fluxo de carga de um sistema, é possível aplicar o fluxo de potência continuado, desde o processo utilizado seja acessível. É necessário conhecer como o problema é formulado, ou seja, como os dados de entrada (características das barras, geradores, linhas, cargas, áreas...) são recebidos e rearranjados, e também o quê é considerado variável ou constante nos cálculos. Além disso, é preciso verificar como os dados de saída são informados para apresentar os resultados do fluxo continuado de forma coerente. Lembrando que não importa como o fluxo de potência convencional é executado e qual método é utilizado, basta que seus resultados sejam verdadeiros.

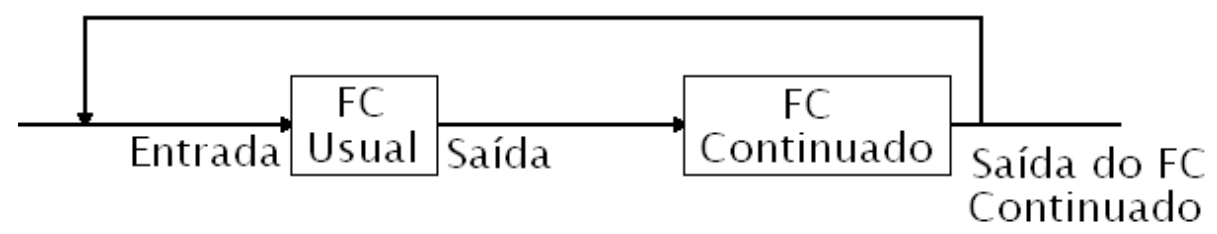

Figura 3.1: Diagrama de Blocos de Fluxo de Carga Continuado.

No problema do FC usual, é necessário conhecer a potência especificada das barras de geração e das barras de carga para montar a Matriz Jacobiana Aumentada da equação 2.15, após a solução do fluxo de potência usual. Em seguida deve-se calcular o vetor tangente $t$ e o tamanho do passo preditor $\sigma$ (equação 
2.19). Ao multiplicar $t$ por $\sigma$, tem-se o incremento das variáveis que devem ser somados a solução inicial do fluxo (equação 2.18). O próximo ponto do conjunto de soluções será encontrado a partir de tais valores, juntamente com a carga multiplicada pelo carregamento, acompanhado pela geração correspondente.

Assim, para executar o método da continuação é criado um laço maior englobando o fluxo usual até que não exista mais solução para o carregamento em questão. Este mecanismo é detalhado a seguir:

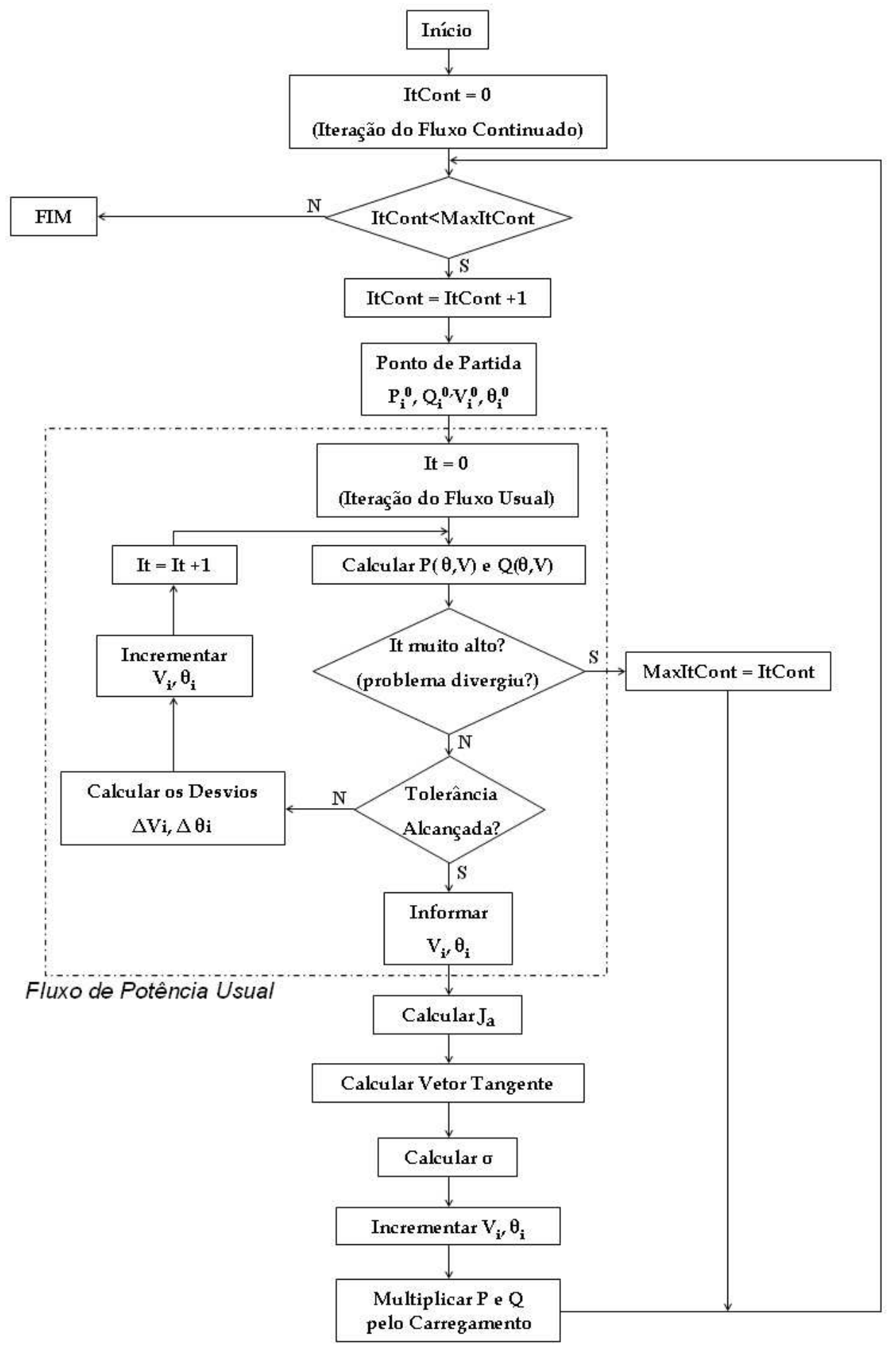

Figura 3.2: Fluxograma do Fluxo Continuado. 


\subsection{UTILIZAÇÃO DO MATPOWER}

O MATPOWER é um pacote gratuito de arquivos tipo m do MATLAB, utilizado para solucionar o fluxo de potência e fluxo de potência otimizado. É considerado uma ferramenta de simulação de sistemas elétricos de fácil uso, entendimento e modificação. A ferramenta foi desenvolvida principalmente por pesquisadores e educadores da Universidade de Cornell em Ithaca, Nova York.

Para utilizar o MATPOWER é necessário MATLAB 5.0 ou versão superior. Neste trabalho, foram utilizados MATPOWER vs 3.1b2 (mais recente) e MATLAB 6.5.

O MATPOWER oferece cinco opções de algoritmos para calcular o fluxo de potência. A utilização de cada um destes está condicionada ao tipo de sistema estudado e ao grau de confiabilidade desejado. O algoritmo padrão utilizado pelo MATPOWER resolve o fluxo de potência pelo método de Newton com matriz Jacobiana completa, que é atualizada a cada iteração. Existem ainda duas variações do algoritmo padrão, que calculam o fluxo de potência através do método desacoplado rápido de Newton. As outras alternativas são o método de Gauss-Seidel e a solução DC. Nesta última, o resultado é obtido diretamente, por um processo não-iterativo, baseado na injeção das potências reais especificadas nas barras.

A função do MATPOWER que calcula o fluxo de potência é denominada runpf. Nesta função, a solução é obtida em matrizes, há um indicador que informa se o algoritmo obteve sucesso ao encontrar uma solução para o problema e é informado o tempo de duração do processo de cálculo. Existem ainda opções que permitem especificar o algoritmo da solução e tipos de saída, bem como salvar o arquivo do caso em formato MATPOWER com um determinado nome especificado, a solução pode ser escrita em formato ".mat" ou em um arquivo do tipo ".m". A rotina runpf é um arquivo principal responsável por chamar outros arquivos com funções distintas, como bustypes.m que lista o tipo de cada barra, o newtonpf.m que calcula o fluxo de potência utilizando o método de Newton, ou o pfsoln.m que organiza os dados de saída para impressão final. Para executar a função runpf, o MATLAB deve apontar para o diretório onde estão os arquivos do MATPOWER, e especifica-se o nome do arquivo de entrada que contém as informações de um sistema elétrico, com o seguinte comando: runpf('nome do arquivo de entrada'). Os exemplos distribuídos junto com o pacote e utilizados neste estudo são casos de 9, 14, 30, 39, 57, 118 e 300 barras, em que os sistemas de 14, 30, 57, 118 e 300 barras são sistemas conhecidos de simulação do IEEE [13].

Por exemplo, quando o comando runpf('case30') é executado, o seguinte resultado do fluxo de potência é apresentado na tela do MATLAB: 
Tabela 3.1: Resultado do Fluxo de Carga Continuado do Sistema 30 Barras.

» runpf('case30')

Newton's method power flow converged in 3 iterations.

Converged in 0.03 seconds

System Summary

\begin{tabular}{rr} 
How many? & \\
\cline { 2 - 2 } Buses & 30 \\
Generators & 6 \\
Lommitted Gens & 6 \\
Loads & 20 \\
Fixed & 20 \\
Dispatchable & 0 \\
Shunts & 2 \\
Branches & 41 \\
Transformers & 0 \\
Inter-ties & 7 \\
Areas & 3
\end{tabular}

\begin{tabular}{rrrrr} 
& How much? & P (MW) & Q (MVAr) \\
\cline { 5 - 5 } 30 & Total Gen Capacity & 335.0 & -95.0 to 405.9 \\
6 & On-line Capacity & 335.0 & -95.0 to 405.9 \\
6 & Generation (actual) & 191.6 & 100.4 \\
20 & Load & 189.2 & 107.2 \\
20 & Fixed & 189.2 & 107.2 \\
0 & Dispatchable & 0.0 of 0.0 & 0.0 \\
2 & Shunt (inj) & 0.0 & 0.2 \\
41 & Losses $\left(I^{2} * Z\right)$ & 2.44 & 8.99 \\
0 & Branch Charging (inj) & - & 15.6 \\
7 & Total Inter-tie Flow & 33.2 & 27.1 \\
3 & & &
\end{tabular}

$\begin{array}{rr}\text { Minimum } & \text { Maximum } \\ \text { 0.961 p.u. @ bus 8 } & 1.000 \text { p.u. @ bus 1 } \\ \text {-3.96 deg @ bus 19 } & 1.48 \text { deg @ bus 13 } \\ - & \text { 0.29 MW @ line 2-6 } \\ - & 2.10 \text { MVAr@ line 12-13 }\end{array}$

Voltage Magnitude

Voltage Angle

P Losses $\left(I^{2} * \mathrm{R}\right)$

$\mathrm{Q} \operatorname{Losses}\left(I^{2} * \mathrm{X}\right)$

Bus Data

\begin{tabular}{|c|c|c|c|c|}
\hline $\begin{array}{r}\text { Voltage } \\
\text { Ang(deg) }\end{array}$ & $\mathbf{P}(\mathbf{M W})$ & $\begin{array}{r}\text { Generation } \\
\text { Q (MVAr) }\end{array}$ & P (MW) & $\begin{array}{r}\text { Load } \\
\text { Q (MVAr) }\end{array}$ \\
\hline 0.000 & 25.97 & -1.00 & - & - \\
\hline-0.415 & 60.97 & 32.00 & 21.70 & 12.70 \\
\hline-1.522 & - & - & 2.40 & 1.20 \\
\hline-1.795 & - & - & 7.60 & 1.60 \\
\hline-1.864 & - & - & - & - \\
\hline-2.267 & - & - & - & - \\
\hline-2.652 & - & - & 22.80 & 10.90 \\
\hline-2.726 & - & - & 30.00 & 30.00 \\
\hline-2.997 & - & - & - & - \\
\hline-3.375 & - & - & 5.80 & 2.00 \\
\hline-2.997 & - & - & - & - \\
\hline-1.537 & - & - & 11.20 & 7.50 \\
\hline 1.476 & 37.00 & 11.35 & - & - \\
\hline-2.308 & - & - & 6.20 & 1.60 \\
\hline-2.312 & - & - & 8.20 & 2.50 \\
\hline-2.644 & - & - & 3.50 & 1.80 \\
\hline-3.392 & - & - & 9.00 & 5.80 \\
\hline-3.478 & - & - & 3.20 & 0.90 \\
\hline-3.958 & - & - & 9.50 & 3.40 \\
\hline-3.871 & - & - & 2.20 & 0.70 \\
\hline-3.488 & - & - & 17.50 & 11.20 \\
\hline-3.393 & 21.59 & 39.57 & - & - \\
\hline-1.589 & 19.20 & 7.95 & 3.20 & 1.60 \\
\hline-2.631 & - & - & 8.70 & 6.70 \\
\hline-1.690 & - & - & - & - \\
\hline-2.139 & - & - & 3.50 & 2.30 \\
\hline-0.828 & 26.91 & 10.54 & - & - \\
\hline-2.266 & - & - & - & - \\
\hline-2.128 & - & - & 2.40 & 0.90 \\
\hline-3.042 & - & - & 10.60 & 1.90 \\
\hline Total: & 191.64 & 100.41 & 189.20 & 107.20 \\
\hline
\end{tabular}


Tabela 3.2: Resultado do Fluxo de Carga Continuado do Sistema 30 Barras - Continuação.

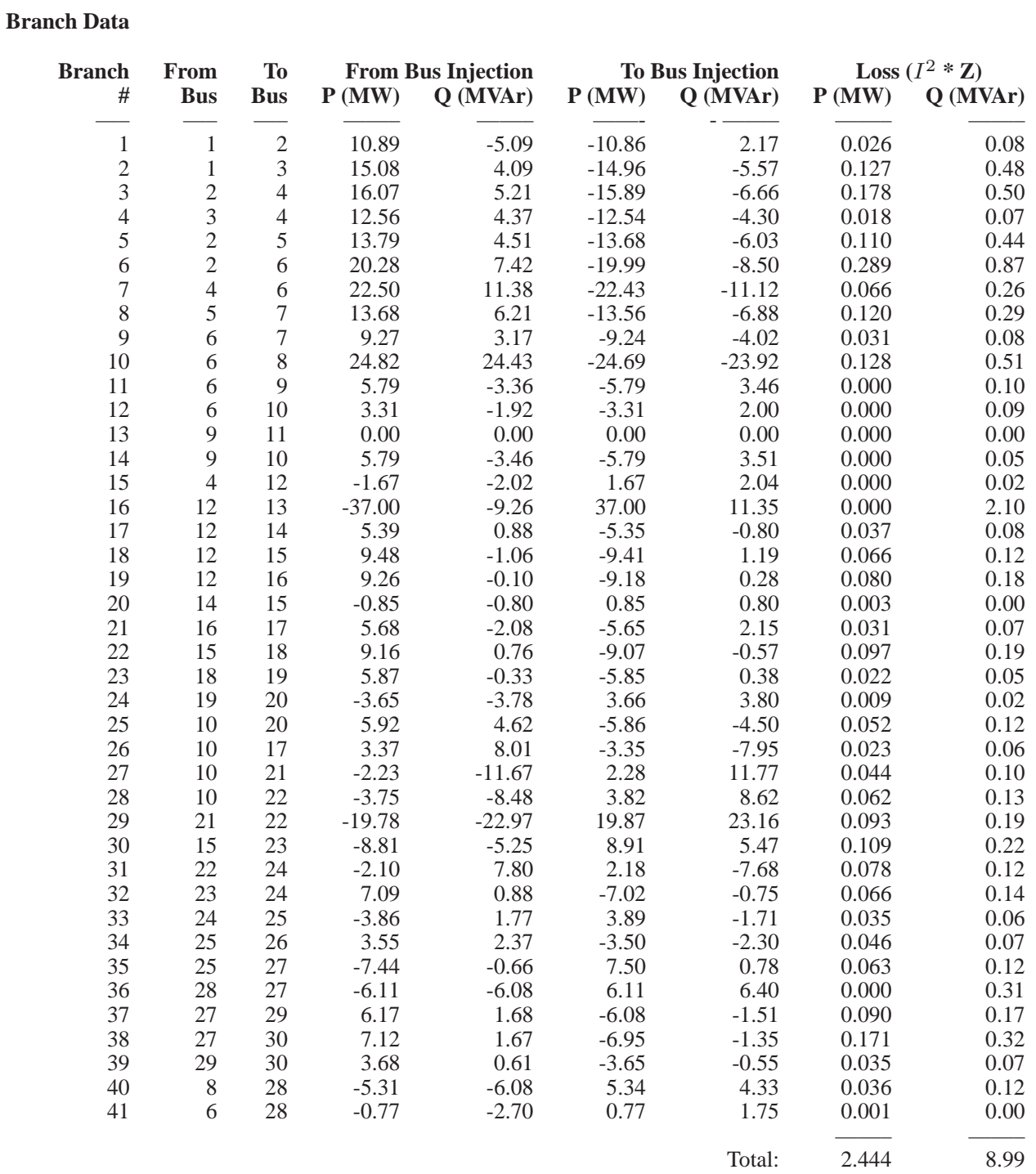

\subsubsection{Fluxo de Potencia Continuado no MATPOWER}

Como o MATPOWER não possui opção de fluxo de carga continuado e calcula o fluxo de potência utilizando algoritmos e estruturas típicos, foi a ferramenta escolhida para testar, estudar e analisar o método da continuação em sistemas de potência.

Os comandos e rotinas do método da continuação foram aplicados ao arquivo newtonpf.m (que calcula o fluxo de carga), conforme o fluxograma da figura 3.2. Tudo que foi acrescentado ao programa original (comandos, rotinas, o método de configuração...) foi feito de forma genérica, em função de características comuns a qualquer sistema para que o código do fluxo continuado funcione para qualquer caso. 
Primeiramente, a equção 2.15 foi inserida após o fluxo de potência usual para calcular a Matriz Jacobiana Aumentada e o vetor tangente da seguinte maneira:

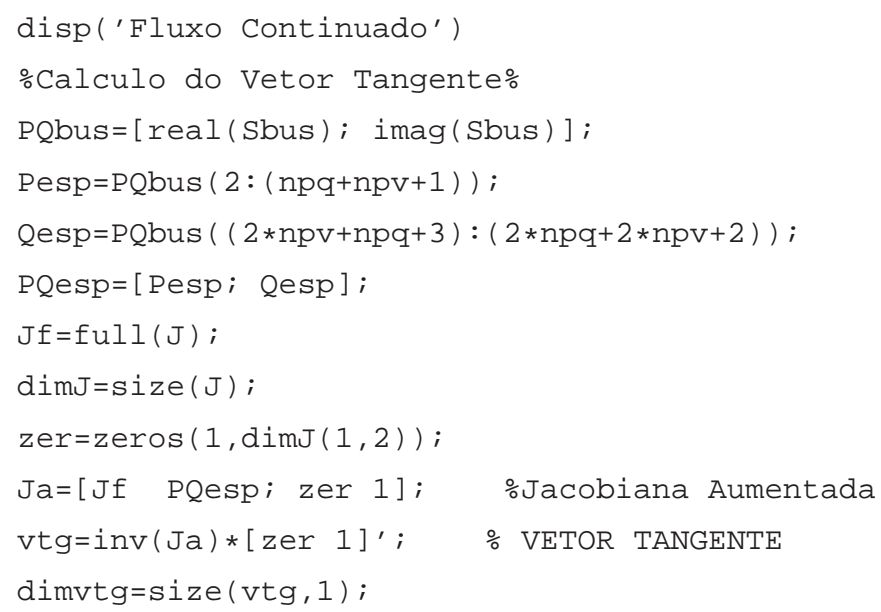

No trecho acima Sbus é a matriz de injeção de potência aparente especificada nas barras, npv é o número de barras de geração, $n p q$ é o número de barras de carga e $J$ é a matriz Jacobiana.

Em seguida, utilizando comandos simples, é calculado o tamanho do do passo $\sigma$, o carregamento $\lambda$ juntamente com seu incremento $\Delta \lambda$.

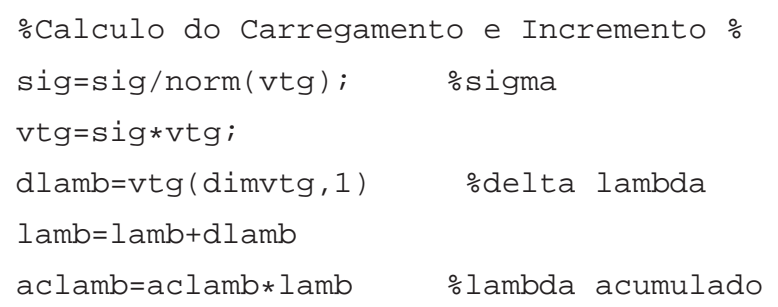

A variável $a c l a m b$ acumula os valores de $\lambda$, indicando o carregamento em relação ao caso base.

Então, as variáveis $V a$ (ângulo das tensões nas barras) e $V m$ (módulo das tensões nas barras) são atualizadas, somando-se seus incrementos, e as constantes $P^{e s p}$ e $Q^{e s p}$ são multiplicadas pelo carregamento $\lambda$, para que o fluxo de carga seja executado novamente.

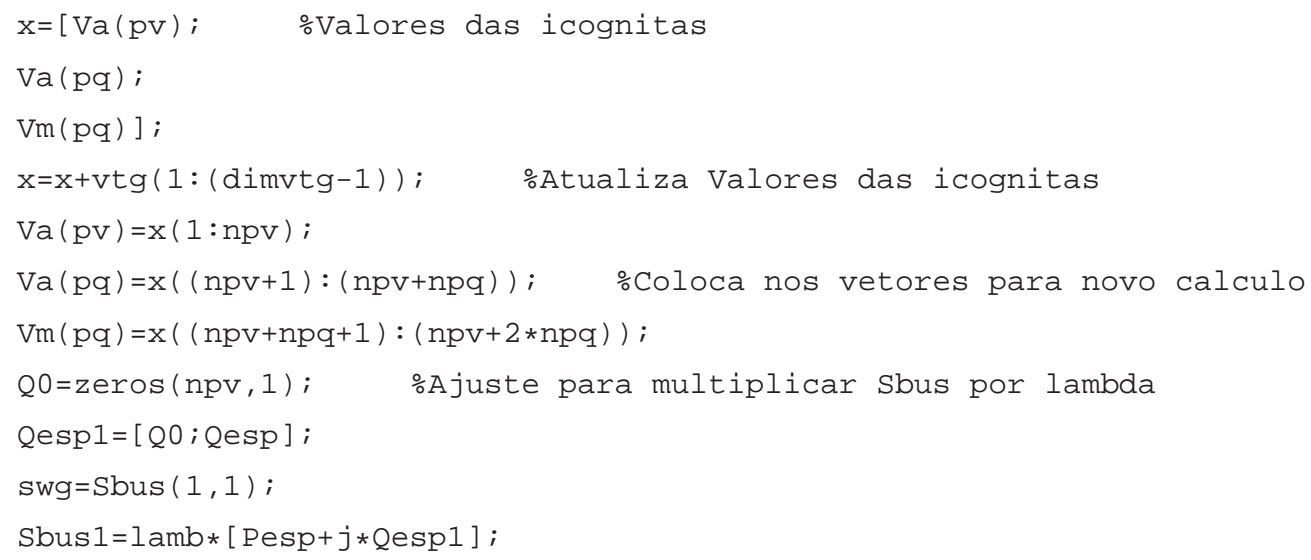


$V a(p v)$ representa os ângulos das barras de geração, $V a(p q)$ representa os ângulos das barras de carga e $V m(p q)$ representa a magnitude das tensões nas barras de geração.

O processo retorna para o início do laço maior do fluxo continuado, onde algumas variáveis importantes recebem seu valor inicial na primeira iteração:

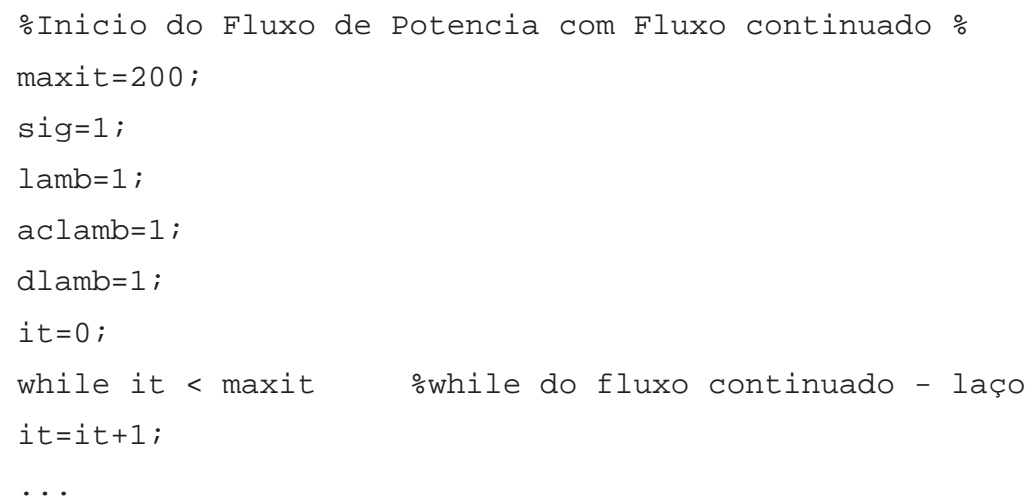

O programa pára quando o carregamento é tamanho que o método de Newton não consegue determinar um ponto de operação e a convergência deixa de ser alcançada.

if verbose

$$
\text { if converged }
$$

end

Quando o programa pára, as tensões na maioria das barras encontram-se baixas e a tensão da barra crítica "afunda", indicando que o ponto de colapso de sistema foi atingido.

\subsubsection{Identificação da Barra Crítica}

Para identificar a barra crítica do sistema é preciso descobrir qual é o elemento que possui maior módulo entre aqueles elementos do vetor tangente que são relativos as tensões do sistema, lembrando que o vetor tangente geralmente é do tipo:

$$
t=\left[\begin{array}{c}
\frac{\delta \theta p v_{i}}{\delta \lambda} \\
\frac{\delta \theta p q_{i}}{\delta \lambda} \\
\frac{\delta \mathbf{V p q}_{\mathbf{i}}}{\delta \lambda} \\
\frac{\delta \Delta \lambda}{\delta \lambda}
\end{array}\right]
$$


Em que $\theta p v_{i}$ representa os ângulos das barras de geração, $\theta p q_{i}$ os ângulos das barras de carga, $V p q_{i}$ a tensão as barras de carga e $\frac{\delta \Delta \lambda}{\delta \lambda}=1$.

Normalmente, este elemento não é único ao longo do processo iterativo, ou seja, pode mudar de uma iteração pra outra, mas pode-se dizer que existe uma tendência nos elementos máximos do vetor tangente de cada iteração em apontar para a barra crítica. Então, assim como em [1], foi feito um ranking dos elementos máximos do vetor tangente, de forma que aquele que ocorre mais vezes é relativo a barra crítica. Para isso, no mesmo arquivo newntonpf.m, a posição do maior elemento do vetor tangente é gravada a cada iteração e também foi criada uma matriz para armazenar todos os vetores tangente do processo iterativo.

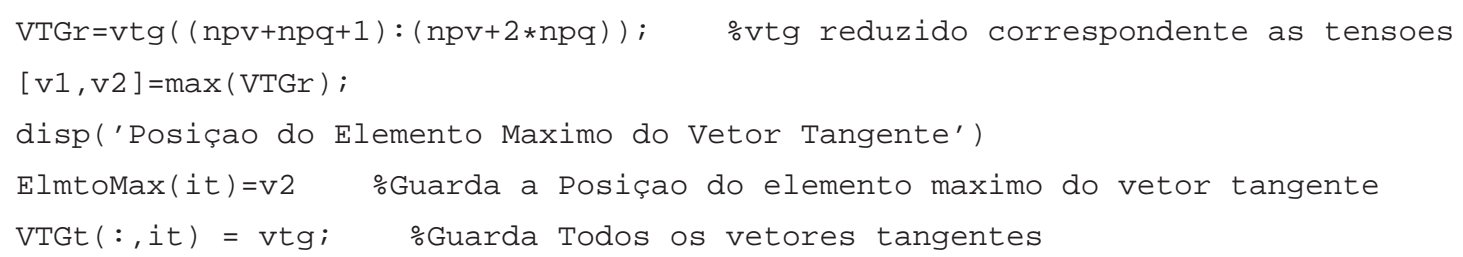

No final, quando o programa pára, a função AchaMais é aplicada ao vetor ElmtoMax. Esta função, baseada em histogramas, mostra qual é o elemento que mais se repete em um determinado vetor.

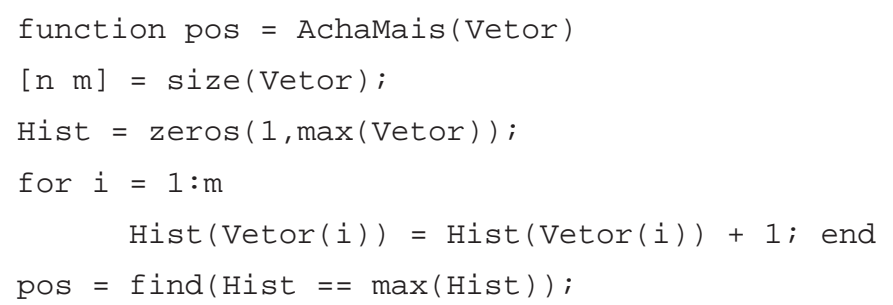

A posição encontrada $b c$ (mostrada a seguir) apenas se refere à barra crítica, não sendo a mesma da barra crítica no vetor $V m$ de saída, pois o vetor tangente reduzido contém somente as derivadas $\frac{\partial V_{i}}{\partial \lambda}$ das barras de carga. Para encontrar a posição que realmente representa a tensão da barra crítica em $V m$ é necessário endereçar o valor $b c$ no vetor de tensões em função do número de barras de geração e do número de barras de carga do sistema.

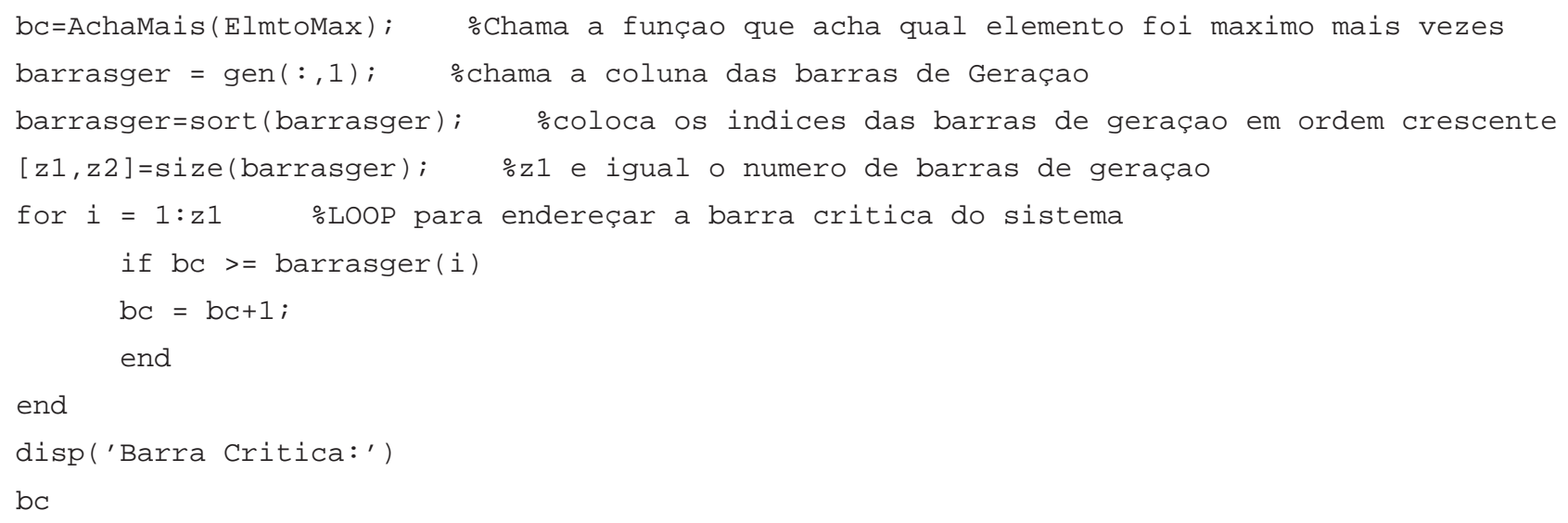


O gráfico do vetor VbarraCritica pelo carregamento do sistema (aclamb) é uma curva PV, e tem o aspecto da figura 2.1 até o ponto crítico. Além da tensão da barra crítica, também são escolhidas para o traçado as tensões da barra de referência, da barra que apresenta tensão mais baixa e de uma barra de carga qualquer para efeito de comparação.

Para traçar as curvas PV, todos os valores de tensão das barras são armazenados ao longo do processo iterativo. No término do programa, deve-se escolher qual barra cuja tensão será traçada e plotá-la em função de $a c l a m b$, ou seja, do carregamento.

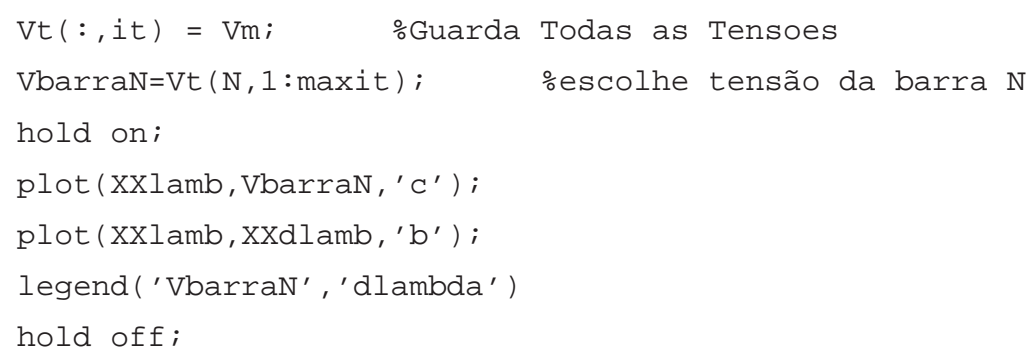

Os resultados obtidos das simulações serão apresentados no próximo capítulo e os principais códigos completos utilizados estão no anexo deste trabalho.

Uma observação importante é que os cálculos realizados até aqui não consideram as restrições de cada gerador (limite de potência ativa) e dos compensadores síncronos, diferentemente da realidade, onde os SEPs nunca suportariam carregamentos tão elevados. Optou-se por executar o fluxo de potência continuado sem restrição de geração devido à sua simplicidade e também para adquirir uma noção do comportamento dos sistemas em sobrecarga em um estudo teórico. Assim, é possível atingir o PMC e visualizar o ponto de colapso, já que são obtidos muitos pontos para traçar as curvas PV.

Para considerar os limites de potência ativa e reativa em cada barra PV seria necessário um código muito complexo para aproveitar a formulação do problema no MATPOWER. Como o presente trabalho aproveita um programa desenvolvido em outra universidade para solucionar o fluxo de carga, seria uma rotina confusa. O procedimento que deve ser adotado é sugerido em [8]. Cada vez que um gerador tem sua capacidade violada, a barra em questão é considerada do tipo PQ e novas variáveis são adicionadas ao problema inicial, então o conjunto de equações é reformulado. Tudo isso exige mais cuidado e detalhamento na identificação da barra crítica, além de maiores esforços computacionais. 


\title{
4 RESULTADOS DAS SIMULAÇÕES E TESTES COMPUTACIONAIS DO FLUXO DE POTÊNCIA CONTINUADO
}

\author{
Os resultados das simulações computacionais \\ executadas no MATPOWER do fluxo de potên- \\ cia continuado são expostos neste capítulo.
}

\subsection{INTRODUÇÃO}

Após o desenvolvimento de um algoritmo para implementação do FC continuado, foram feitos vários testes e simulações para sua validação com alguns dos sistemas distribuídos junto com o pacote MATPOWER, principalmente com os sistemas de 9 barras, 14 barras (IEEE) e 57 barras (IEEE). Neste capítulo, serão apresentados os resultados das principais simulações, incluindo curvas PV, identificação da barra crítica, sensibilidade do processo em relação ao tamanho inicial do passo preditor $\sigma^{0}$ e também o comportamento dos sistemas estudados após inserção de bancos de capacitores para compensação de potência reativa.

\subsection{PONTO INICIAL DE OPERAÇÃO}

Primeiramente, para efeito de comparação, será mostrado o resultado do fluxo de potência do caso base do fluxo continuado, em que $\lambda_{0}=1$ e $\Delta \lambda=0$. Em outras palavras, é o resultado do fluxo de carga usual apresentado pelo MATPOWER a partir dos dados de entrada de cada sistema, constituindo o ponto inicial de operação.

O primeiro sistema estudado foi o de 9 barras, que possui três geradores. Seus dados de entrada se encontram no anexo. Após o comando $\operatorname{runp} f\left({ }^{\prime} c a s e 9^{\prime}\right)$, os resultados do ponto inicial de operação é mostrado na tabela 4.1 da próxima página.

É possível notar que todas as tensões nas barras se encontram em torno de 1 p.u., os ângulos possuem valores pequenos, os geradores operam com potência ativa nominal e a carga é a mesma dos dados de entrada. 
Tabela 4.1: Dados Iniciais do Sistema 09 Barras.

System Summary

\begin{tabular}{r} 
How many? \\
\hline Buses \\
Generators \\
Committed Gens \\
Loads \\
Fixed \\
Dispatchable \\
Shunts \\
Branches \\
Transformers \\
Inter-ties \\
Areas
\end{tabular}

$\begin{array}{rrr}\text { How much? } & \text { P (MW) } & \text { Q (MVAr) } \\ \text { Total Gen Capacity } & 820.0 & -900.0 \text { to } 900.0 \\ \text { On-line Capacity } & 820.0 & -900.0 \text { to } 900.0 \\ \text { Generation (actual) } & 320.0 & 34.9 \\ \text { Load } & 315.0 & 115.0 \\ \text { Fixed } & 315.0 & 115.0 \\ \text { Dispatchable } & 0.0 \text { of } & 0.00 .0 \\ \text { Shunt (inj) } & 0.0 & 0.0 \\ \text { Losses }\left(I^{2} * \text { Z) }\right. & 4.95 & 51.31 \\ \text { Branch Charging (inj) } & - & 131.4 \\ \text { Total Inter-tie Flow } & 0.0 & 0.0\end{array}$

Bus Data

\begin{tabular}{rr} 
Bus & \\
$\#$ & Mag(pu) \\
\hline 1 & \\
2 & 1.000 \\
3 & 1.000 \\
4 & 1.000 \\
5 & 0.987 \\
6 & 0.975 \\
7 & 1.003 \\
8 & 0.986 \\
9 & 0.996 \\
& 0.958
\end{tabular}

\begin{tabular}{|c|c|c|c|c|}
\hline $\begin{array}{r}\text { Voltage } \\
\text { Ang(deg) }\end{array}$ & P (MW) & $\begin{array}{r}\text { Generation } \\
\text { Q (MVAr) }\end{array}$ & P (MW) & $\begin{array}{r}\text { Load } \\
Q \text { (MVAr) }\end{array}$ \\
\hline 0.000 & 71.95 & 24.07 & - & - \\
\hline 9.669 & 163.00 & 14.46 & - & - \\
\hline 4.771 & 85.00 & -3.65 & - & - \\
\hline-2.407 & - & - & - & - \\
\hline-4.017 & - & - & 90.00 & 30.00 \\
\hline 1.926 & - & - & - & - \\
\hline 0.622 & - & - & 100.00 & 35.00 \\
\hline 3.799 & - & - & - & - \\
\hline-4.350 & - & - & 125.00 & 50.00 \\
\hline Total: & 319.95 & 34.88 & 315.00 & 115.00 \\
\hline
\end{tabular}

Em seguida foi analisado o sistema de 14 barras com cinco geradores, em que três inicialmente não geram potência ativa. Os demais dados de entrada se encontram no anexo. Os resultados do comando runpf('case14') mostram regularidade nos dados do sistema com valores normais de tensão, ângulo, geração e carga.

Tabela 4.2: Dados Iniciais do Sistema 14 Barras.

System Summary

\begin{tabular}{r} 
How many? \\
\hline Buses \\
Generators \\
Committed Gens \\
Loads \\
Fixed \\
Dispatchable \\
Shunts \\
Branches \\
Transformers \\
Inter-ties \\
Areas
\end{tabular}

$\begin{array}{rr} & \text { How much? } \\ 14 & \text { Total Gen Capacity } \\ 5 & \text { On-line Capacity } \\ 5 & \text { Generation (actual) } \\ 11 & \text { Load } \\ 11 & \text { Fixed } \\ 0 & \text { Dispatchable } \\ 1 & \text { Shunt (inj) } \\ 20 & \text { Losses }\left(I^{2} * \mathrm{Z}\right) \\ 3 & \text { Branch Charging (inj) } \\ 0 & \text { Total Inter-tie Flow } \\ 1 & \end{array}$

$\begin{array}{rr}\mathbf{P} \text { (MW) } & \mathbf{Q} \text { (MVAr) } \\ 772.4 & -52.0 \text { to } 148.0 \\ 772.4 & -52.0 \text { to } 148.0 \\ 272.4 & 82.4 \\ 259.0 & 73.5 \\ 259.0 & 73.5 \\ 0.0 \text { of } 0.0 & 0.0 \\ 0.0 & 21.2 \\ 13.39 & 54.54 \\ - & 24.4 \\ 0.0 & 0.0\end{array}$

Bus Data

\begin{tabular}{rrrr}
$\begin{array}{r}\text { Bus } \\
\#\end{array}$ & Mag(pu) & $\begin{array}{r}\text { Voltage } \\
\text { Ang(deg) }\end{array}$ & P (MW) \\
\hline 1 & $\frac{1}{1.060}$ & 0.000 & 232.39 \\
2 & 1.045 & -4.983 & 40.00 \\
3 & 1.010 & -12.725 & 0.00 \\
4 & 1.018 & -10.313 & - \\
5 & 1.020 & -8.774 & - \\
6 & 1.070 & -14.221 & 0.00 \\
7 & 1.062 & -13.360 & - \\
8 & 1.090 & -13.360 & 0.00 \\
9 & 1.056 & -14.939 & - \\
10 & 1.051 & -15.097 & - \\
11 & 1.057 & -14.791 & - \\
12 & 1.055 & -15.076 & - \\
13 & 1.050 & -15.156 & - \\
14 & 1.036 & -16.034 & - \\
& & & - \\
& & Total: & 272.39
\end{tabular}

\begin{tabular}{rrr}
$\begin{array}{r}\text { Generation } \\
\text { Q (MVAr) }\end{array}$ & $\mathbf{P}(\mathbf{M W})$ & $\begin{array}{r}\text { Load } \\
\mathbf{Q} \text { (MVAr) }\end{array}$ \\
-16.55 & - & - \\
43.56 & 21.70 & 12.70 \\
25.08 & 94.20 & 19.00 \\
- & 47.80 & -3.90 \\
- & 7.60 & 1.60 \\
12.73 & 11.20 & 7.50 \\
- & - & - \\
17.62 & - & - \\
- & 29.50 & 16.60 \\
- & 9.00 & 5.80 \\
- & 3.50 & 1.80 \\
- & 6.10 & 1.60 \\
- & 13.50 & 5.80 \\
- & 14.90 & 5.00 \\
\hline 82.44 & 259.00 & 73.50
\end{tabular}


O terceiro sistema estudado é o de 57 barras IEEE, que possui sete geradores, em que três inicialmente não geram potência ativa. O restante de seus dados de entrada também se encontram no anexo e o ponto inicial de operação normal é mostrado na tabela seguinte.

Tabela 4.3: Dados Iniciais do Sistema 57 Barras.

\begin{tabular}{|c|c|c|c|c|c|c|}
\hline \multicolumn{7}{|l|}{ nary } \\
\hline How many? & \multicolumn{2}{|r|}{ How much? } & $\mathbf{P}(\mathbf{M W})$ & Q (MVAr) & & \\
\hline Buses & 57 & Total Gen Capacity & 1975.9 & -468.0 to 699.0 & & \\
\hline Generators & 7 & On-line Capacity & 1975.9 & -468.0 to 699.0 & & \\
\hline Committed Gens & 7 & Generation (actual) & 1278.7 & 321.1 & & \\
\hline Loads & 42 & Load & 1250.8 & 336.4 & & \\
\hline Fixed & 42 & Fixed & 1250.8 & 336.4 & & \\
\hline Dispatchable & 0 & Dispatchable & 0.0 of & 0.00 .0 & & \\
\hline Shunts & 3 & Shunt (inj) & 0.0 & 21.6 & & \\
\hline Branches & 80 & Losses $\left(I^{2} * \mathrm{Z}\right)$ & 27.86 & 121.67 & & \\
\hline Transformers & 17 & Branch Charging (inj) & & 115.3 & & \\
\hline Inter-ties & 0 & Total Inter-tie Flow & 0.0 & 0.0 & & \\
\hline Areas & 1 & & & & & \\
\hline \multicolumn{7}{|l|}{ Bus Data } \\
\hline $\begin{array}{r}\text { Bus } \\
\#\end{array}$ & & Voltage & & Generation & & $\begin{array}{r}\text { Load } \\
\text { Lear }\end{array}$ \\
\hline \# & $\operatorname{Mag}(\mathbf{p u})$ & Ang(deg) & $\mathbf{P}(\mathbf{M W})$ & Q (MVAr) & $\mathbf{P}(\mathrm{MW})$ & Q (MVAr) \\
\hline 1 & 1.040 & 0.000 & 478.66 & 128.85 & 55.00 & 17.00 \\
\hline 2 & 1.010 & -1.188 & 0.00 & -0.75 & 3.00 & 88.00 \\
\hline 3 & 0.985 & -5.988 & 40.00 & -0.90 & 41.00 & 21.00 \\
\hline 4 & 0.981 & -7.337 & - & - & & \\
\hline 5 & 0.976 & -8.546 & - & - & 13.00 & 4.00 \\
\hline 6 & 0.980 & -8.674 & 0.00 & 0.87 & 75.00 & 2.00 \\
\hline 7 & 0.984 & -7.601 & & & & \\
\hline 8 & 1.005 & -4.478 & 450.00 & 62.10 & 150.00 & 22.00 \\
\hline 9 & 0.980 & -9.585 & 0.00 & 2.29 & 121.00 & 26.00 \\
\hline 10 & 0.986 & -11.450 & - & - & 5.00 & 2.00 \\
\hline 11 & 0.974 & -10.193 & - & - & & \\
\hline 12 & 1.015 & -10.471 & 310.00 & 128.63 & 377.00 & 24.00 \\
\hline 13 & 0.979 & -9.804 & - & - & 18.00 & 2.30 \\
\hline 14 & 0.970 & -9.350 & - & - & 10.50 & 5.30 \\
\hline 15 & 0.988 & -7.190 & - & - & 22.00 & 5.00 \\
\hline 16 & 1.013 & -8.859 & - & - & 43.00 & 3.00 \\
\hline 17 & 1.017 & -5.396 & - & - & 42.00 & 8.00 \\
\hline 18 & 1.001 & -11.730 & - & - & 27.20 & 9.80 \\
\hline 19 & 0.970 & -13.227 & - & - & 3.30 & 0.60 \\
\hline 20 & 0.964 & -13.444 & - & - & 2.30 & 1.00 \\
\hline 21 & 1.008 & -12.929 & - & - & - & - \\
\hline 22 & 1.010 & -12.874 & - & - & - & - \\
\hline 23 & 1.008 & -12.940 & - & - & 6.30 & 2.10 \\
\hline 24 & 0.999 & -13.292 & - & - & 0.00 & - \\
\hline 25 & 0.983 & -18.173 & - & - & 6.30 & 3.20 \\
\hline 26 & 0.959 & -12.981 & - & - & & \\
\hline 27 & 0.982 & -11.514 & - & - & 9.30 & 0.50 \\
\hline 28 & 0.997 & -10.482 & - & - & 4.60 & 2.30 \\
\hline 29 & 1.010 & -9.772 & - & - & 17.00 & 2.60 \\
\hline 30 & 0.963 & -18.720 & - & - & 3.60 & 1.80 \\
\hline 31 & 0.936 & -19.384 & - & - & 5.80 & 2.90 \\
\hline 32 & 0.950 & -18.512 & - & - & 1.60 & 0.80 \\
\hline 33 & 0.948 & -18.552 & - & - & 3.80 & 1.90 \\
\hline 34 & 0.959 & -14.149 & - & - & - & - \\
\hline 35 & 0.966 & -13.906 & - & - & 6.00 & 3.00 \\
\hline 36 & 0.976 & -13.635 & - & - & - & - \\
\hline 37 & 0.985 & -13.446 & - & - & & - \\
\hline 38 & 1.013 & -12.735 & - & - & 14.00 & 7.00 \\
\hline 39 & 0.983 & -13.491 & - & - & - & - \\
\hline 40 & 0.973 & -13.658 & - & - & - & - \\
\hline 41 & 0.996 & -14.077 & - & - & 6.30 & 3.00 \\
\hline 42 & 0.967 & -15.533 & - & - & 7.10 & 4.40 \\
\hline 43 & 1.010 & -11.354 & - & - & 2.00 & 1.00 \\
\hline 44 & 1.017 & -11.856 & - & - & 12.00 & 1.80 \\
\hline 45 & 1.036 & -9.270 & - & - & 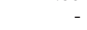 & - \\
\hline 46 & 1.060 & -11.116 & - & - & - & - \\
\hline 47 & 1.033 & -12.512 & - & - & 29.70 & 11.60 \\
\hline 48 & 1.027 & -12.611 & - & - & & - \\
\hline 49 & 1.036 & -12.936 & - & - & 18.00 & 8.50 \\
\hline 50 & 1.023 & -13.413 & - & - & 21.00 & 10.50 \\
\hline 51 & 1.052 & -12.533 & - & - & 18.00 & 5.30 \\
\hline 52 & 0.980 & -11.498 & - & - & 4.90 & 2.20 \\
\hline 53 & 0.971 & -12.253 & - & - & 20.00 & 10.00 \\
\hline 54 & 0.996 & -11.710 & - & - & 4.10 & 1.40 \\
\hline 55 & 1.031 & -10.801 & - & - & 6.80 & 3.40 \\
\hline \multirow{3}{*}{$\begin{array}{l}56 \\
57\end{array}$} & 0.968 & -16.065 & - & - & 7.60 & 2.20 \\
\hline & 0.965 & -16.584 & - & - & 6.70 & 2.00 \\
\hline & & Total: & 1278.66 & 321.08 & 1250.80 & 336.40 \\
\hline
\end{tabular}




\subsection{RESULTADO DO FLUXO DE POTÊNCIA CONTINUADO}

Para rodar o fluxo de carga continuado, deve-se inserir os novos arquivos adaptados runpf_1.m, NewtonContinuado.m, pnsolve1.m e a função AchaMais.m (descrita no capítulo anterior) ao diretório do MATPOWER. O arquivo runpf_1.m chama o arquivo NewtonContinuado.m que executa o método da continuação no lugar do arquivo newtonpf.m do fluxo usual, e o pnsolve1.m substitui o arquivo pnsolve.m para atualizar os dados de saída calculados no fluxo continuado. Assim como no programa original, o comando a ser executado é runpf_1('nome do arquivo de entrada'), a diferença é que além de apresentar os mesmo dados de saída, também é apresentado o gráfico Tensão vs Carregamento (curva PV) de algumas barras, incluindo a barra crítica que é identificada ao longo do processo iterativo.

\subsubsection{Resultado do Fluxo de Potência Continuado do Sistema 09 barras}

Após 13 iterações do laço maior do fluxo de potência continuado, que resulta em uma carga aproximadamente 2.6 vezes maior que a carga inicial, a saída do programa MATPOWER é igual à:

Tabela 4.4: Resultado do Fluxo de Potência Continuado - Sistema 09 Barras. System Summary

\begin{tabular}{|c|c|c|c|c|c|c|}
\hline How many? & & How much? & $\mathbf{P}(\mathbf{M W})$ & Q (MVAr) & & \\
\hline Buses & 9 & Total Gen Capacity & 820.0 & -900.0 to 900.0 & & \\
\hline Generators & 3 & On-line Capacity & 820.0 & -900.0 to 900.0 & & \\
\hline Committed Gens & 3 & Generation (actual) & 857.9 & 1027.4 & & \\
\hline Loads & 3 & Load & 785.1 & 286.6 & & \\
\hline Fixed & 3 & Fixed & 785.1 & 286.6 & & \\
\hline Dispatchable & 0 & Dispatchable & 0.0 of 0.0 & 0.0 & & \\
\hline Shunts & 0 & Shunt (inj) & 0.0 & 0.0 & & \\
\hline Branches & 9 & $\operatorname{Losses}\left(I^{2} * \mathrm{Z}\right)$ & 73.74 & 817.27 & & \\
\hline Transformers & 0 & Branch Charging (inj) & - & 75.3 & & \\
\hline Inter-ties & 0 & Total Inter-tie Flow & 0.0 & 0.0 & & \\
\hline Areas & 1 & & & & & \\
\hline & Bus Data & & & & & \\
\hline Bus & & Voltage & & Generation & & Load \\
\hline$\#$ & $\operatorname{Mag}(\mathbf{p u})$ & Ang(deg) & $\mathbf{P}(\mathbf{M W})$ & Q (MVAr) & P (MW) & Q (MVAr) \\
\hline 1 & 1000 & 0.000 & 240.30 & 416.00 & - & - \\
\hline 2 & 1000 & 33624 & 405.79 & 388.40 & - & - \\
\hline 3 & 1000 & 13256 & 211.79 & 223.00 & - & - \\
\hline 4 & 0.773 & -10317 & - & - & - & - \\
\hline 5 & 0.686 & -17685 & - & - & 224.30 & 74.77 \\
\hline 6 & 0.878 & 5131 & - & - & - & - \\
\hline 7 & 0.759 & 1523 & - & - & 249.22 & 87.23 \\
\hline 8 & 0.799 & 15108 & - & - & - & - \\
\hline \multirow[t]{2}{*}{9} & 0.518 & -25705 & - & - & 311.53 & 124.61 \\
\hline & & Total: & $\overline{857.88}$ & 1027.40 & $\overline{785.06}$ & 286.61 \\
\hline
\end{tabular}

Estes resultados mostram que o sistema atingiu seu PMC, gerando quantidades de energia ativa e reativa elevadas e a magnitude das tensões nas barras de carga encontram-se baixas, longe de qualquer ponto real de operação admissível. 
Os resultados obtidos durante as iterações mostram que a barra crítica do sistema é a barra 9, pois o elemento que mais se repete no vetor ElmtoMax (explicado no capítulo anterior) é aquele que o ocupa a $6^{\mathrm{a}}$ posição do vetor tangente, que se refera à derivada $\frac{\delta V_{9}}{\delta \lambda}$.

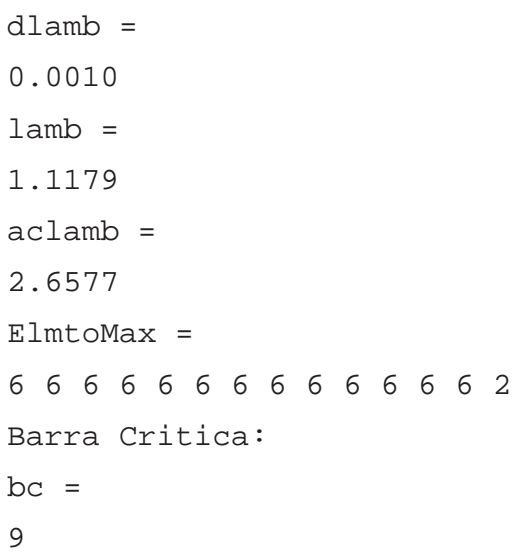

Na figura a seguir VbarraCritica é a tensão da barra 9. São traçadas também as tensões da barra 5 (VbarraMeio), escolhida aleatoriamente entre as barras PQ, e da barra 1 para efeito de comparação. Nota-se que a tensão da barra crítica de fato decai mais rapidamente nas proximidades do PMC. E neste caso, a barra crítica também é aquela cuja tensão é mais baixa, no entanto isto é apenas uma coincidência.

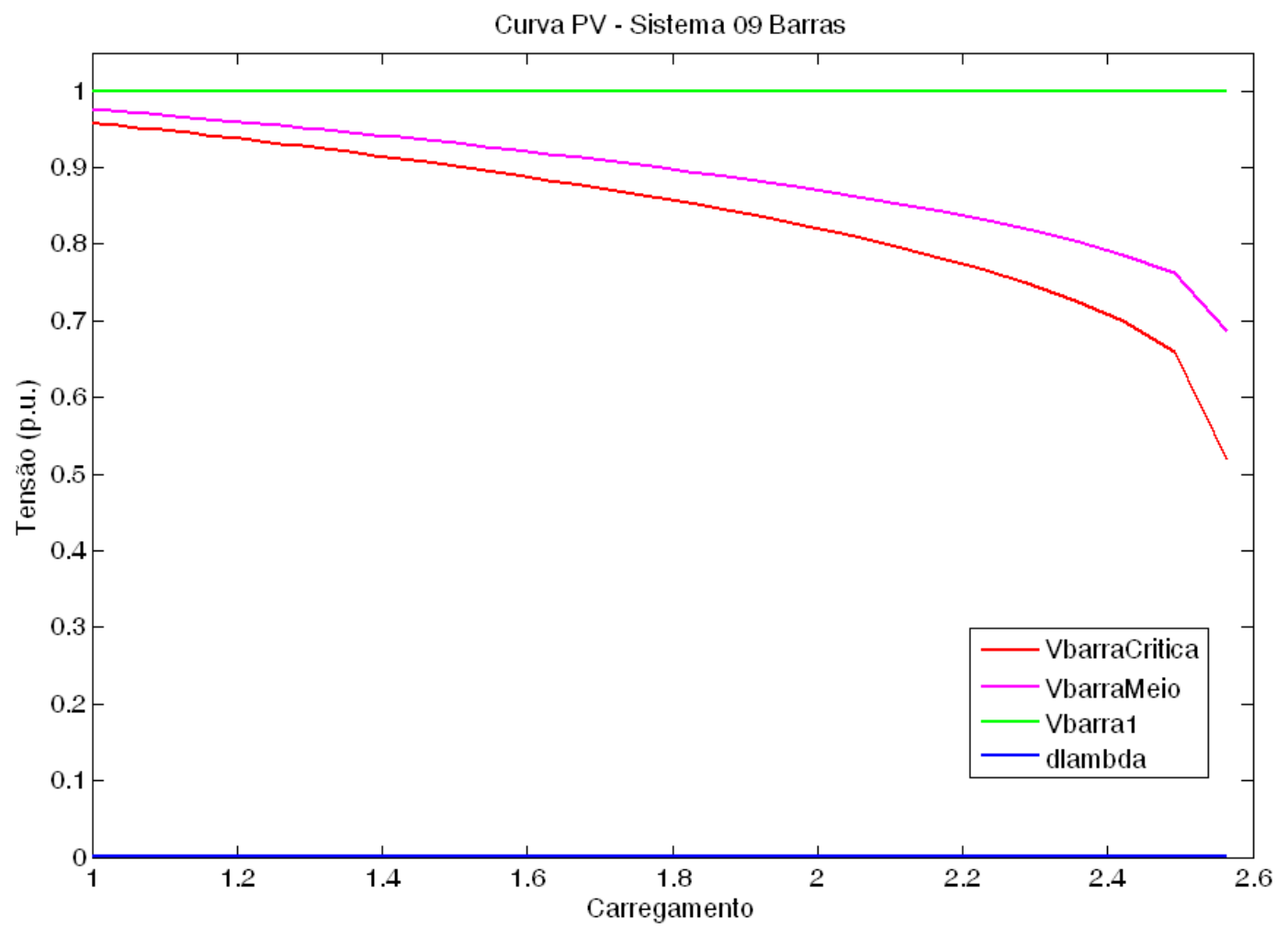

Figura 4.1: Curva PV do Sistema de 09 barras Após o Fluxo Continuado de Potência. 
Na figura anterior não é possível notar o decaimento exponencial de $\Delta \lambda$ devido à escala utilizada, mas ao aproximar a imagem da origem é possível perceber tal característica, comprovando que este parâmetro diminui à cada iteração.

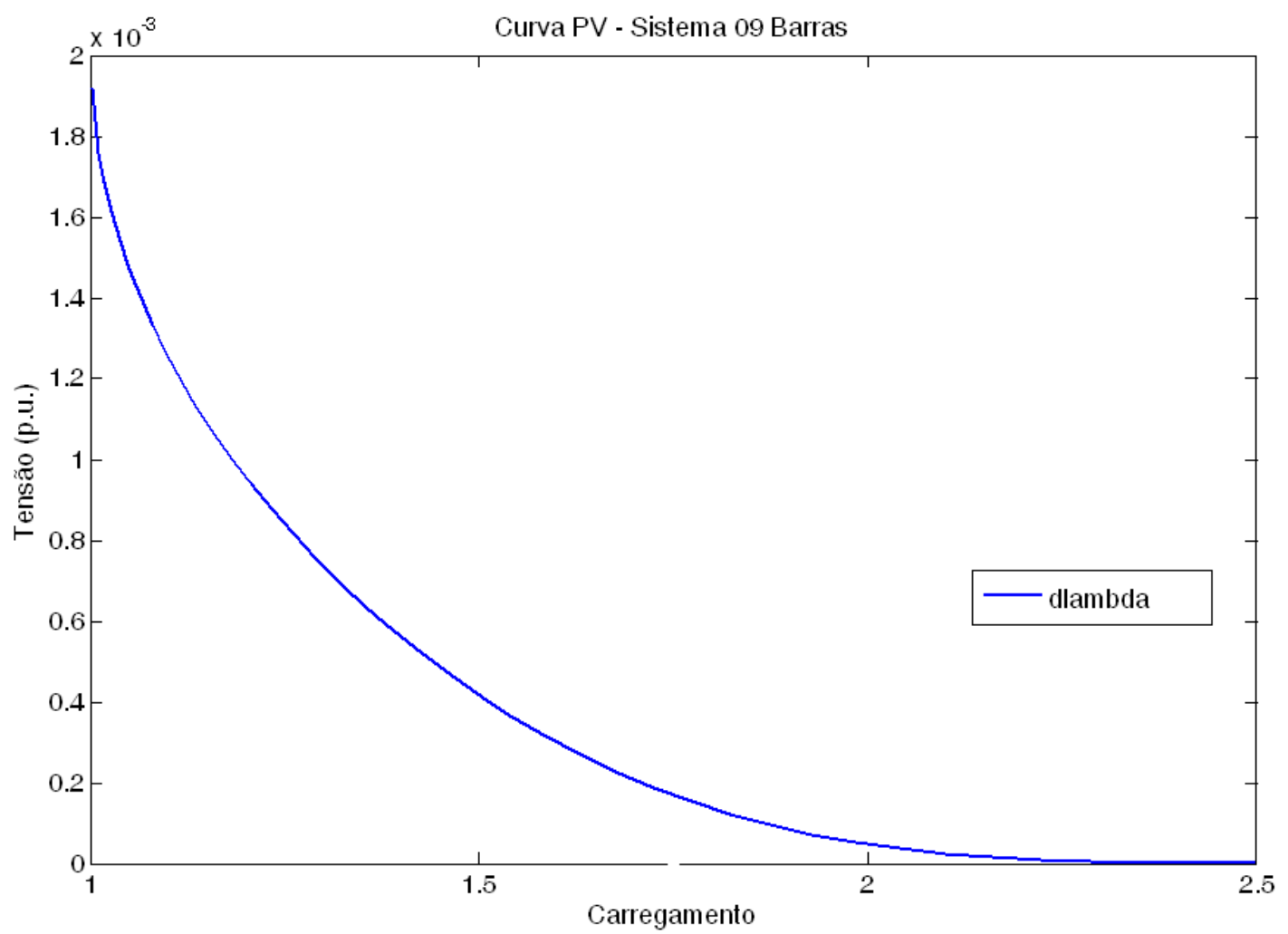

Figura 4.2: Decaimento Exponencial de $\Delta \lambda$ no Fluxo de Potência Continuado do Sistema de 09 barras.

\subsubsection{Resultado do Fluxo de Potência Continuado do Sistema 14 barras}

O mesmo procedimento anterior foi adotado para o sistema de 14 barras. A distinção é que foi ativada uma opção do MATPOWER chamada de ENFORCE_Q_LIMS. Esta opção funciona da seguinte maneira: se algum dos geradores tem seu limite de potência reativa (especificado nos dados de entrada), a barra PV é convertida para PQ e o caso é resolvido mais uma vez com esta nova condição. Novamente é necessário lembrar que isto não significa que as restrições de potência ativa dos geradores foram respeitadas e mantidas, é apenas uma opção para que os resultados de saída sejam apresentados de maneira aceitável. Caso contrário, haveriam geradores com "potência negativa" gerada, levando a resultados absurdos.

Após 46 iterações e carga aproximadamente 4,16 vezes maior que a inicial, os resultados foram: 
Tabela 4.5: Resultado do Fluxo de Potência Continuado - Sistema 14 Barras.

System Summary

\begin{tabular}{r} 
How many? \\
\hline Buses \\
Generators \\
Committed Gens \\
Loads \\
Fixed \\
Dispatchable \\
Shunts \\
Branches \\
Transformers \\
Inter-ties \\
Areas
\end{tabular}

$\begin{array}{rrr}\text { How much? } & \text { P (MW) } & \text { Q (MVAr) } \\ \text { Total Gen Capacity } & 772.4 & -52.0 \text { to } 148.0 \\ \text { On-line Capacity } & 332.4 & 0.0 \text { to } 10.0 \\ \text { Generation (actual) } & 1040.9 & 2776.1 \\ \text { Load } & 969.4 & 251.2 \\ \text { Fixed } & 969.4 & 251.2 \\ \text { Dispatchable } & 0.0 \text { of } 0.0 & 0.0 \\ \text { Shunt (inj) } & 0.0 & 3.9 \\ \text { Losses }\left(I^{2} * \text { Z) }\right. & 4653.57 & 16732.32 \\ \text { Branch Charging (inj) } & - & 16.5 \\ \text { Total Inter-tie Flow } & 0.0 & 0.0\end{array}$

Bus Data

$\begin{array}{rr}\text { Bus } & \\ \# & \text { Mag(pu) } \\ 1 & 1.060 \\ 2 & 0.103 \\ 3 & 1.135 \\ 4 & 0.825 \\ 5 & 1.139 \\ 6 & 0.33 \\ 7 & 0.425 \\ 8 & 0.489 \\ 9 & 0.456 \\ 10 & 0.387 \\ 11 & 0.210 \\ 12 & 0.013 \\ 13 & 0.019 \\ 14 & 0.841\end{array}$

$\begin{array}{rrrrr}\begin{array}{r}\text { Voltage } \\ \text { Ang(deg) }\end{array} & \mathbf{P}(\mathbf{M W}) & \begin{array}{r}\text { Generation } \\ \mathbf{Q}(\mathbf{M V A r})\end{array} & \mathbf{P}(\mathbf{M W}) & \begin{array}{r}\text { Load } \\ \mathbf{Q} \text { (MVAr) }\end{array} \\ 0.000 & 1040.89 & 2776.07 & - & - \\ -152.374 & - & - & 38.34 & 37.30 \\ 18.791 & - & - & 366.35 & 21.00 \\ 21.346 & - & - & 199.04 & 0.00 \\ -166.650 & - & - & 31.65 & 0.00 \\ -68.345 & - & - & 15.49 & 16.50 \\ -161.531 & - & - & - & - \\ -161.473 & - & - & 0.00 & 24.00 \\ 151.217 & - & - & 122.84 & 69.12 \\ 78.217 & - & - & 37.48 & 24.15 \\ 4.860 & - & - & 14.57 & 7.50 \\ -53.874 & - & - & 25.40 & 6.66 \\ -86.174 & - & - & 56.21 & 24.15 \\ -147.363 & - & - & 62.04 & 20.82 \\ & - & & & \\ \text { Total: } & 1040.89 & 2776.07 & 969.40 & 251.20\end{array}$

Conforme os resultados acima, os geradores 2, 3, 6 e 8 atingiram seu limite máximo de potência reativa e as tensões se encontram muito baixas, caracterizando o ponto de colapso.

Outros parâmetros importantes como lamb, dlamb, aclamb, ElmtoMax e barra crítica (bc), neste caso, são iguais a:

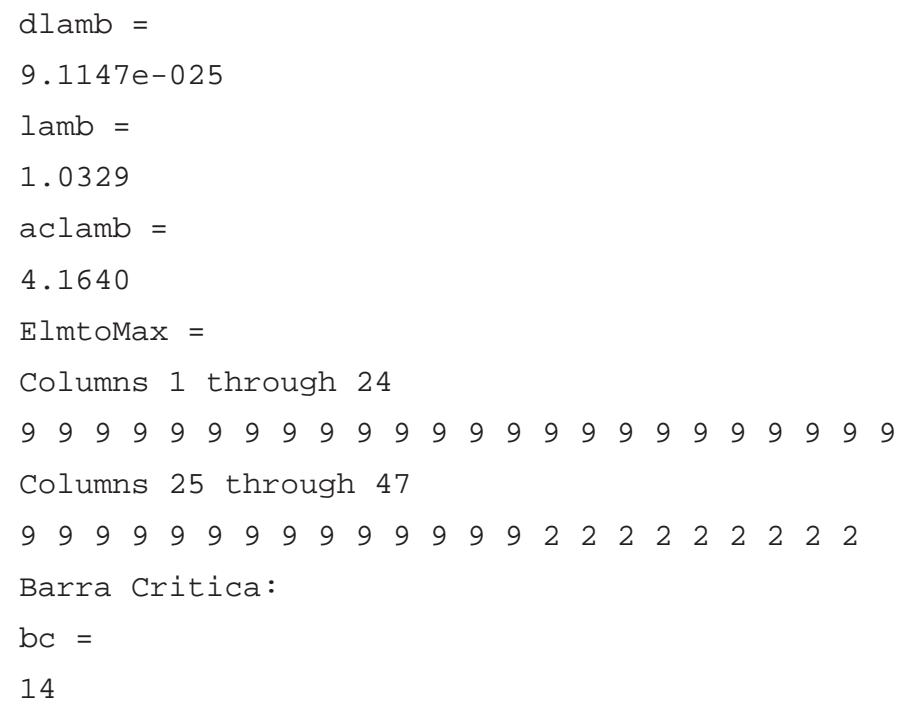

Na próxima figura, VbarraCritica é a tensão da barra 14, VbarraMinimo é a barra 5, VbarraMeio é a barra 7 (tipo PQ) e também é traçada a tensão na barra 1. 


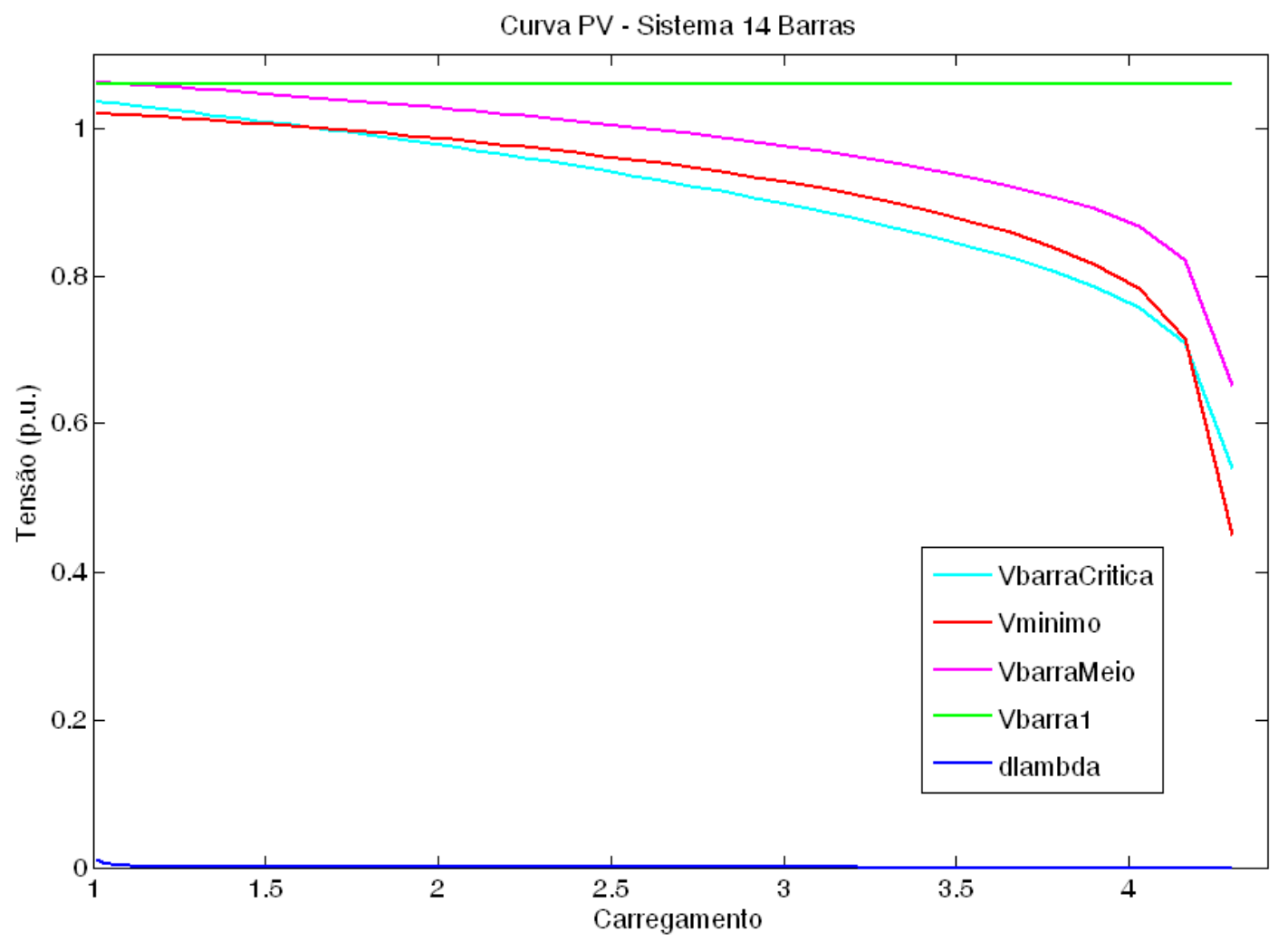

Figura 4.3: Curva PV do Sistema de 14 barras Após o Fluxo Continuado de Potência.

No gráfico acima é fácil perceber a principal característica da barra crítica, que se destaca entre as demais, pois sua tensão decai mais rapidamente do que das outras barras.

O decaimento exponencial de $\Delta \lambda$ deste caso também é mostrado a seguir.

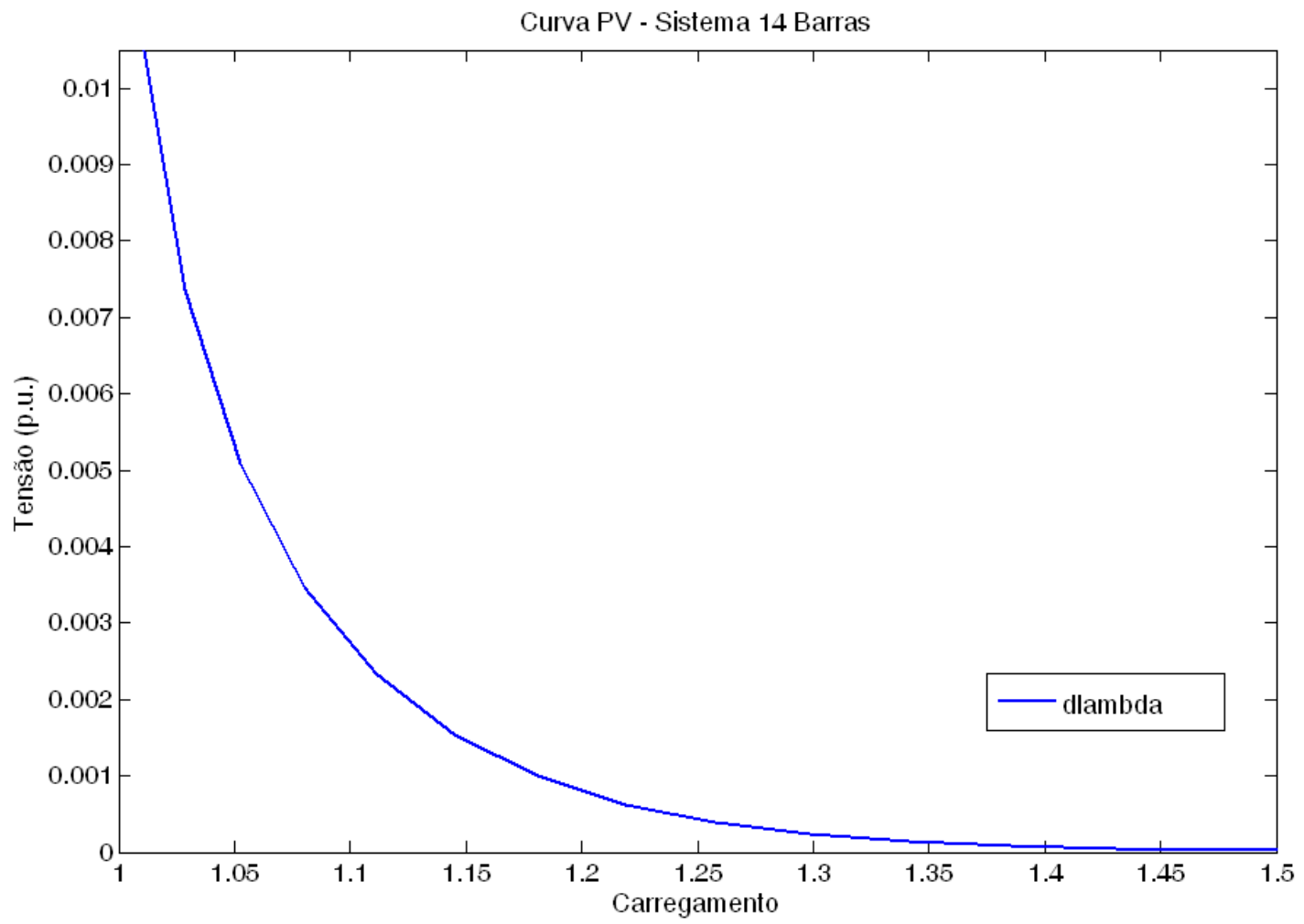

Figura 4.4: Decaimento Exponencial de $\Delta \lambda$ no Fluxo de Potência Continuado do Sistema de 14 barras. 


\subsubsection{Resultado do Fluxo de Potência Continuado do Sistema 57 barras}

O procedimento adotado para os sistemas anteriores também foi aplicado para o sistema 57 barras, incluindo a opção ENFORCE_Q_LIMS. O processo teve 46 iterações até uma carga 1,9 vezes maior que a inicial, resultando em:

Tabela 4.6: Resultado do Fluxo de Potência Continuado - Sistema 57 Barras.

\begin{tabular}{|c|c|c|c|c|c|c|}
\hline \multicolumn{7}{|c|}{ System Summary } \\
\hline How many? & & How much? & $\mathbf{P}(\mathbf{M W})$ & Q (MVAr) & & \\
\hline Buses & 57 & Total Gen Capacity & 1975.9 & -468.0 to 699.0 & & \\
\hline Generators & 7 & On-line Capacity & 550.0 & -140.0 to 200.0 & & \\
\hline Committed Gens & 1 & Generation (actual) & 1789.3 & 3500.3 & & \\
\hline Loads & 42 & Load & 3053.2 & 705.8 & & \\
\hline Fixed & 42 & Fixed & 3053.2 & 705.8 & & \\
\hline Dispatchable & 0 & Dispatchable & 0.0 of & 0.00 .0 & & \\
\hline Shunts & 3 & Shunt (inj) & 0.0 & 14.7 & & \\
\hline Branches & 80 & Losses $\left(I^{2} * \mathrm{Z}\right)$ & 19193.98 & 80178.38 & & \\
\hline Transformers & 17 & Branch Charging (inj) & - & 104.2 & & \\
\hline Inter-ties & 0 & Total Inter-tie Flow & 0.0 & 0.0 & & \\
\hline \multirow[t]{2}{*}{ Areas } & 1 & & & & & \\
\hline & \multicolumn{6}{|l|}{ Bus Data } \\
\hline $\begin{array}{r}\text { Bus } \\
\#\end{array}$ & $\operatorname{Mag}(\mathbf{p u})$ & $\begin{array}{r}\text { Voltage } \\
\text { Ang(deg) }\end{array}$ & $\mathbf{P}(\mathbf{M W})$ & $\begin{array}{r}\text { Generation } \\
\text { Q (MVAr) }\end{array}$ & $\mathbf{P}(\mathbf{M W})$ & $\begin{array}{r}\text { Load } \\
Q \text { (MVAr) }\end{array}$ \\
\hline 1 & $\overline{1.040}$ & $-\overline{56.800}$ & - & - & 1218.85 & 183.00 \\
\hline 2 & 1.569 & 92.546 & - & - & 362.27 & 38.00 \\
\hline 3 & 0.169 & -117.422 & - & - & 1.54 & 39.00 \\
\hline 4 & 1.046 & 39.180 & - & - & - & \\
\hline 5 & 1.659 & 13.991 & - & - & 24.83 & 0.00 \\
\hline 6 & 0.234 & -93.435 & - & - & 143.11 & 23.00 \\
\hline 7 & 0.095 & -138.989 & - & - & & \\
\hline 8 & 1.005 & -4.450 & 1789.32 & 3500.31 & 150.00 & 22.00 \\
\hline 9 & 0.393 & -72.804 & - & - & 231.00 & 17.00 \\
\hline 10 & 2.677 & 167.747 & - & - & 9.55 & 3.82 \\
\hline 11 & 1.934 & -100.223 & - & - & & \\
\hline 12 & 0.110 & -29.715 & - & - & 127.57 & 131.00 \\
\hline 13 & 0.054 & -130.516 & - & - & 34.37 & 4.39 \\
\hline 14 & 0.274 & 39.373 & - & - & 20.05 & 10.12 \\
\hline 15 & 0.794 & $\begin{array}{r}-38.174 \\
\end{array}$ & - & $=$ & 42.01 & 9.55 \\
\hline 16 & 0.080 & -123.569 & - & - & 82.11 & 5.73 \\
\hline 17 & 0.442 & 61.972 & - & - & 80.21 & 15.28 \\
\hline 18 & 0.075 & -49.797 & - & - & 51.94 & 18.71 \\
\hline 19 & 0.174 & 129.599 & - & - & 6.30 & 1.15 \\
\hline 20 & 0.002 & -75.343 & - & - & 4.39 & 1.91 \\
\hline 21 & 0.053 & -85.928 & - & - & - & . \\
\hline 22 & 0.062 & -59.108 & - & - & & \\
\hline 23 & 0.018 & -171.533 & - & - & 12.03 & 4.01 \\
\hline 24 & 0.249 & -128.525 & - & - & & \\
\hline 25 & 1.502 & -123.838 & - & - & 12.03 & 6.11 \\
\hline 26 & 0.319 & 3.632 & - & - & & \\
\hline 27 & 0.696 & -90.990 & - & - & 17.76 & 0.95 \\
\hline 28 & 0.296 & -138.812 & - & - & 8.78 & 4.39 \\
\hline 29 & 0.398 & 116.753 & - & $=$ & 32.46 & 4.97 \\
\hline 30 & 0.456 & -153.834 & - & - & 6.87 & 3.44 \\
\hline 31 & 0.212 & 91.732 & - & - & 11.08 & 5.54 \\
\hline 32 & 0.324 & 87.430 & - & - & 3.06 & 1.53 \\
\hline 33 & 0.354 & -49.231 & - & - & 7.26 & 3.63 \\
\hline 34 & 0.028 & 23.382 & - & - & & \\
\hline 35 & 0.043 & 132.402 & - & - & 11.46 & 5.73 \\
\hline 36 & 0.012 & -46.236 & - & - & - & 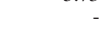 \\
\hline 37 & 0.011 & 29.795 & - & - & - & - \\
\hline 38 & 0.133 & -50.721 & - & - & 26.74 & 13.37 \\
\hline 39 & 0.035 & 51.698 & - & - & 0.17 & וס.010 \\
\hline 40 & 0.015 & 93.337 & - & - & - & - \\
\hline 41 & 0.146 & -4.806 & - & - & 12.03 & 5.73 \\
\hline 42 & 0.018 & -169.347 & - & - & 13.56 & 8.40 \\
\hline 43 & 0.164 & 88.368 & - & - & 3.82 & 1.91 \\
\hline 44 & 0.036 & 158.361 & - & - & 22.92 & 3.44 \\
\hline 45 & 0.210 & 133.556 & - & - & - & 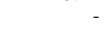 \\
\hline 46 & 0.011 & -123.296 & - & - & - & 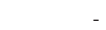 \\
\hline 47 & 0.018 & 39.724 & - & - & 56.72 & 22.15 \\
\hline 48 & 0.130 & 103.999 & - & - & & \\
\hline 49 & 0.100 & -46.616 & - & - & 34.37 & 16.23 \\
\hline 50 & 0.087 & -92.664 & - & - & 40.10 & 20.05 \\
\hline 51 & 0.068 & -156.276 & - & - & 34.37 & 10.12 \\
\hline 52 & 0.287 & -27.435 & - & - & 9.36 & 4.20 \\
\hline 53 & 0.462 & 20.306 & - & - & 38.19 & 19.10 \\
\hline 54 & 0.546 & 32.360 & - & - & 7.83 & 2.67 \\
\hline 55 & 0.265 & 89.049 & - & - & 12.99 & 6.49 \\
\hline 56 & 0.075 & 87.542 & - & - & 14.51 & 4.20 \\
\hline \multirow[t]{2}{*}{57} & 0.155 & 83.975 & - & - & 12.79 & 3.82 \\
\hline & & Total: & $1 \overline{1789.32}$ & $3 \overline{500.31}$ & 3053.19 & 705.84 \\
\hline
\end{tabular}


Aqui também é possível notar que houve violação nos limites de geração das barras 1, 2, 3, 6, 9 e 12, e que o sistema não se encontra em um ponto normal de operação devido aos valores muito altos ou muito baixos mostrados acima.

Os valores de lamb, dlamb, aclamb, ElmtoMax e a barra crícica (bc) nestes caso são:

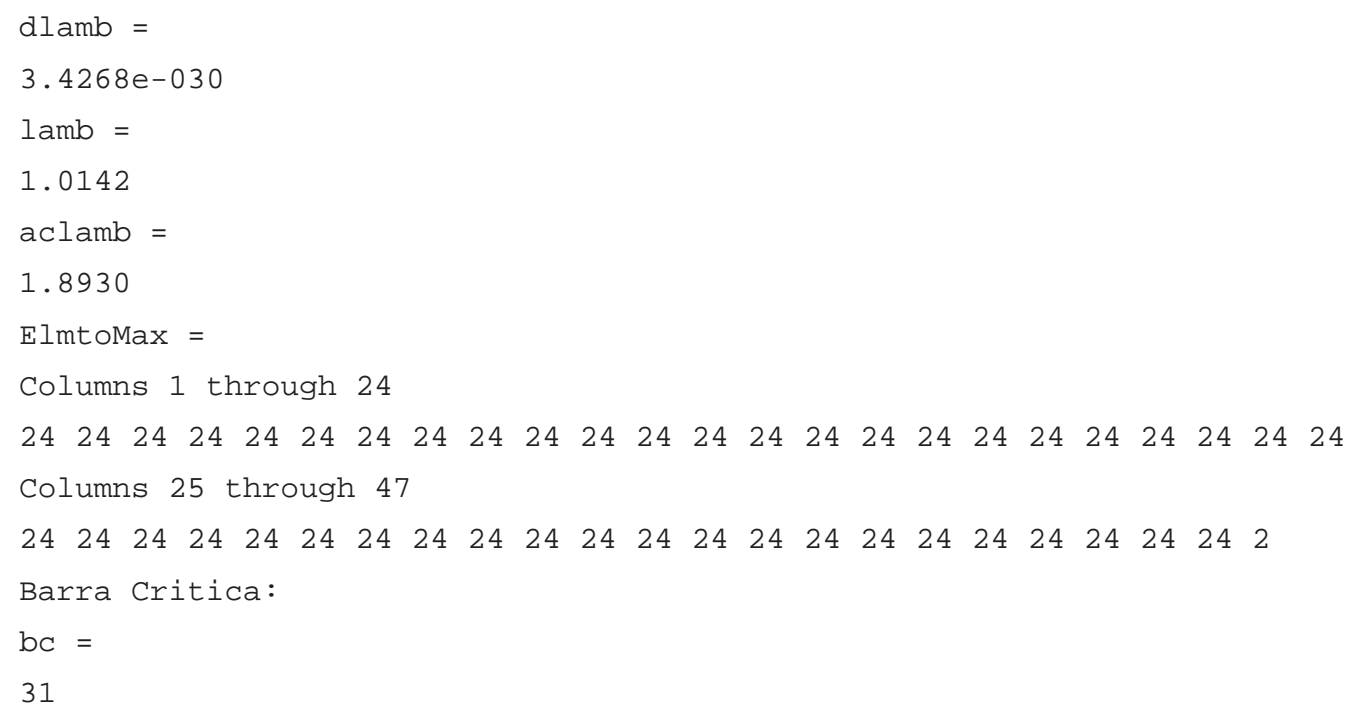

As tensões traçadas foram VbarraCritica da barra 31, VbarraMinimo da barra 53, VbarraMeio da barra 29 (tipo PQ) e também da barra 1.

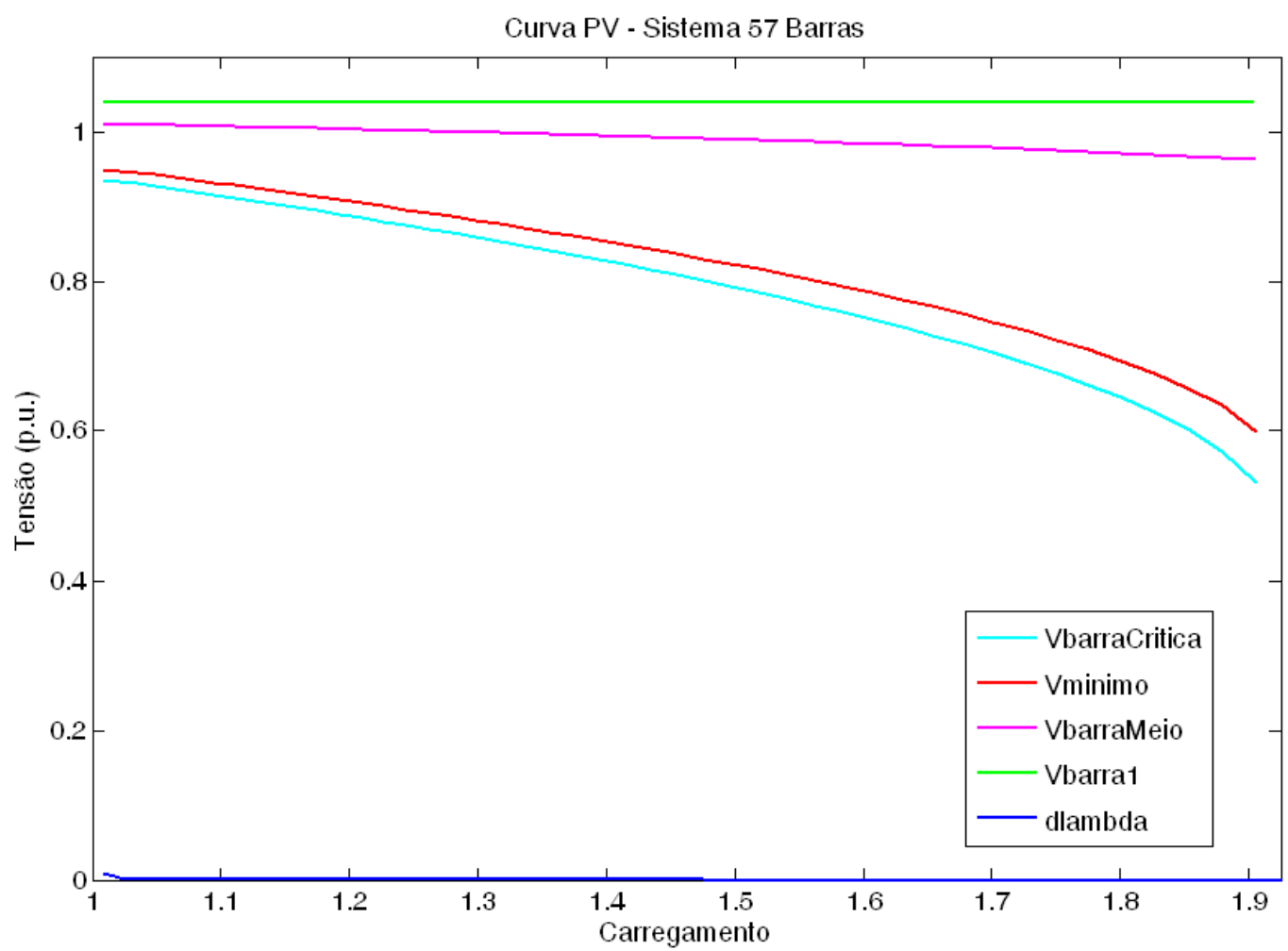

Figura 4.5: Curva PV do Sistema de 57 barras Após o Fluxo Continuado de Potência. 
Aqui a barra crítica também de destaca das demais, pois sua tensão "afunda"primeiro.

Conforme esperado, $\Delta \lambda$ também possui decaimento exponencial.

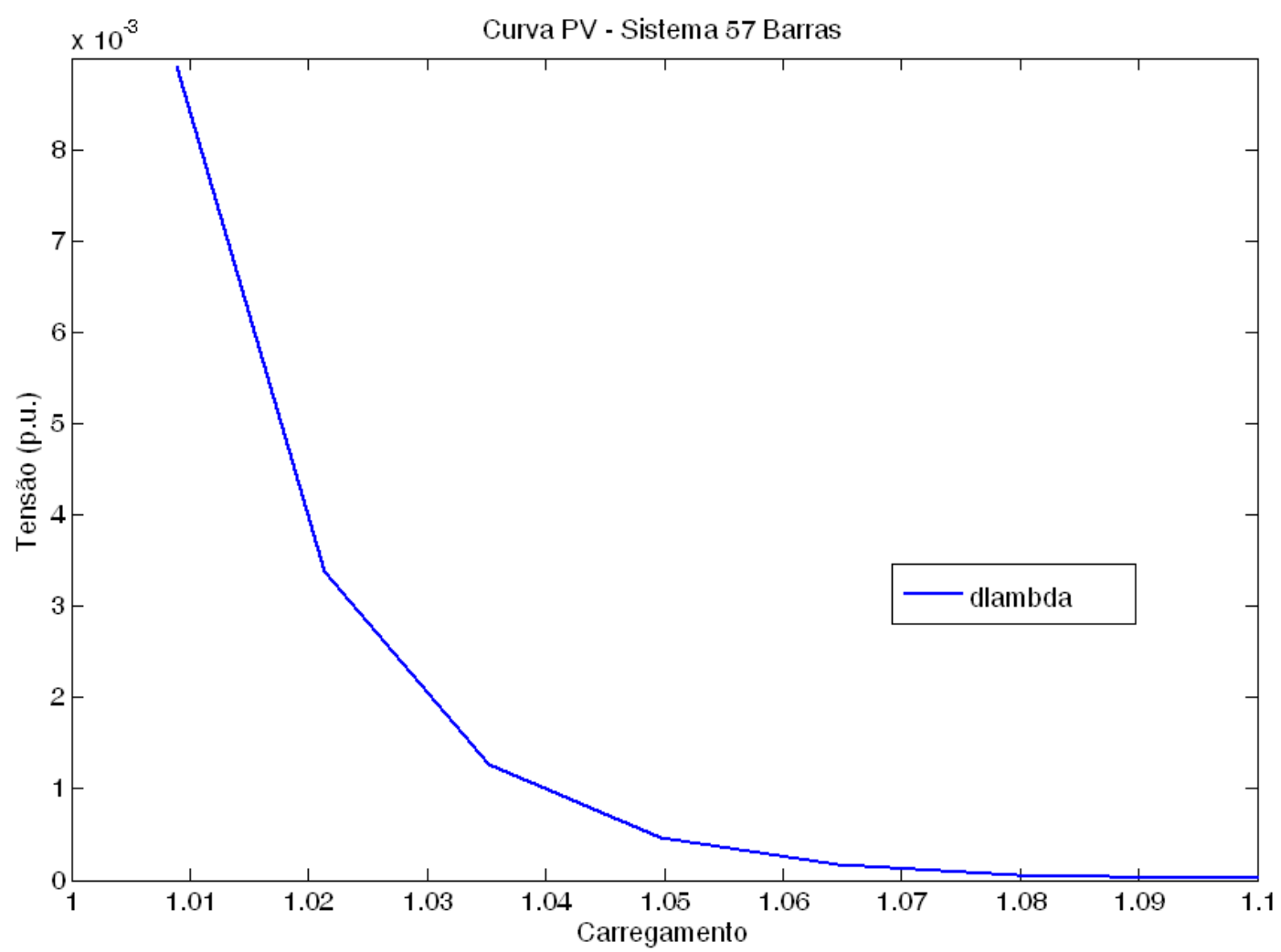

Figura 4.6: Decaimento Exponencial de $\Delta \lambda$ no Fluxo de Potência Continuado do Sistema de 57 barras.

\subsection{INFLUÊNCIA DE $\sigma^{0}$}

Conforme dito no capítulo 3, o escalar $\sigma^{0}$ tem papel fundamental na eficiência do método da continuação. Valores pequenos de $\sigma^{0}$ fazem com que o número de iterações seja muito grande e ainda assim o sistema pode não atingir seu PMC. Por outro lado, valores mais altos de $\sigma^{0}$ fazem com que o sistema ultrapasse o PMC, apresentando curvas PV distorcidas.

Esta seção exemplifica como $\sigma^{0}$ afeta a qualidade do processo testando diferentes valores deste elemento, pois os resultados da seção anterior foram obtidos utilizando o valor mais adequado de $\sigma^{0}$ de cada caso.

Para alterar o valor de $\sigma^{0}$, basta mudar o valor da variável sig que aparece no início do código do arquivo runp $_{1} \cdot m$ 


\subsubsection{Influência de $\sigma^{0}$ no Sistema 09 barras}

Na seção anterior as curvas PV traçadas para este caso foram obtidas com $\sigma^{0}$ igual a 0.002 . Também foram testados valores de $\sigma^{0}$ igual à 0.0002 (pequeno), 0.003 (maior) e 0.005 (um pouco maior). $\mathrm{O}$ resultado é mostrado a seguir:

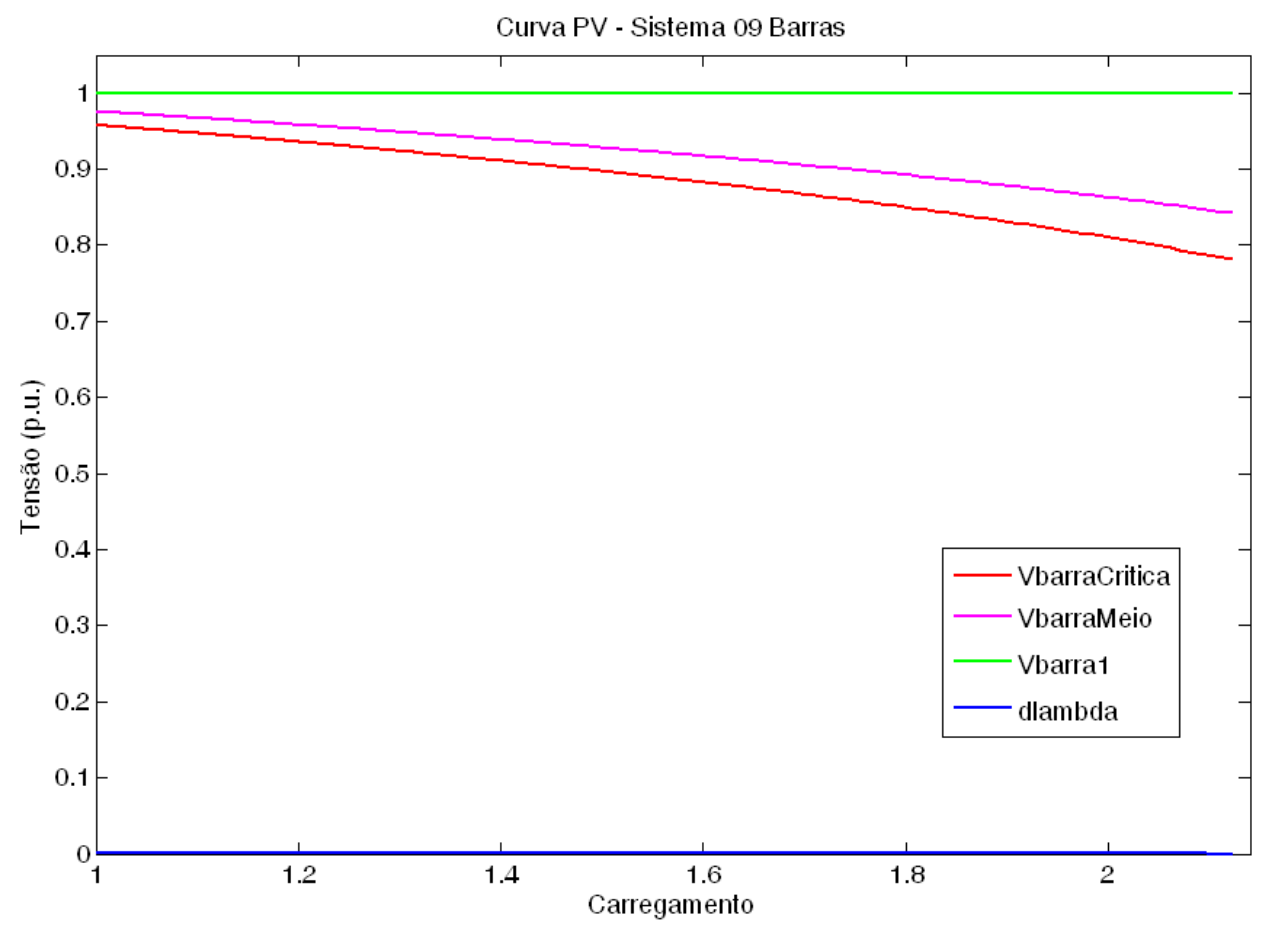

Figura 4.7: Curva PV do Sistema de 09 barras pós o Fluxo Continuado $\operatorname{com} \sigma^{0}=\mathbf{0 . 0 0 0 2}$.

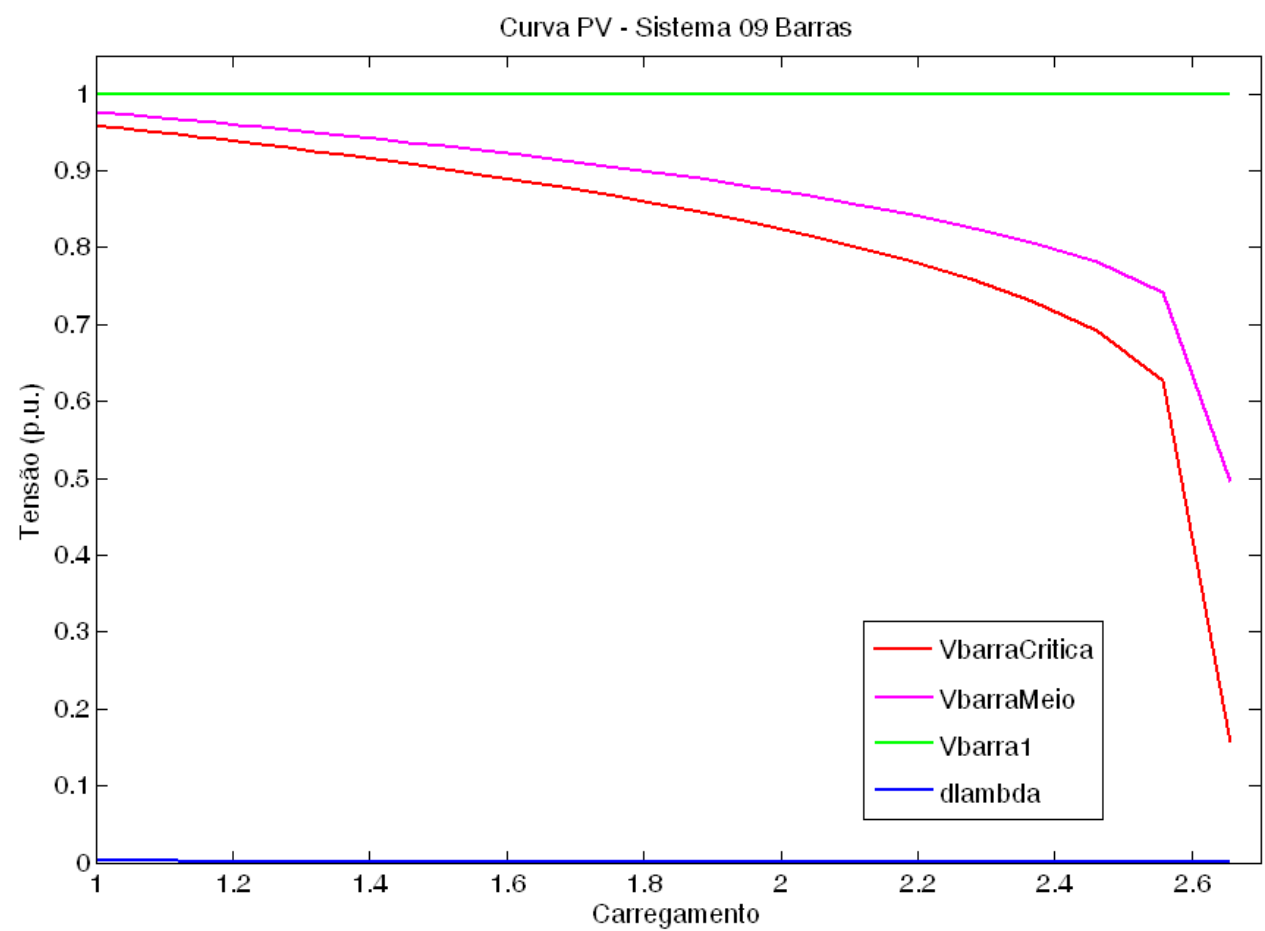

Figura 4.8: Curva PV do Sistema de 09 barras pós o Fluxo Continuado $\operatorname{com} \sigma^{0}=\mathbf{0 . 0 0 3}$. 


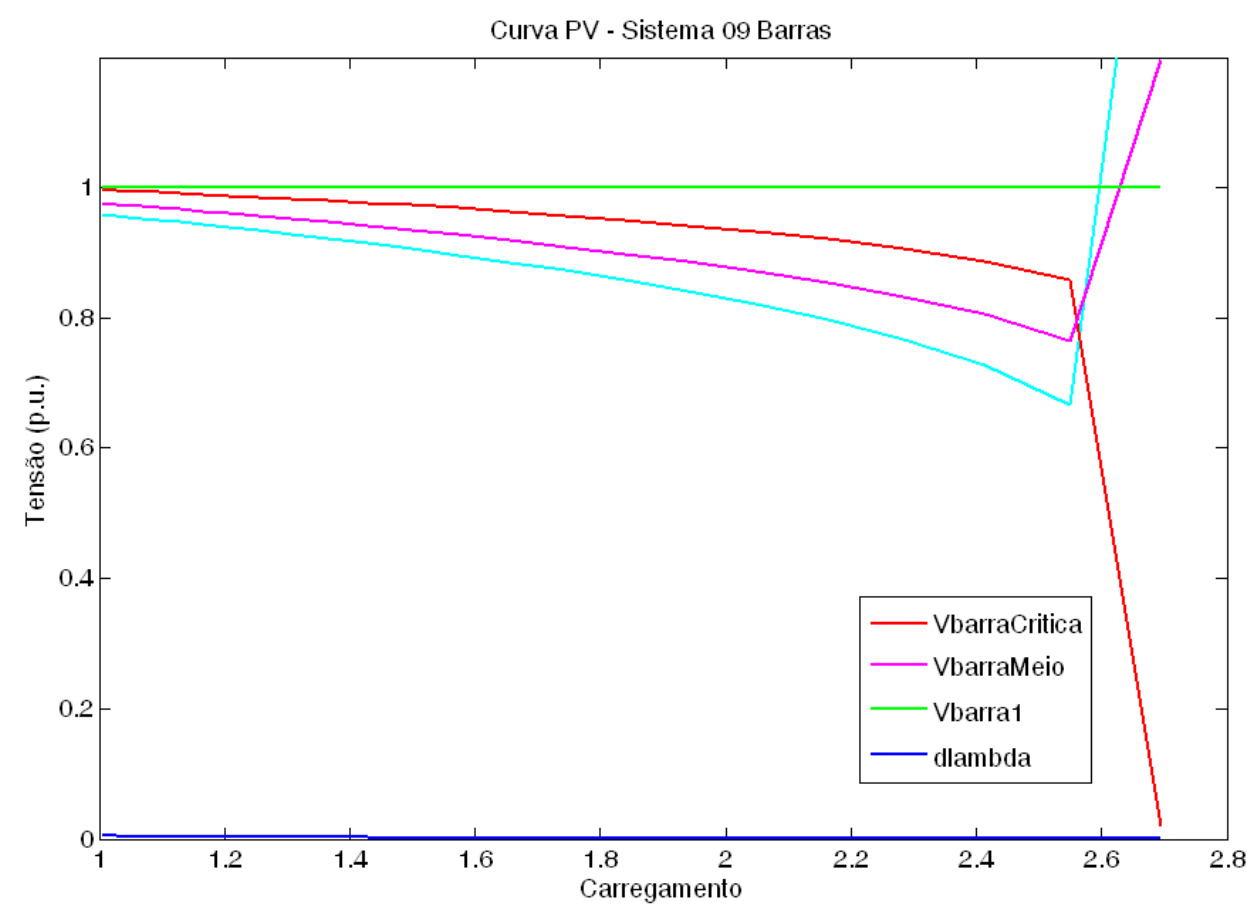

Figura 4.9: Curva PV do Sistema de 09 barras pós o Fluxo Continuado $\operatorname{com} \sigma^{0}=\mathbf{0 . 0 0 5}$.

\subsubsection{Influência de $\sigma^{0}$ no Sistema 14 barras}

O melhor valor de $\sigma^{0}$ (que foi utilizado na seção anterior) é igual à 0.015 , o valor mais baixo de $\sigma^{0}$ testado foi de 0.0025 os outros valores testados foram 0.0175 (maior) e 0.02 (um pouco maior).

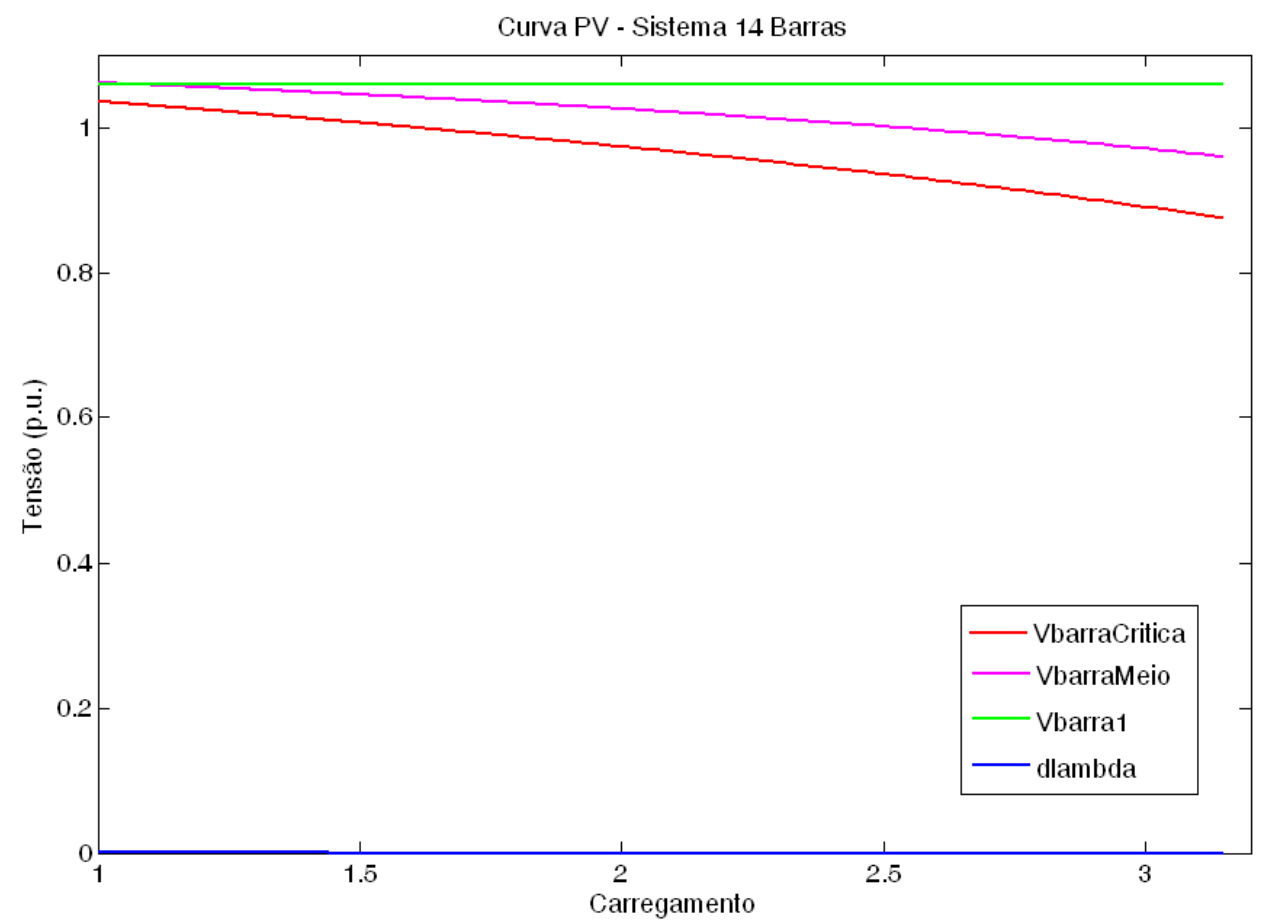

Figura 4.10: Curva PV do Sistema de 14 barras pós o Fluxo Continuado $\operatorname{com} \sigma^{0}=\mathbf{0 . 0 0 2 5}$. 


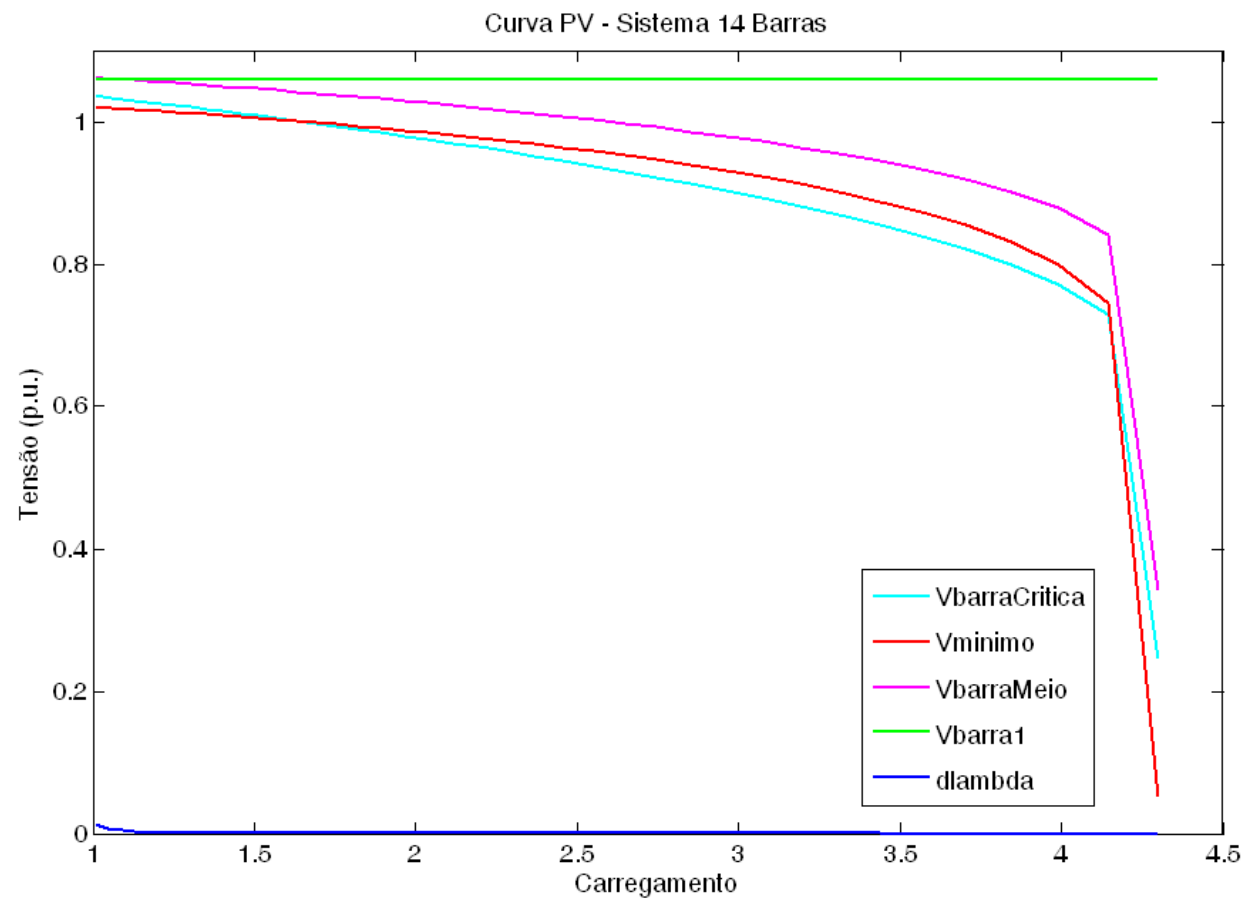

Figura 4.11: Curva PV do Sistema de 14 barras pós o Fluxo Continuado $\operatorname{com} \sigma^{0}=\mathbf{0 . 0 1 7 5}$.

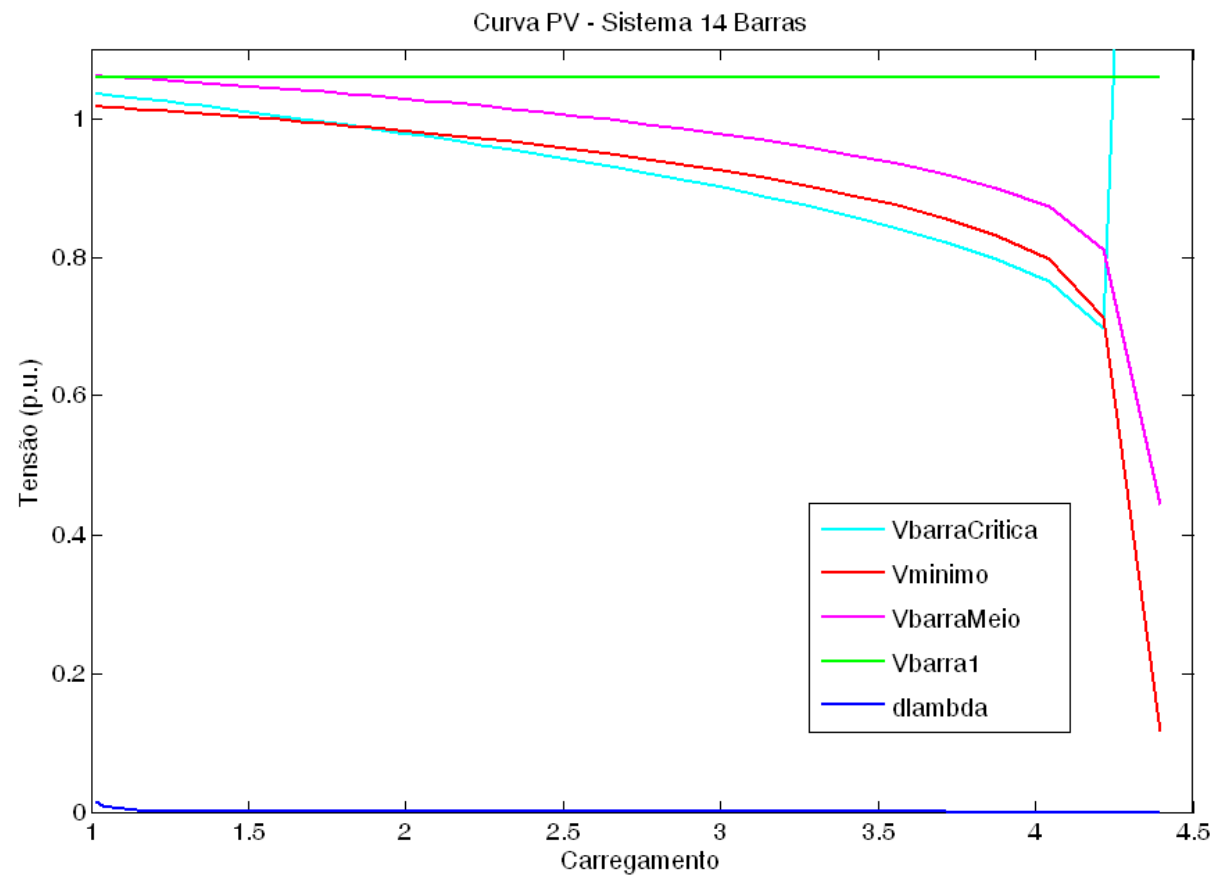

Figura 4.12: Curva PV do Sistema de 14 barras pós o Fluxo Continuado $\operatorname{com} \sigma^{0}=\mathbf{0 . 0 2}$. 


\subsubsection{Influência de $\sigma^{0}$ no Sistema 57 barras}

O mesmo procedimento anterior foi adotado para este sistema, que se mostrou mais sensível em relação a $\sigma^{0}$. Os valores utilizados foram iguais à 0.023 (melhor, da seção anterior), agora $\sigma^{0}$ é igual à 0.004(pequeno), 0.025(alto), 0.0275(pouco mais alto).

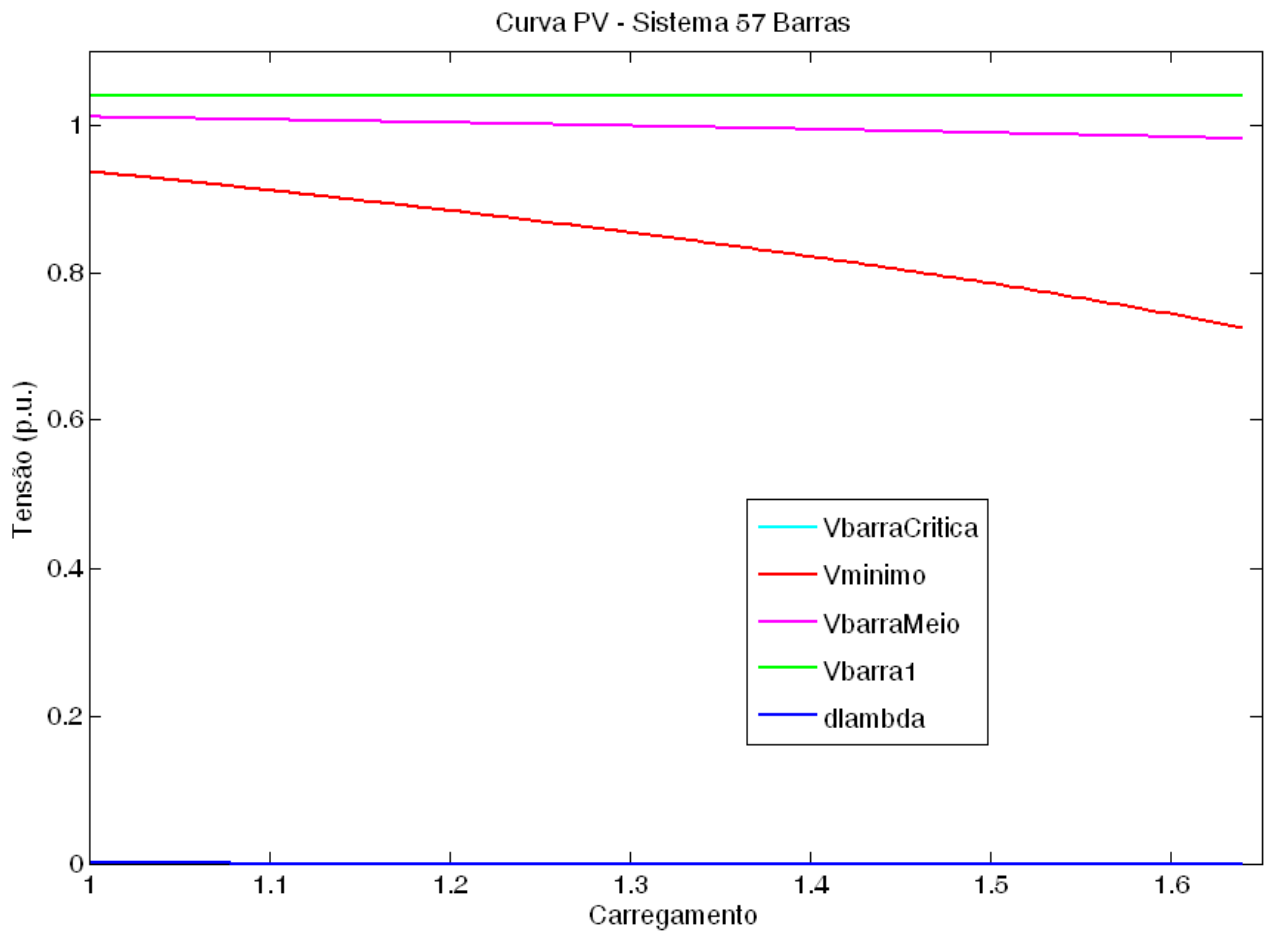

Figura 4.13: Curva PV do Sistema de 57 barras pós o Fluxo Continuado $\operatorname{com} \sigma^{0}=\mathbf{0 . 0 0 4}$.

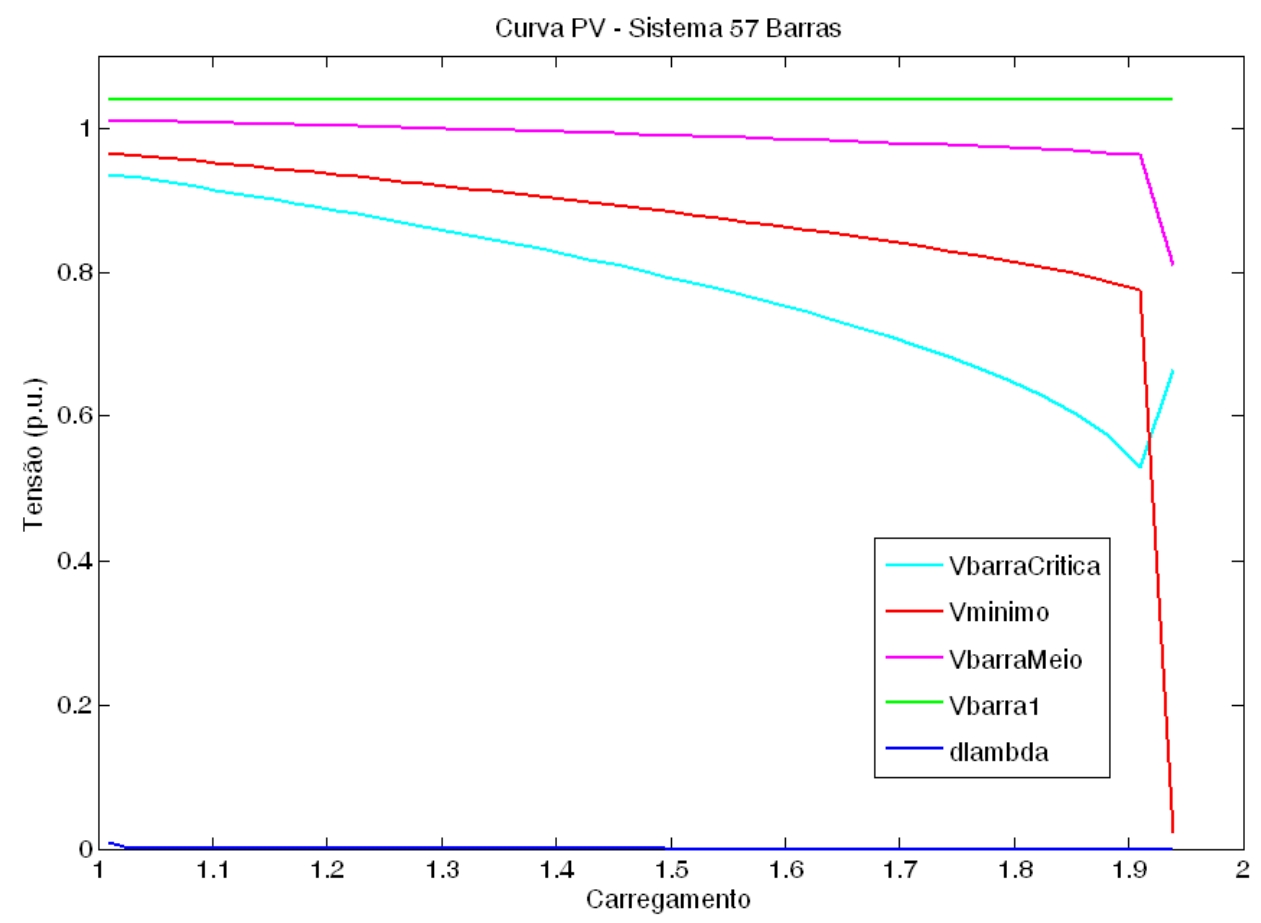

Figura 4.14: Curva PV do Sistema de 57 barras pós o Fluxo Continuado $\operatorname{com} \sigma^{0}=\mathbf{0 . 0 2 5}$. 


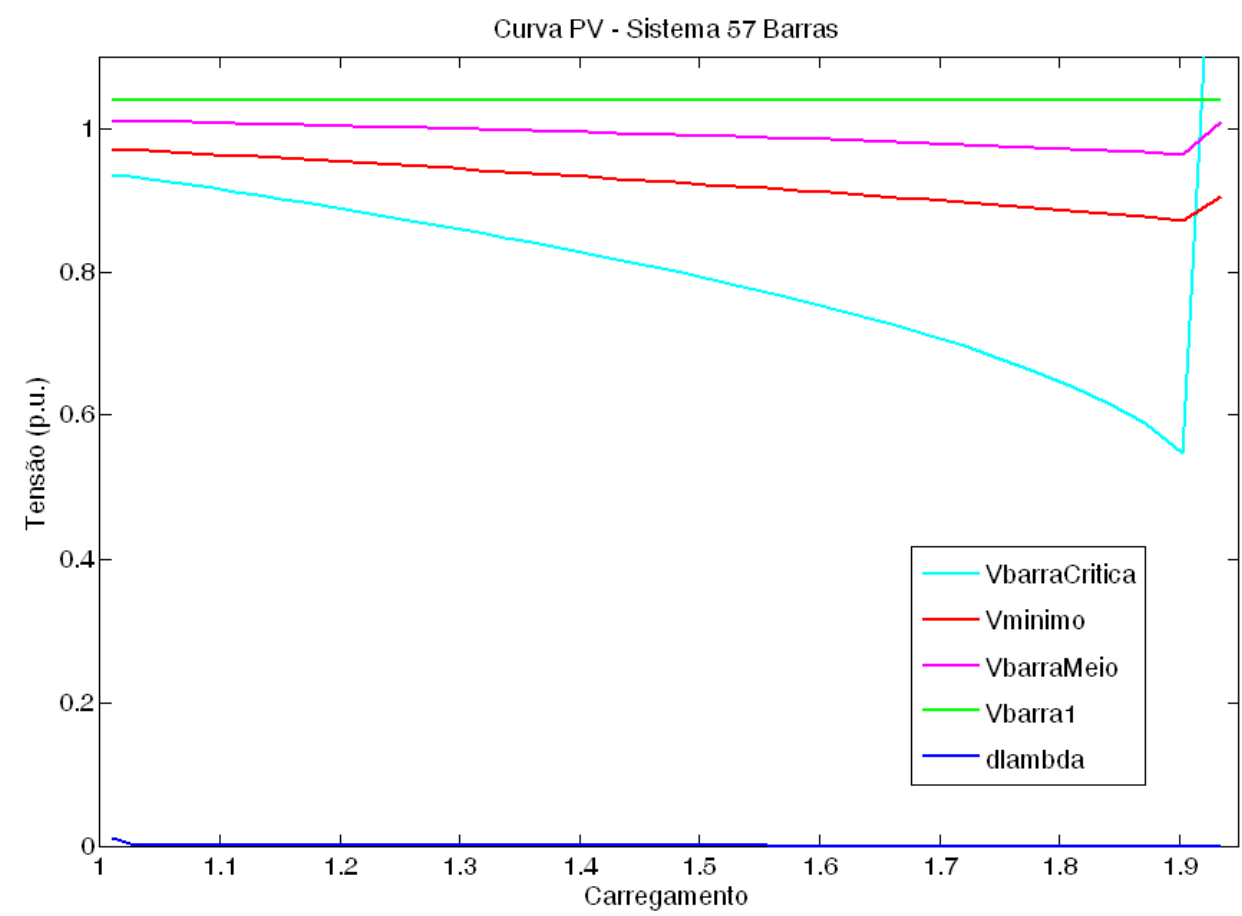

Figura 4.15: Curva PV do Sistema de 57 barras pós o Fluxo Continuado $\operatorname{com} \sigma^{0}=\mathbf{0 . 0 2 7 5}$.

Nos três casos é possível perceber que para obter curvas PV com qualidade, é necessária a boa escolha de $\sigma^{0}$. Além disso, é preciso analisá-lo com cuidado, pois pequenas diferenças em $\sigma^{0}$ causam grandes diferenças nos resultados finais.

\subsection{COMPENSAÇÃO DE POTÊNCIA REATIVA NAS BARRAS CRÍTICAS}

Após análise dos resultados do fluxo de potência continuado, foram feitos alguns testes inserindo-se bancos de capacitores nas barras críticas dos sistemas de 09,14 e 57 barras para que o problema de colapso de tensão fosse amenizado pela compensação de potência reativa.

A inserção de bancos de capacitores é feita no arquivo de dados de entrada. Na matriz correspondente às barras do sistema, deve-se localizar a coluna $B s$ (susceptância em paralelo) e alterar a linha de determinada barra com o valor desejado de injeção de potência reativa em $M V A r$.

A quantidade de energia reativa utilizada foi escolhida empiricamente para cada caso. Os valores utilizados foram aqueles que apresentaram melhoria mais significativa nas curvas PV e que não resultaram em tensões elevadas na condição de carga leve. 


\subsubsection{Compensação de Potência Reativa na Barras Crítica do Sistema 09 barras}

Neste sistema foi injetado 80 MVar de potência reativa na barra 9(barra crítica do sistema, determinada anteriormente), o fluxo continuado foi executado com os mesmo parâmetros da figura 4.1(Curva PV do Sistema de 09 barras Após o Fluxo Continuado de Potência), ou seja $\sigma^{0}=0.02$, resultando em:

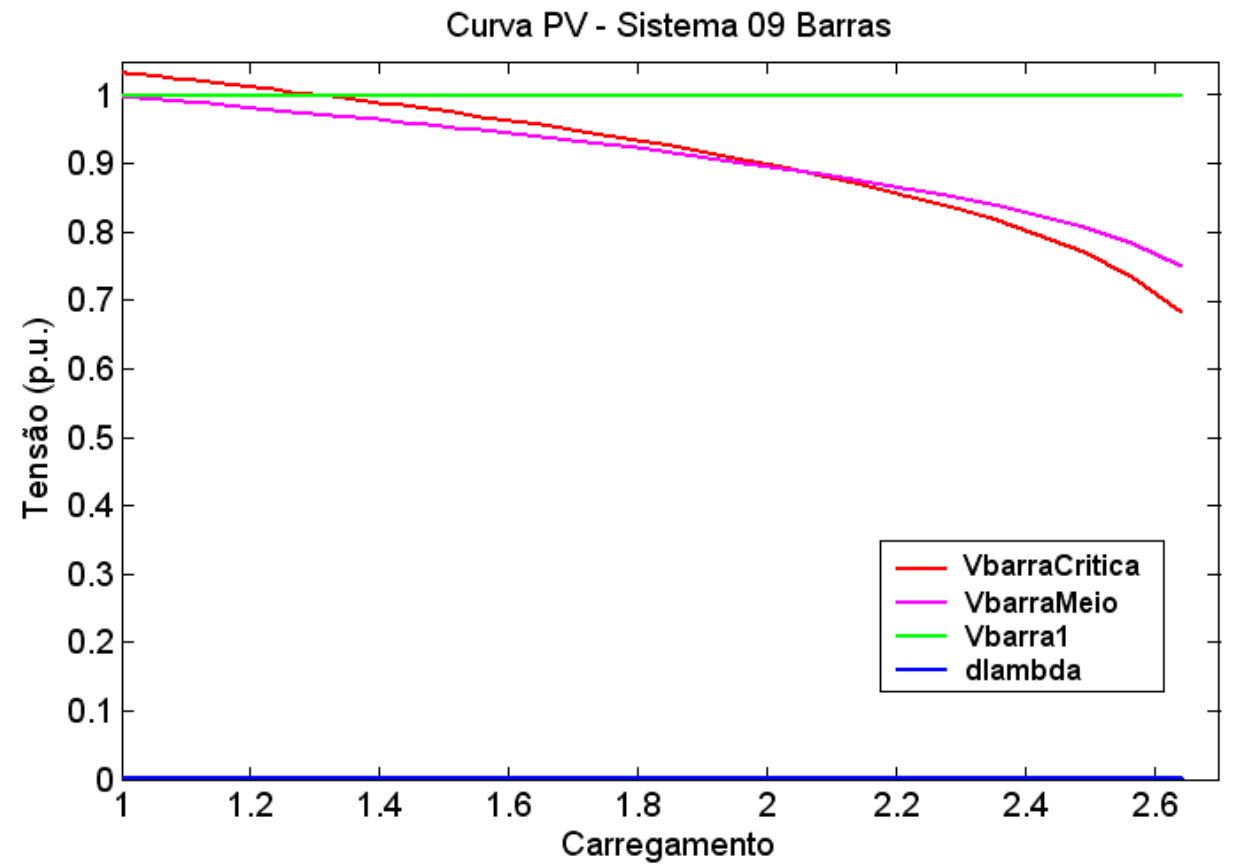

Figura 4.16: Curva PV do Sistema de 09 barras com Banco de Capacitores na Barra Crítica

Apesar de inserir o banco de capacitores em paralelo, a barra crítica do sistema permanece a mesma, por isso na figura acima VbarraCritica é a tensão da barra 9, (VbarraMeio) da barra 5 e (Vbarra1) da barra 1 para efeito de comparação. A diferença entre esta figura e a figura 4.1, é que a tensão na barra crítica foi elevada devido à susceptância em paralelo conectada ao barramento.

\subsubsection{Compensação de Potência Reativa na Barras Crítica do Sistema 14 barras}

A compensação de potência reativa neste sistema foi feita com a injeção de 30 MVAr na barra crítica do sistema (barra 14). A curva PV a seguir foi obtida com mesmo $\sigma^{0}$ da figura 4.3, o quê significa $\sigma^{0}=.015$. 


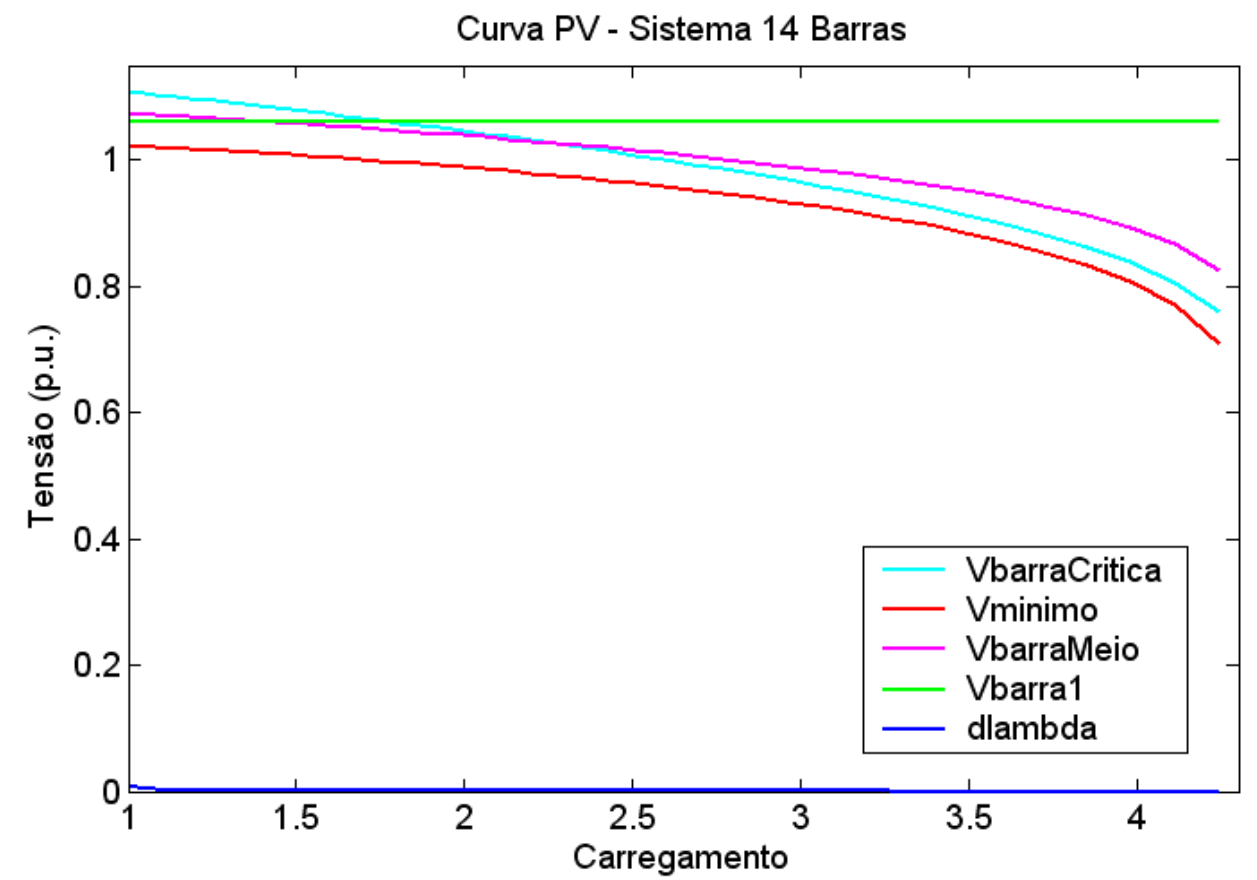

Figura 4.17: Curva PV do Sistema de 14 barras com Banco de Capacitores na Barra Crítica

Novamente não houve mudança no índice da barra crítica do sistema. Assim, na figura anterior VbarraCritica é a tensão da barra 14, VbarraMinimo é a barra 5, VbarraMeio é a barra 7 e também é traçada a tensão na barra 1. Também nota-se um aumento na tensão da barra crítica em relação a figura 4.3.

\subsubsection{Compensação de Potência Reativa na Barras Crítica do Sistema 57 barras}

O mesmo procedimento foi adotado para o sistema de 57 barras, com injeção de potência reativa igual à 30 MVAr, o gráfico abaixo também foi traçado com o mesmo $\sigma^{0}=0.23$ da figura 4.5. As tensões traçadas foram VbarraCritica da barra 31, VbarraMinimo da barra 53, VbarraMeio da barra 29 e também da barra 1. 


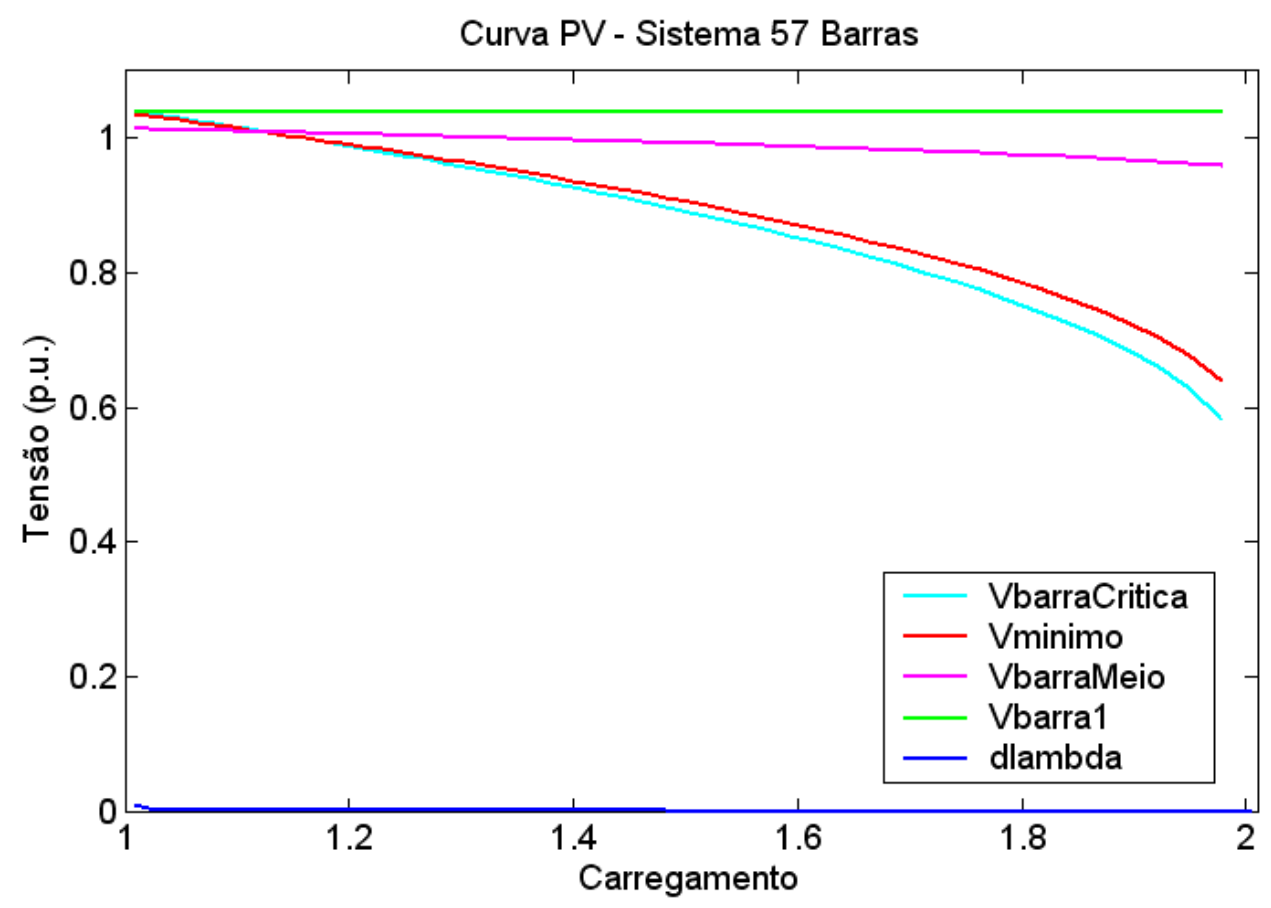

Figura 4.18: Curva PV do Sistema de 57 barras com Banco de Capacitores na Barra Crítica

Obteve-se um resultado parecido com o encontrado anteriormente. Houve elevação na barra crítica em relação a figura 4.5 (Curva PV do Sistema de 57 barras Após o Fluxo Continuado de Potência Continuado), sem alteração de seu índice.

Nos três casos, foi possível perceber que a compensação de energia reativa por meio de banco de capacitores em paralelo é uma medida simples que deixa o sistema um pouco mais seguro e robusto em relação ao problema de colapso de tensão. Percebe-se que este procedimento apenas elevou a tensão da barra crítica, sendo insuficiente para alterar seu o índice da e para aumentar a capacidade de carga dos sistemas. 


\section{CONCLUSÕES}

\subsection{ASPECTOS GERAIS}

Um estudo básico sobre o colapso de tensão baseado no fluxo de carga continuado e no método do vetor tangente foi apresentado neste trabalho. Para isso, após a introdução do capítulo 1, o capítulo 2 apresentou os principais conceitos para o entendimento e aplicação do método da continuação, e também considerações sobre a barra crítica do sistema e a compensação de potência reativa.

O $3^{\circ}$ capítulo mostrou como pode ser feita a aplicação dos conceitos do capítulo anterior, a partir do programa MATPOWER, e por isso foram apresentados os principais trechos do código desenvolvido. Na seqüência, o capítulo 4 expõe os resultados obtidos para os sistemas de 09,14 e 57 barras através de curvas PV que mostram o comportamento da amplitude tensão em algumas barras, inclusive na barra crítica.

O fluxo continuado de potência pode ser considerado como mais uma ferramenta de simulação computacional para auxiliar decisões de operação, planejamento e investimento em sistemas de potência, tendo em vista evitar o problema de colapso de tensão. Apesar de seu esforço computacional em sistemas maiores, sua implementação é simples e fácil. Além disso, é capaz traçar curvas PV, apresentando dados válidos que obedecem seus fundamentos teóricos.

Algumas características do método da continuação aplicado ao fluxo de carga foram comprovadas, como a sensibilidade do processo em relação ao tamanho do passo inicial $\sigma^{0}$. E o método do vetor tangente associado ao fluxo continuado mostrou-se seguro e satisfatório na identificação precoce da barra crítica.

A tentativa de amenizar o problema do colapso de tensão utilizando-se bancos de capacitores provocou melhorias discretas nos resultados obtidos, sem que houvesse mudança na localização da área crítica dos sistemas estudados.

\subsection{SUGESTÕES PARA ESTUDOS FUTUROS}

A principal sugestão para estudos futuros é a aplicação do fluxo continuado na simulação de sistemas maiores e reais, como trechos do SIN, considerando-se de forma fiel à realidade suas restrições de geração, transmissão e características mais detalhas das cargas. 
Com os métodos estudados aqui também é possível analisar outras medidas preventivas e corretivas mais eficazes do que aquela escolhida neste trabalho, com objetivo de evitar o colapso de tensão. E assim, gerar um lista de prioridade dos procedimentos a serem adotados por ordem de severidade.

E finalmente, reunir todos estes aspectos em um único programa que pode contribuir para assegurar a continuidade do suprimento de energia elétrica para todos consumidores. 


\section{REFERÊNCIAS BIBLIOGRÁFICAS}

[1] JúNIOR, J. N. de R. Ações Corretivas de Controle de Tensão no Sistema Mato Grosso Baseadas em Estudo de Estabilidade de Tensão. Dissertação (Mestrado) — Universidade de Brasília, Brasília, 1999.

[2] ALVES, D. et al. Esquemas alternativos para o passo de parametrização do método da continuação baseado em parâmetros físicos. Revista Controle e Automação, v. 13, no.3, 2002.

[3] FERRAZ, J. C. R. et al. Fluxo de potência continuado e análise modal na avaliação e melhoria da estabilidade de tensão do sistema sul-sudeste. VII Simpósio de Especialistas em Planejamento da Operação e Expansão Elétrica, 2000.

[4] DAMASCENO, F. F. Notas de Aula-Análise de Sistemas de Potência. [S.1.], 2005. Diponível on-line em: http://www.gsep.ene.unb.br/osem_damasceno.php.

[5] PRADA, R. et al. Identificação do ramo de transmissão crítico para reforço das condições de segurança de tensão. Revista Controle e Automação, v. 17, 2006.

[6] KUNDUR, P. Power system stability and control. In: BALU, N. J.; LAUBY, M. G. (Ed.). Eletric Power Research Institute, 3412 Hillview Avenue, Palo Alto, California: McGraw-Hill, 1994, (Power Systems Engineering Series).

[7] FERREIRA, C.; COSTA, V. da. Controle de tensão no fluxo de potência continuado - modelagens e efeitos na estabilidade de tensão. Revista Controle e Automação, 2004.

[8] SOUZA, A. C. Z. de et al. Increasing the loadability of power systems through optimal-local-controle actions. IEEE Transactions on Power Systems, v. 19, 2004.

[9] HERNáNDEZ, E. et al. Fluxo de carda da continuação: Determinação automática do parâmetro de continuação. UNICAMP/UNESP, 2000.

[10] SOUZA, A. C. Z. de; CAñIZARES, A.; QUINTANA, V. New techniques to speed up voltage collpase computations using tangent vectors. PSE/IEEE-Paper PE-PWSR-0-11-1996, 1996.

[11] TAYLOR, C. W. Power system voltage stability. In: BALU, N. J.; MARATUKULAM, D. (Ed.). Eletric Power Research Institute, 3412 Hillview Avenue, Palo Alto, California: McGraw-Hill, 1992, (Power Systems Engineering Series). 
[12] [S.l.]. Disponível on-line em: http://www.pi.gov.br/materia.php?id=15866 - Piauí investe R\$ 78 milhões em capacidade energética.

[13] ZIMMERMAN, R. D.; MURILLO-SáNCHEZ, C. E.; GAN, D. MATPOWER Power System Simulation Package Userśs Manual. [S.1.], 2006. Diponível on-line em: http://www.pserc.cornell.edu/matpower/. 
ANEXOS 


\section{DADOS DE ENTRADA DOS SISTEMAS 09,14 E 57 BARRAS}

\section{I.1 DADOS DE ENTRADA DOS SISTEMAS 09 BARRAS}

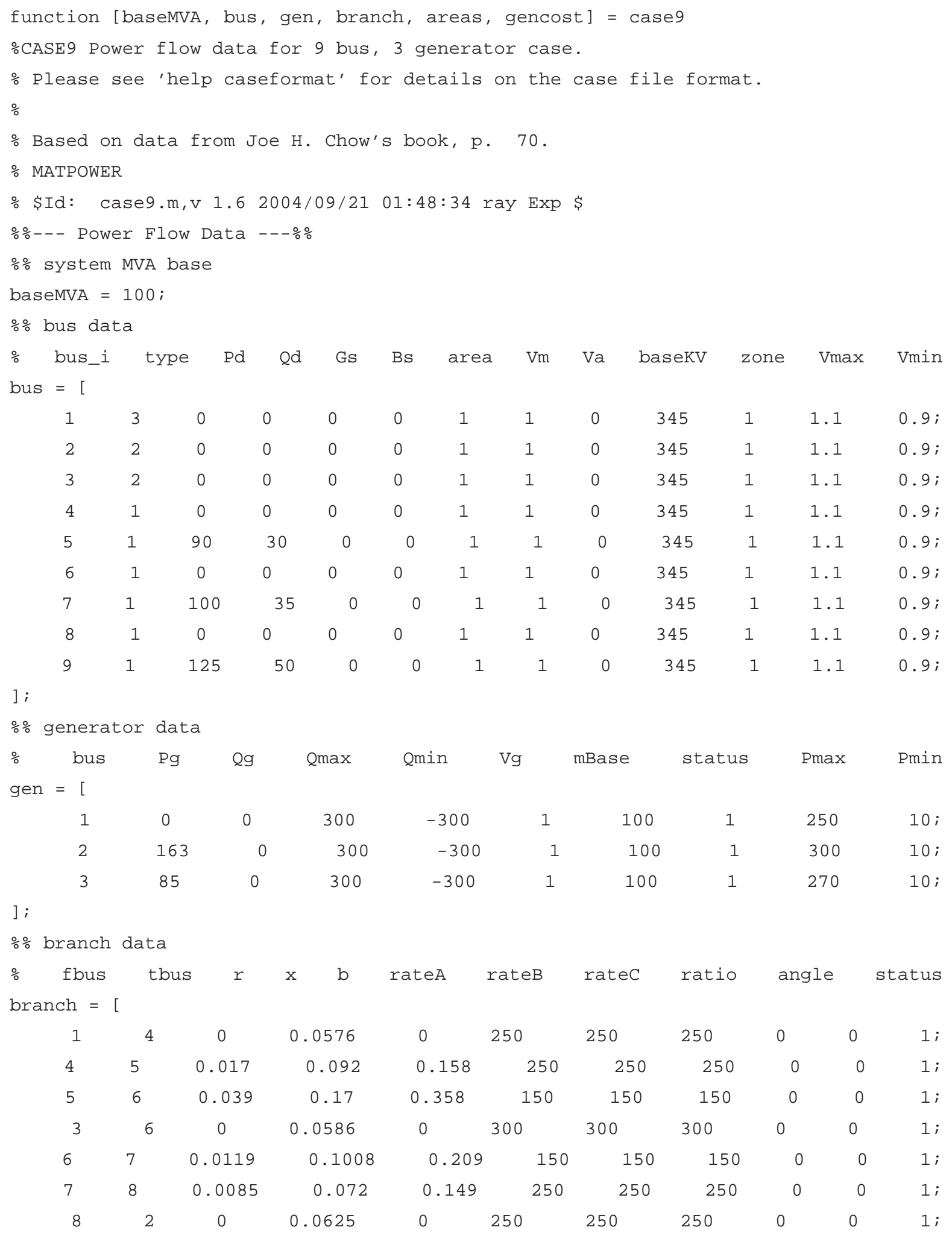




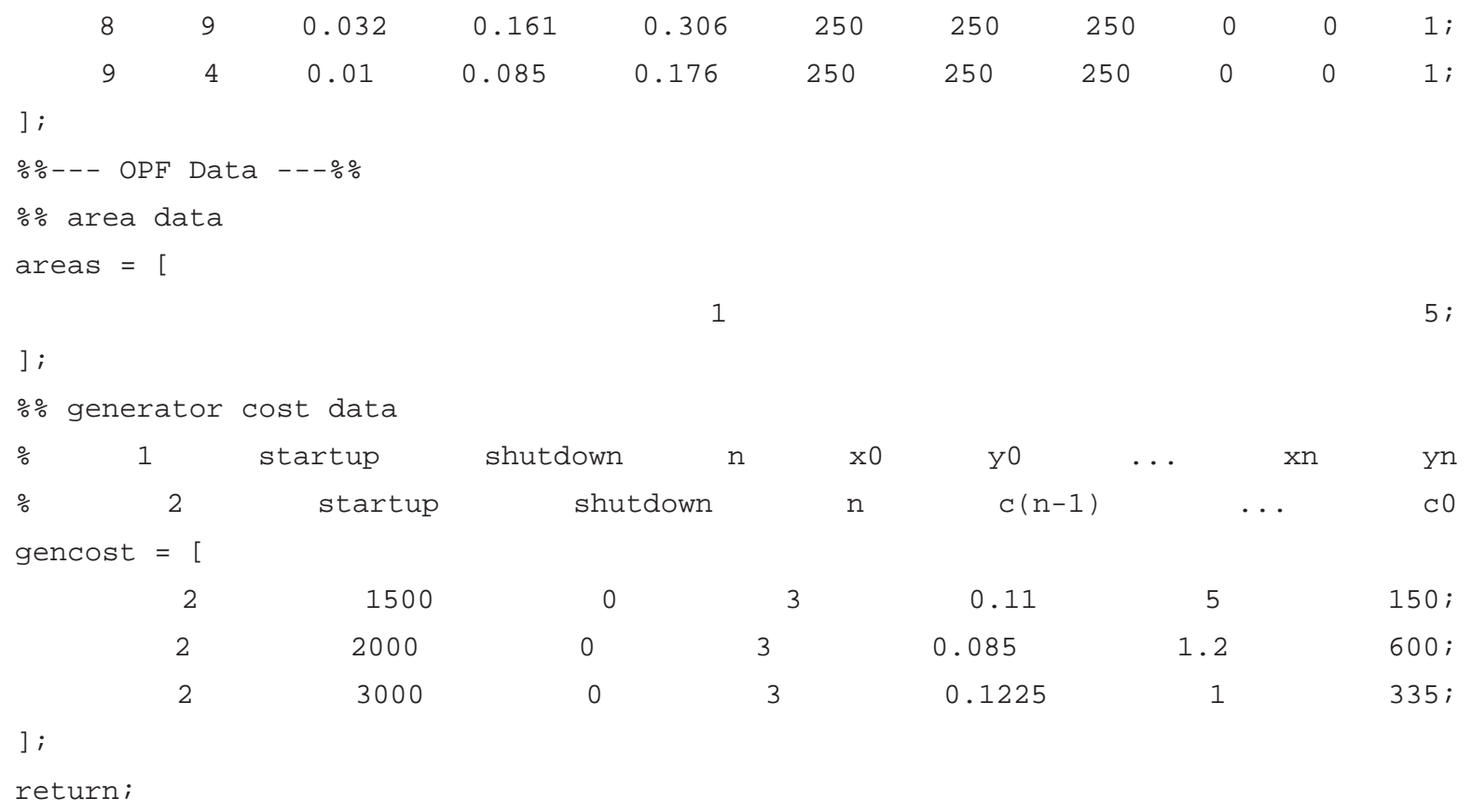

\section{I.2 DADOS DE ENTRADA DOS SISTEMAS 14 BARRAS}

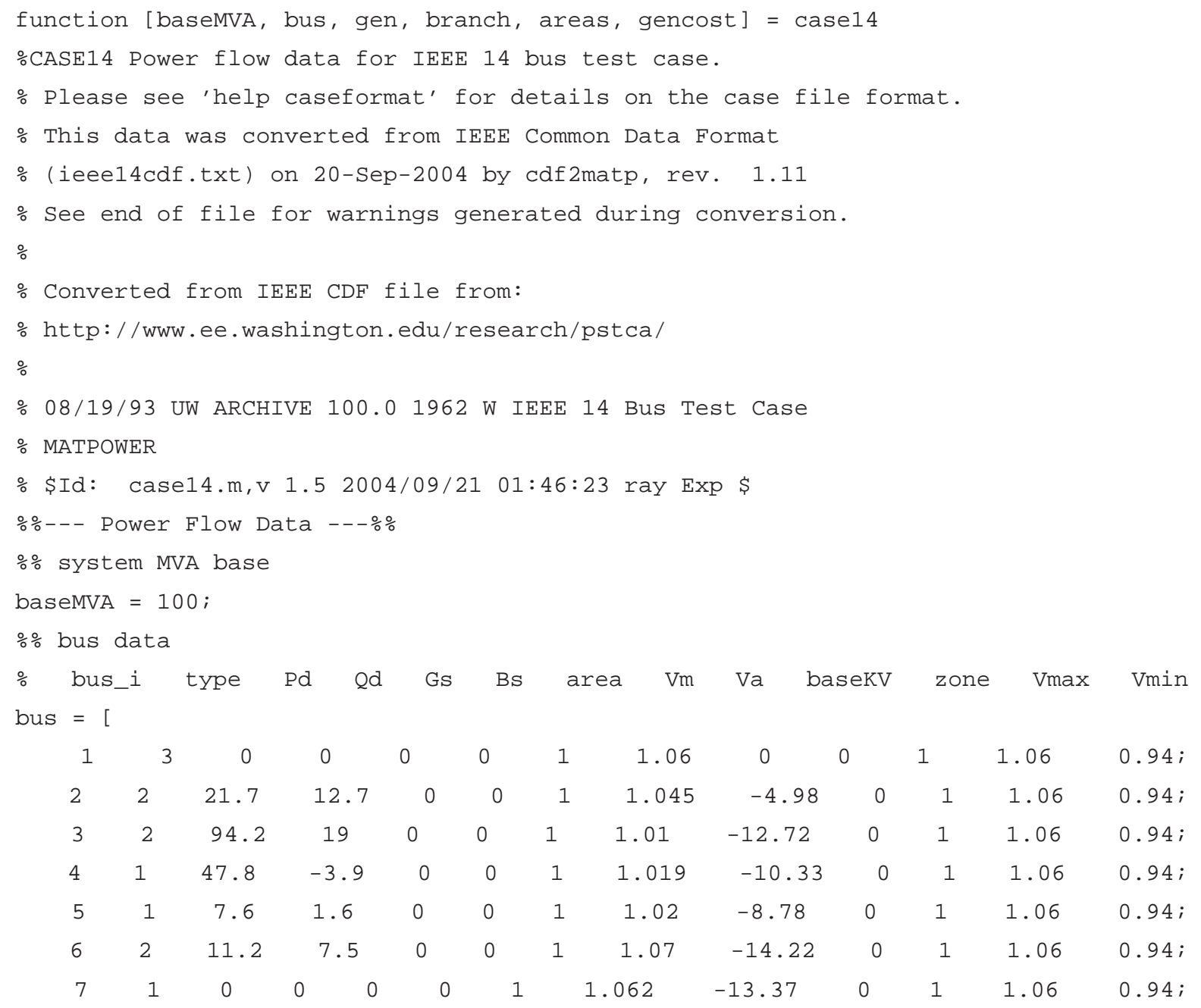




$\begin{array}{cccccccccccccc}8 & 2 & 0 & 0 & 0 & 0 & 1 & 1.09 & -13.36 & 0 & 1 & 1.06 & 0.94 ; \\ 9 & 1 & 29.5 & 16.6 & 0 & 19 & 1 & 1.056 & -14.94 & 0 & 1 & 1.06 & 0.94 ; \\ 10 & 1 & 9 & 5.8 & 0 & 0 & 1 & 1.051 & -15.1 & 0 & 1 & 1.06 & 0.94 ; \\ 11 & 1 & 3.5 & 1.8 & 0 & 0 & 1 & 1.057 & -14.79 & 0 & 1 & 1.06 & 0.94 ; \\ 12 & 1 & 6.1 & 1.6 & 0 & 0 & 1 & 1.055 & -15.07 & 0 & 1 & 1.06 & 0.94 ; \\ 13 & 1 & 13.5 & 5.8 & 0 & 0 & 1 & 1.05 & -15.16 & 0 & 1 & 1.06 & 0.94 ; \\ 14 & 1 & 14.9 & 5 & 0 & 0 & 1 & 1.036 & -16.04 & 0 & 1 & 1.06 & 0.94 ; ;\end{array}$
] ;

응 generator data

\% bus Pg Qg Qmax Qmin Vg mBase status Pmax Pmin gen $=[$

$\begin{array}{cccccccccc}1 & 232.4 & -16.9 & 10 & 0 & 1.06 & 100 & 1 & 332.4 & 0 ; \\ 2 & 40 & 42.4 & 50 & -40 & 1.045 & 100 & 1 & 140 & 0 ; \\ 3 & 0 & 23.4 & 40 & 0 & 1.01 & 100 & 1 & 100 & 0 ; \\ 6 & 0 & 12.2 & 24 & -6 & 1.07 & 100 & 1 & 100 & 0 ; \\ 8 & 0 & 17.4 & 24 & -6 & 1.09 & 100 & 1 & 100 & 0 ;\end{array}$

] ;

응 branch data

fbus tbus $r \quad x \quad b$ rateA rateB ratec ratio angle status branch $=[$

\begin{tabular}{|c|c|c|c|c|c|c|c|c|c|}
\hline 1 & 2 & 0.01938 & 0.05917 & $0.052 \varepsilon$ & 9900 & 0 & c & 0 & 0 \\
\hline 1 & 5 & 0.05403 & 0.22304 & 0.0492 & 9900 & 0 & c & 0 & 0 \\
\hline 2 & 3 & 0.04699 & 0.19797 & 0.0438 & 9900 & 0 & c & 0 & 0 \\
\hline 2 & 4 & 0.05811 & 0.17632 & 0.034 & 9900 & 0 & 0 & 0 & 0 \\
\hline 2 & 5 & 0.05695 & 0.17388 & 0.034 & 9900 & 0 & c & 0 & 0 \\
\hline 3 & 4 & 0.06701 & 0.17103 & $0.012 \varepsilon$ & 9900 & 0 & c & 0 & 0 \\
\hline 4 & 5 & 0.01335 & 0.04211 & 0 & 9900 & 0 & 0 & 0 & 0 \\
\hline 4 & 7 & 0 . & .20912 & 99 & 0 & 0 & & 78 & 0 \\
\hline 4 & 9 & 0 . & .55618 & 99 & 0 & 0 & & 69 & 0 \\
\hline 5 & 6 & 0 . & .25202 & 99 & 0 & 0 & & & 0 \\
\hline 6 & 11 & 0.09498 & 0.1989 & 0 & 9900 & 0 & 0 & 0 & 0 \\
\hline 6 & 12 & 0.12291 & 0.25581 & 0 & 9900 & 0 & 0 & 0 & 0 \\
\hline 6 & 13 & 0.06615 & 0.13027 & 0 & 9900 & 0 & 0 & 0 & 0 \\
\hline 7 & 8 & 0 & 0.17615 & 0 & 9900 & 0 & 0 & 0 & 0 \\
\hline 7 & 9 & 0 & 0.11001 & 0 & 9900 & 0 & 0 & 0 & 0 \\
\hline 9 & 10 & 0.03181 & 0.0845 & 0 & 9900 & 0 & 0 & 0 & 0 \\
\hline 9 & 14 & 0.12711 & 0.27038 & 0 & 9900 & 0 & 0 & 0 & 0 \\
\hline 10 & 11 & 0.08205 & 0.19207 & 0 & 9900 & 0 & 0 & 0 & 0 \\
\hline 12 & 13 & 0.22092 & 0.19988 & 0 & 9900 & 0 & 0 & 0 & 0 \\
\hline 13 & 14 & 0.17093 & 0.34802 & 0 & 9900 & 0 & 0 & 0 & 0 \\
\hline
\end{tabular}

] ;

응--- OPF Data --- 응

응 area data

areas $=[$

] ;

응 generator cost data 


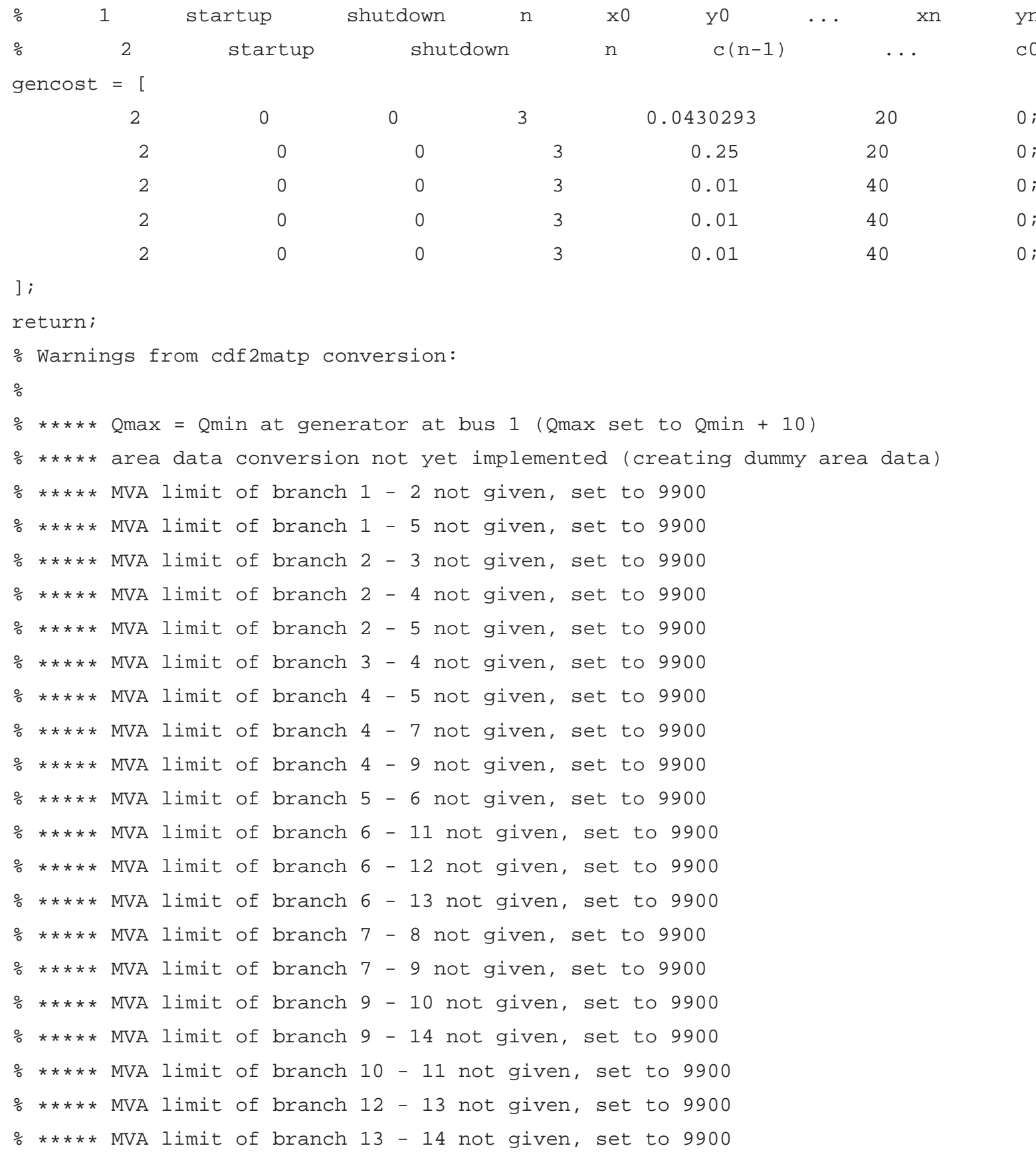

\section{I.3 DADOS DE ENTRADA DOS SISTEMAS 57 BARRAS}

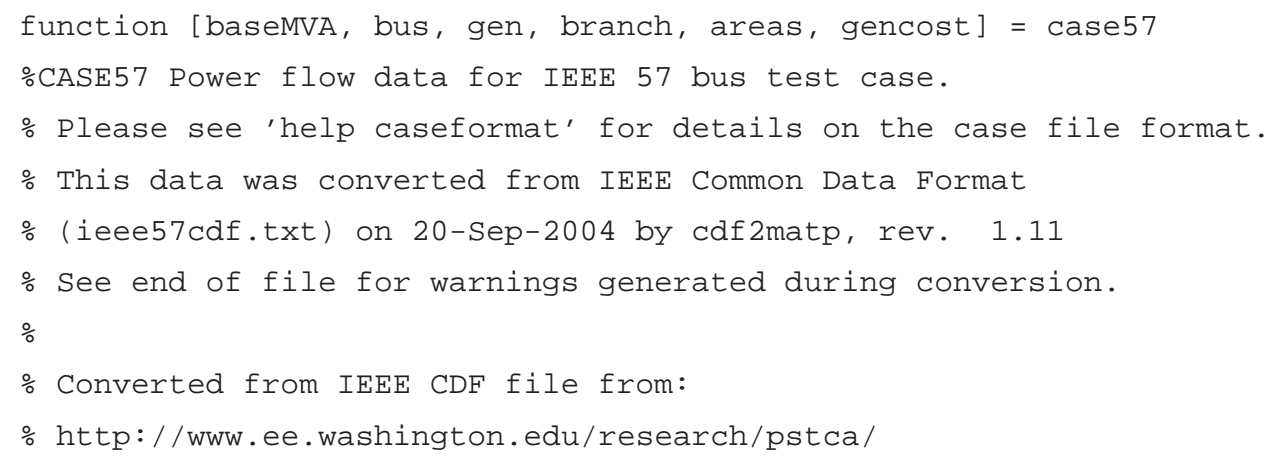


응

\% Manually modified Qmax, Qmin on generator 1 to 200, -140, respectively.

응

응 $08 / 25 / 93$ UW ARCHIVE 100.01961 W IEEE 57 Bus Test Case

\% MATPOWER

응 \$d: case57.m,v 1.5 2004/09/21 01:47:48 ray Exp \$

응--- Power Flow Data --- 응

응 system MVA base

baseMVA $=100$;

응 bus data

\% bus_i type Pd Qd Gs Bs area Vm Va baseKV zone Vmax Vmin bus $=[$

\begin{tabular}{|c|c|c|c|c|c|c|c|c|c|c|c|c|}
\hline 1 & 3 & 55 & 17 & 0 & 0 & 1 & 1.04 & 0 & 0 & 1 & 1.06 & $0.94 ;$ \\
\hline 2 & 2 & 3 & 88 & 0 & 0 & 1 & 1.01 & -1.18 & 0 & 1 & 1.06 & $0.94 ;$ \\
\hline 3 & 2 & 41 & 21 & 0 & 0 & 1 & 0.985 & -5.97 & 0 & 1 & 1.06 & $0.94 ;$ \\
\hline 4 & 1 & 0 & 0 & 0 & 0 & 1 & 0.981 & -7.32 & 0 & 1 & 1.06 & $0.94 ;$ \\
\hline 5 & 1 & 13 & 4 & 0 & 0 & 1 & 0.976 & -8.52 & 0 & 1 & 1.06 & $0.94 ;$ \\
\hline 6 & 2 & 75 & 2 & 0 & 0 & 1 & 0.98 & -8.65 & 0 & 1 & 1.06 & $0.94 ;$ \\
\hline 7 & 1 & 0 & 0 & 0 & 0 & 1 & 0.984 & -7.58 & 0 & 1 & 1.06 & $0.94 ;$ \\
\hline 8 & 2 & 150 & 22 & 0 & 0 & 1 & 1.005 & -4.45 & 0 & 1 & 1.06 & $0.94 ;$ \\
\hline 9 & 2 & 121 & 26 & 0 & 0 & 1 & 0.98 & -9.56 & 0 & 1 & 1.06 & 0.94 ; \\
\hline 10 & 1 & 5 & 2 & 0 & 0 & 1 & 0.986 & -11.43 & 0 & 1 & 1.06 & $0.94 ;$ \\
\hline 11 & 1 & 0 & 0 & 0 & 0 & 1 & 0.974 & -10.17 & 0 & 1 & 1.06 & $0.94 ;$ \\
\hline 12 & 2 & 377 & 24 & 0 & 0 & 1 & 1.015 & -10.46 & 0 & 1 & 1.06 & $0.94 ;$ \\
\hline 13 & 1 & 18 & 2.3 & 0 & 0 & 1 & 0.979 & -9.79 & 0 & 1 & 1.06 & $0.94 ;$ \\
\hline 14 & 1 & 10.5 & $5 \cdot 3$ & & 0 & 1 & 0.97 & -9.33 & 0 & 1 & 1.06 & 0.94 ; \\
\hline 15 & 1 & 22 & 5 & 0 & 0 & 1 & 0.988 & -7.18 & 0 & 1 & 1.06 & 0.94 ; \\
\hline 16 & 1 & 43 & 3 & 0 & 0 & 1 & 1.013 & -8.85 & 0 & 1 & 1.06 & $0.94 ;$ \\
\hline 17 & 1 & 42 & 8 & 0 & 0 & 1 & 1.017 & -5.39 & 0 & 1 & 1.06 & $0.94 ;$ \\
\hline 8 & 1 & 27.2 & 9.8 & 0 & 10 & 1 & 1.001 & -11.71 & 0 & 1 & 1.06 & $0.94 ;$ \\
\hline 19 & 1 & 3.3 & 0.6 & 0 & 0 & 1 & 0.97 & -13.2 & 0 & 1 & 1.06 & 0.94 ; \\
\hline 20 & 1 & 2.3 & 1 & 0 & 0 & 1 & 0.964 & -13.41 & 0 & 1 & 1.06 & $0.94 ;$ \\
\hline 21 & 1 & 0 & 0 & 0 & 0 & 1 & 1.008 & -12.89 & 0 & 1 & 1.06 & 0.94 ; \\
\hline 22 & 1 & 0 & 0 & 0 & 0 & 1 & 1.01 & -12.84 & 0 & 1 & 1.06 & $0.94 ;$ \\
\hline 23 & 1 & 6.3 & 2.1 & 0 & 0 & 1 & 1.008 & -12.91 & 0 & 1 & 1.06 & 0.94 \\
\hline 24 & 1 & 0 & 0 & 0 & 0 & 1 & 0.999 & -13.25 & 0 & 1 & 1.06 & $0.94 ;$ \\
\hline 25 & 1 & 6.3 & 3.2 & 0 & 5.9 & 1 & 0.982 & -18.13 & 0 & 1 & 1.06 & $0.94 ;$ \\
\hline 26 & 1 & 0 & 0 & 0 & 0 & 1 & 0.959 & -12.95 & 0 & 1 & 1.06 & $0.94 ;$ \\
\hline 27 & 1 & 9.3 & 0.5 & 0 & 0 & 1 & 0.982 & -11.48 & 0 & 1 & 1.06 & $0.94 ;$ \\
\hline 28 & 1 & 4.6 & 2.3 & 0 & 0 & 1 & 0.997 & -10.45 & 0 & 1 & 1.06 & 0.94 ; \\
\hline 29 & 1 & 17 & 2.6 & 0 & 0 & 1 & 1.01 & -9.75 & 0 & 1 & 1.06 & $0.94 ;$ \\
\hline 30 & 1 & 3.6 & 1.8 & 0 & 0 & 1 & 0.962 & -18.68 & 0 & 1 & 1.06 & $0.94 ;$ \\
\hline 31 & 1 & 5.8 & 2.9 & 0 & 0 & 1 & 0.936 & $-19 \cdot 34$ & 0 & 1 & 1.06 & $0.94 ;$ \\
\hline 32 & 1 & 1.6 & 0.8 & 0 & 0 & 1 & 0.949 & -18.46 & 0 & 1 & 1.06 & $0.94 ;$ \\
\hline 33 & 1 & 3.8 & 1.9 & 0 & 0 & 1 & 0.947 & -18.5 & 0 & 1 & 1.06 & $0.94 ;$ \\
\hline 34 & 1 & 0 & 0 & 0 & 0 & 1 & 0.959 & -14.1 & 0 & 1 & 1.06 & $0.94 ;$ \\
\hline 3 & 1 & 6 & 3 & 0 & 0 & 1 & 0.966 & -13.86 & 0 & 1 & 1.06 & 0.94 \\
\hline
\end{tabular}




$\begin{array}{ccccccccccccc}36 & 1 & 0 & 0 & 0 & 0 & 1 & 0.976 & -13.59 & 0 & 1 & 1.06 & 0.94 ; \\ 37 & 1 & 0 & 0 & 0 & 0 & 1 & 0.985 & -13.41 & 0 & 1 & 1.06 & 0.94 ; \\ 38 & 1 & 14 & 7 & 0 & 0 & 1 & 1.013 & -12.71 & 0 & 1 & 1.06 & 0.94 ; \\ 39 & 1 & 0 & 0 & 0 & 0 & 1 & 0.983 & -13.46 & 0 & 1 & 1.06 & 0.94 ; \\ 40 & 1 & 0 & 0 & 0 & 0 & 1 & 0.973 & -13.62 & 0 & 1 & 1.06 & 0.94 ; \\ 41 & 1 & 6.3 & 3 & 0 & 0 & 1 & 0.996 & -14.05 & 0 & 1 & 1.06 & 0.94 ; \\ 42 & 1 & 7.1 & 4.4 & 0 & 0 & 1 & 0.966 & -15.5 & 0 & 1 & 1.06 & 0.94 ; \\ 43 & 1 & 2 & 1 & 0 & 0 & 1 & 1.01 & -11.33 & 0 & 1 & 1.06 & 0.94 ; \\ 44 & 1 & 12 & 1.8 & 0 & 0 & 1 & 1.017 & -11.86 & 0 & 1 & 1.06 & 0.94 ; \\ 45 & 1 & 0 & 0 & 0 & 0 & 1 & 1.036 & -9.25 & 0 & 1 & 1.06 & 0.94 ; \\ 46 & 1 & 0 & 0 & 0 & 0 & 1 & 1.05 & -11.89 & 0 & 1 & 1.06 & 0.94 ; \\ 47 & 1 & 29.7 & 11.6 & 0 & 0 & 1 & 1.033 & -12.49 & 0 & 1 & 1.06 & 0.94 ; \\ 48 & 1 & 0 & 0 & 0 & 0 & 1 & 1.027 & -12.59 & 0 & 1 & 1.06 & 0.94 ; \\ 49 & 1 & 18 & 8.5 & 0 & 0 & 1 & 1.036 & -12.92 & 0 & 1 & 1.06 & 0.94 ; \\ 50 & 1 & 21 & 10.5 & 0 & 0 & 1 & 1.023 & -13.39 & 0 & 1 & 1.06 & 0.94 ; \\ 51 & 1 & 18 & 5.3 & 0 & 0 & 1 & 1.052 & -12.52 & 0 & 1 & 1.06 & 0.94 ; \\ 52 & 1 & 4.9 & 2.2 & 0 & 0 & 1 & 0.98 & -11.47 & 0 & 1 & 1.06 & 0.94 ; \\ 53 & 1 & 20 & 10 & 0 & 6.3 & 1 & 0.971 & -12.23 & 0 & 1 & 1.06 & 0.94 ; ; \\ 54 & 1 & 4.1 & 1.4 & 0 & 0 & 1 & 0.996 & -11.69 & 0 & 1 & 1.06 & 0.94 ; \\ 55 & 1 & 6.8 & 3.4 & 0 & 0 & 1 & 1.031 & -10.78 & 0 & 1 & 1.06 & 0.94 ; \\ 56 & 1 & 7.6 & 2.2 & 0 & 0 & 1 & 0.968 & -16.04 & 0 & 1 & 1.06 & 0.94 ; \\ 57 & 1 & 6.7 & 2 & 0 & 0 & 1 & 0.965 & -16.56 & 0 & 1 & 1.06 & 0.94 ; ;\end{array}$

$\begin{array}{cccccccccc}1 & 128.9 & -16.1 & 200 & -140 & 1.04 & 100 & 1 & 575.88 & 0 ; \\ 2 & 0 & -0.8 & 50 & -17 & 1.01 & 100 & 1 & 100 & 0 ; \\ 3 & 40 & -1 & 60 & -10 & 0.985 & 100 & 1 & 140 & 0 ; \\ 6 & 0 & 0.8 & 25 & -8 & 0.98 & 100 & 1 & 100 & 0 ; \\ 8 & 450 & 62.1 & 200 & -140 & 1.005 & 100 & 1 & 550 & 0 ; \\ 9 & 0 & 2.2 & 9 & -3 & 0.98 & 100 & 1 & 100 & 0 ; \\ 12 & 310 & 128.5 & 155 & -150 & 1.015 & 100 & 1 & 410 & 0 ;\end{array}$

\begin{tabular}{|c|c|c|c|c|c|c|c|c|c|}
\hline 1 & 2 & 0.0083 & 0.028 & 0.129 & 9900 & 0 & 0 & 0 & 0 \\
\hline 2 & 3 & 0.0298 & 0.085 & 0.0818 & 9900 & 0 & 0 & 0 & 0 \\
\hline 3 & 4 & 0.0112 & 0.0366 & 0.038 & 9900 & 0 & 0 & 0 & 0 \\
\hline 4 & 5 & 0.0625 & 0.132 & 0.0258 & 9900 & 0 & 0 & 0 & 0 \\
\hline 4 & 6 & 0.043 & 0.148 & 0.0348 & 9900 & 0 & 0 & 0 & 0 \\
\hline 6 & 7 & 0.02 & 0.102 & 0.0276 & 9900 & 0 & 0 & 0 & 0 \\
\hline 6 & 8 & 0.0339 & 0.173 & 0.047 & 9900 & 0 & 0 & 0 & 0 \\
\hline 8 & 9 & 0.0099 & 0.0505 & 0.0548 & 9900 & 0 & 0 & 0 & 0 \\
\hline 0 & 10 & 0.0369 & 0.1679 & 0.044 & 9900 & 0 & 0 & 0 & 0 \\
\hline 9 & 11 & 0.0258 & 0.0848 & 0.0218 & 9900 & 0 & 0 & 0 & 0 \\
\hline
\end{tabular}




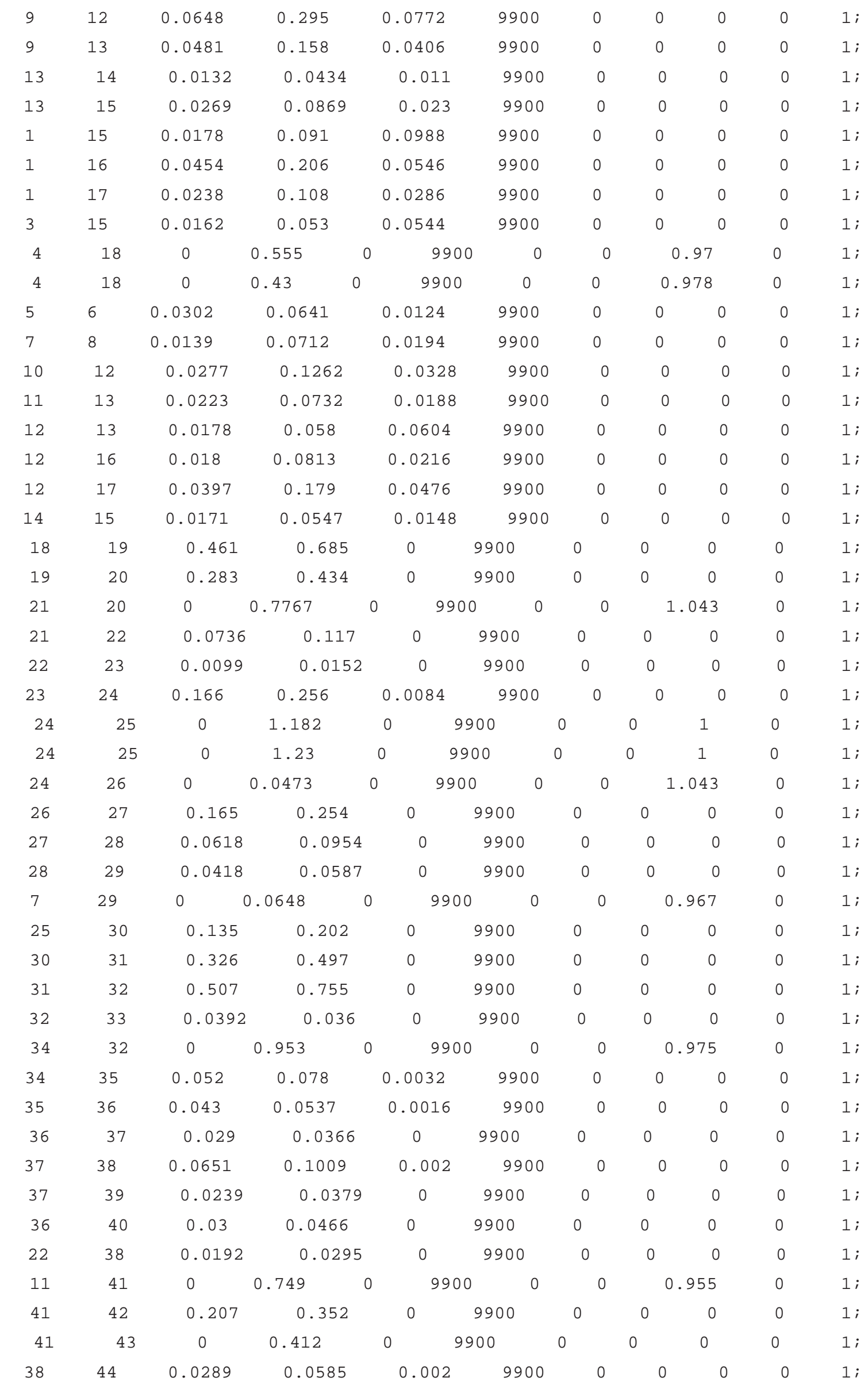




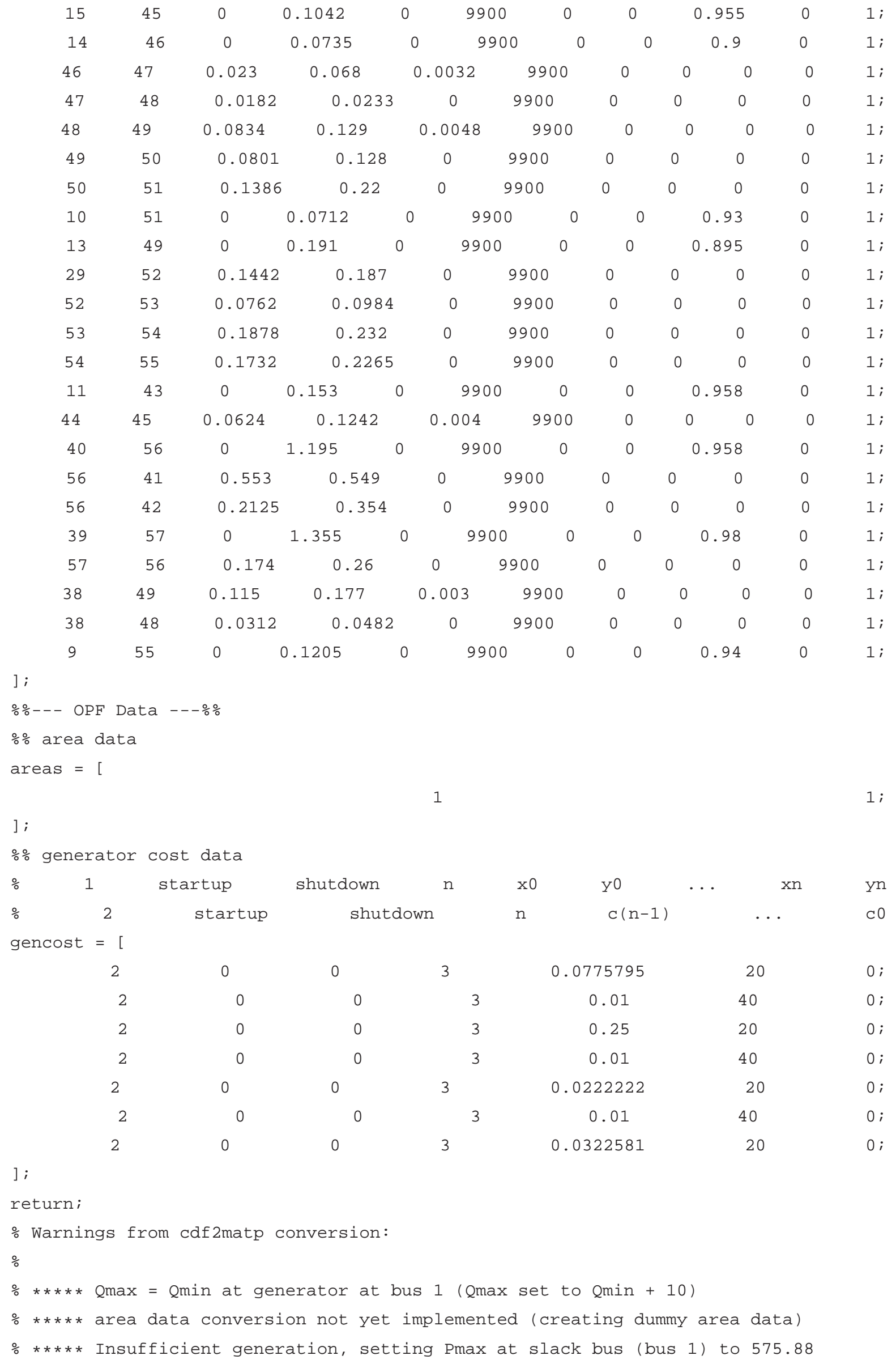


\% $\star \star \star \star \star *$ MVA limit of branch 1 - 2 not given, set to 9900

\% $\star \star \star \star *$ MVA limit of branch 2 - 3 not given, set to 9900

\% $* * * *$ MVA limit of branch 3 - 4 not given, set to 9900

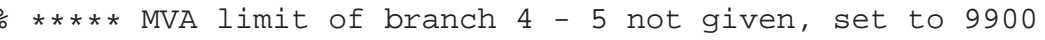

$\div * \star \star * *$ MVA limit of branch 4 - 6 not given, set to 9900

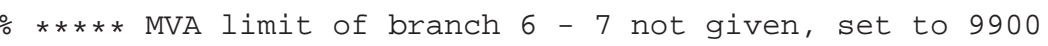

ㅇ $* * \star \star *$ MVA limit of branch 6 - 8 not given, set to 9900

ㅇ $* * * * *$ MVA limit of branch 8 - 9 not given, set to 9900

\% $* * \star * *$ MVA limit of branch 9 - 10 not given, set to 9900

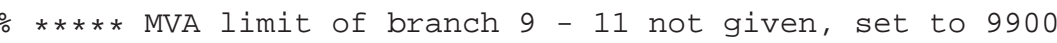

ㅇ $* * \star \star *$ MVA limit of branch 9 - 12 not given, set to 9900

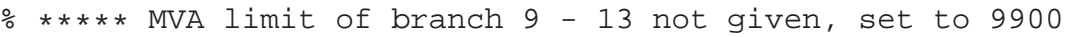

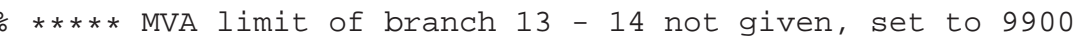

\% $* * * * *$ MVA limit of branch 13 - 15 not given, set to 9900

\% $* \star \star \star *$ MVA limit of branch 1 - 15 not given, set to 9900

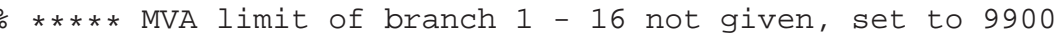

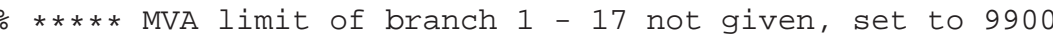

\% $* * * * *$ MVA limit of branch 3 - 15 not given, set to 9900

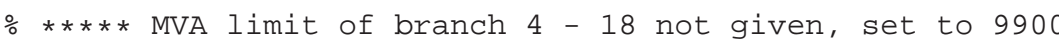

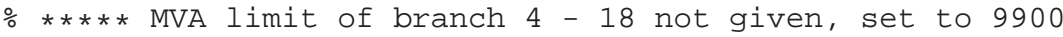

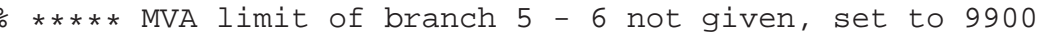

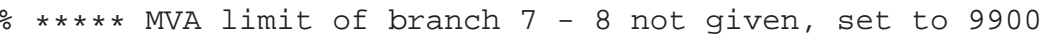

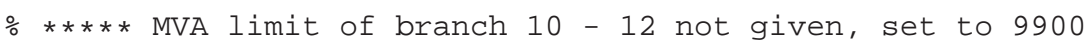

\% $\star * \star \star *$ MVA limit of branch 11 - 13 not given, set to 9900

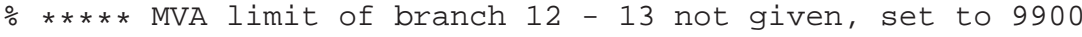

읓*** MVA limit of branch 12 - 16 not given, set to 9900

\% $\star * \star \star *$ MVA limit of branch 12 - 17 not given, set to 9900

\% $* * * \star *$ MVA limit of branch 14 - 15 not given, set to 9900

$\circ * \star \star * *$ MVA limit of branch 18 - 19 not given, set to 9900

ㅇ $* \star \star \star *$ MVA limit of branch 19 - 20 not given, set to 9900

\% $* * * * *$ MVA limit of branch 21 - 20 not given, set to 9900

\% $* * \star \star *$ MVA limit of branch 21 - 22 not given, set to 9900

ㅇ $* * * *$ MVA limit of branch 22 - 23 not given, set to 9900

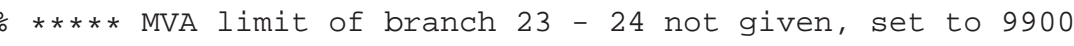

읓 $* \star * \star$ MVA limit of branch 24 - 25 not given, set to 9900

ㅇ $* * * * *$ MVA limit of branch 24 - 25 not given, set to 9900

ㅇ $* * \star \star *$ MVA limit of branch 24 - 26 not given, set to 9900

ㅇ $* \star \star \star \star$ MVA limit of branch 26 - 27 not given, set to 9900

ㅇ $* \star \star \star *$ MVA limit of branch 27 - 28 not given, set to 9900

。 $\star * \star \star \star$ MVA limit of branch 28 - 29 not given, set to 9900

o $* \star \star \star *$ MVA limit of branch 7 - 29 not given, set to 9900

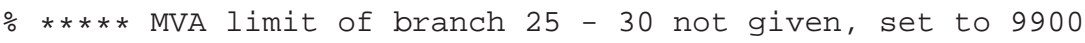

\% $* * * *$ MVA limit of branch 30 - 31 not given, set to 9900

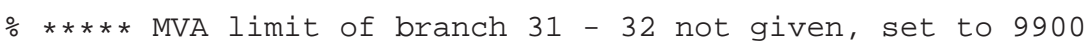

읓 $* * *$ MVA limit of branch 32 - 33 not given, set to 9900

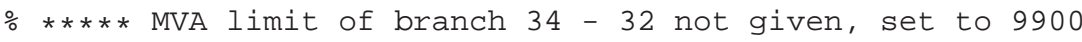

$\circ * \star * * *$ MVA limit of branch 34 - 35 not given, set to 9900 


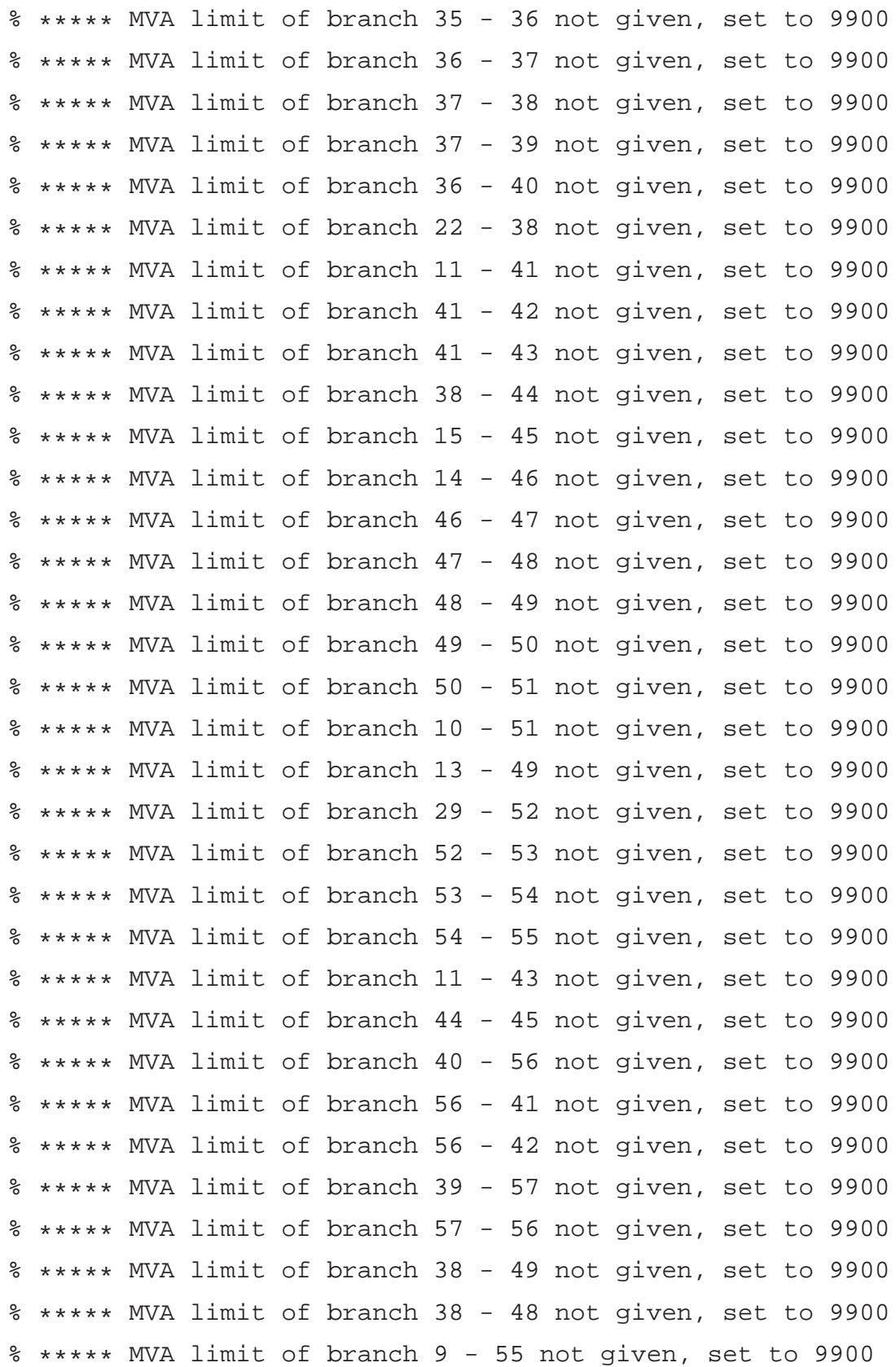




\section{PRINCIPAIS CÓDIGOS ADAPTADOS DO MATPOWER}

\section{II.1 NEWTONPF.M}

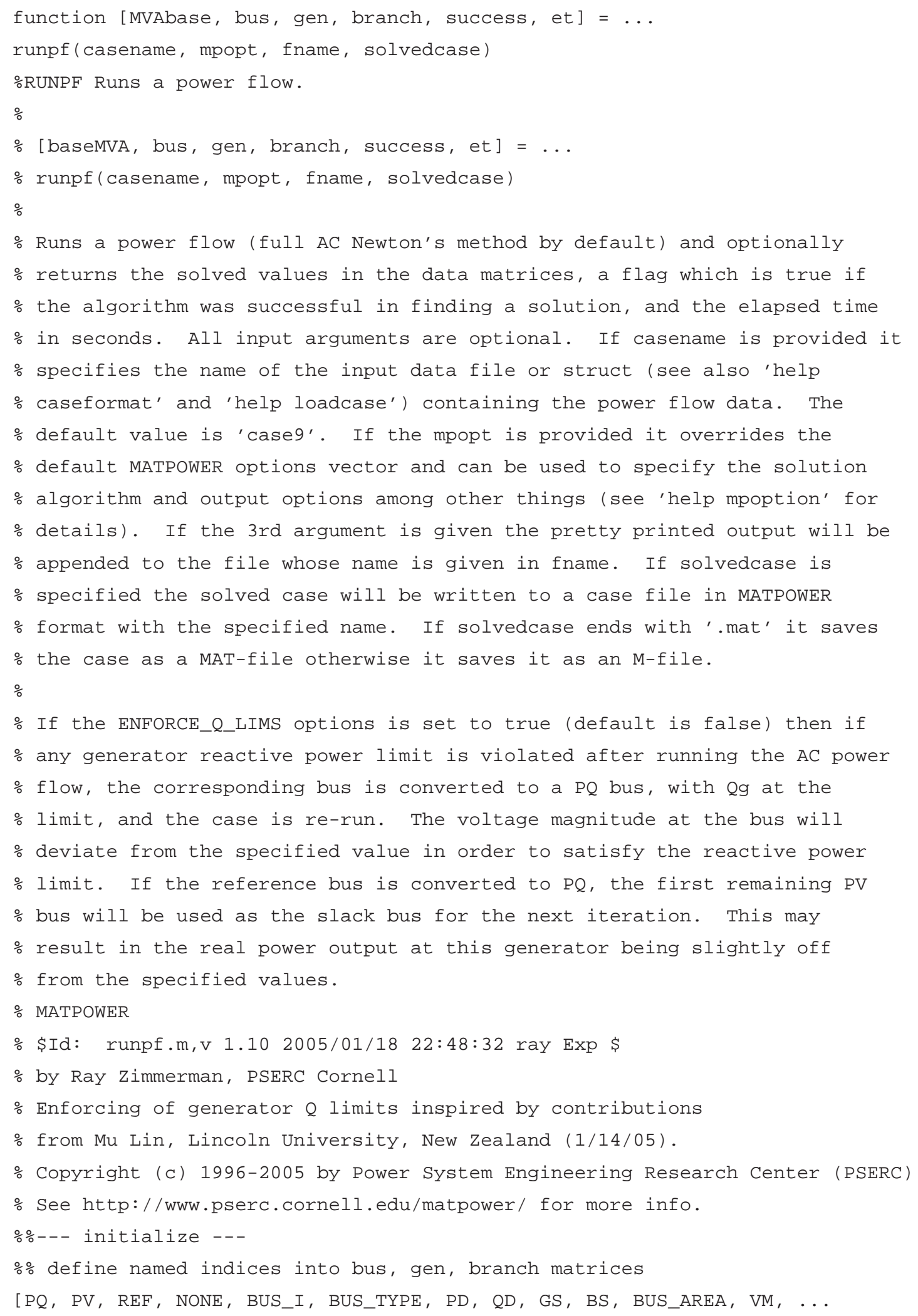




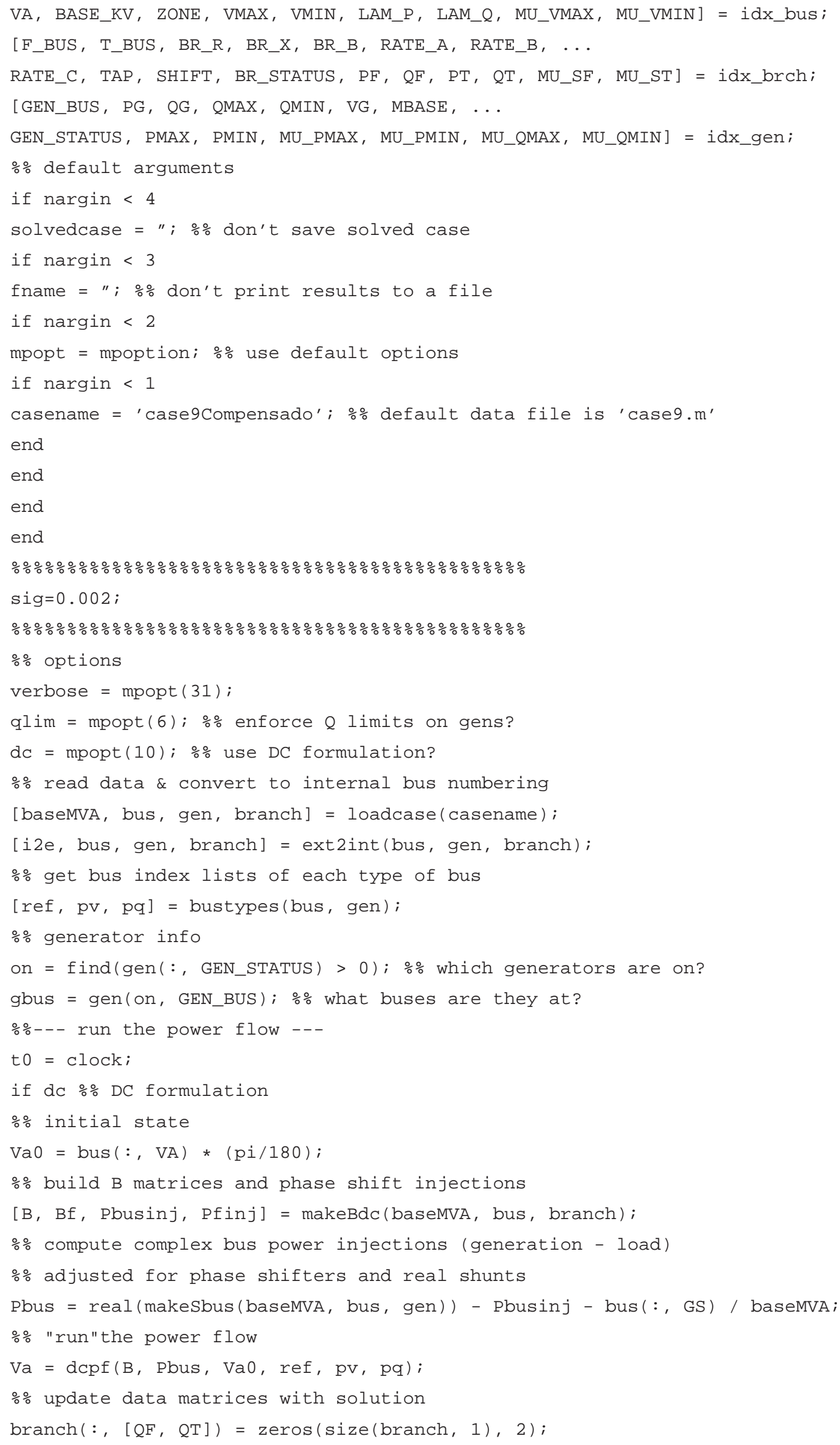




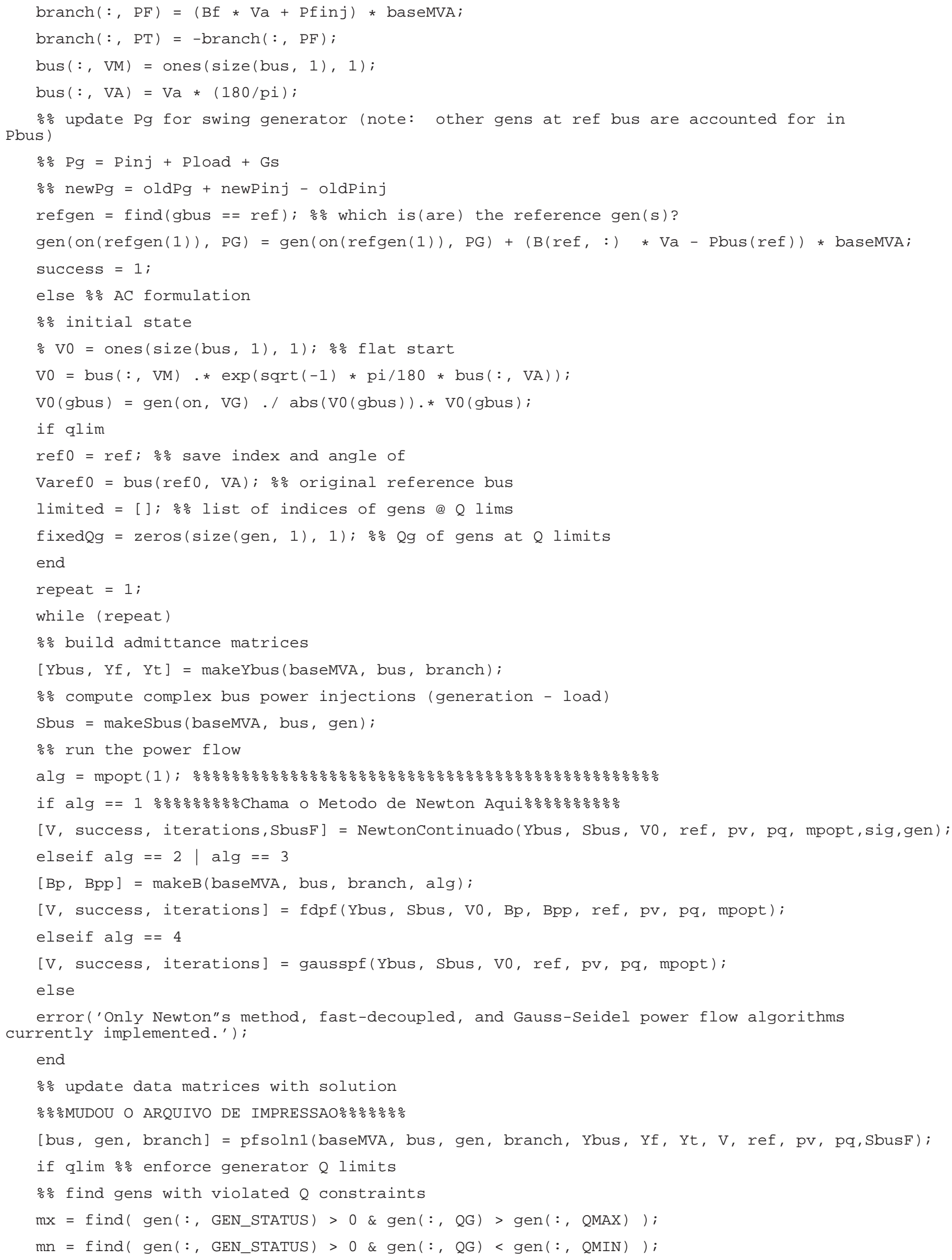




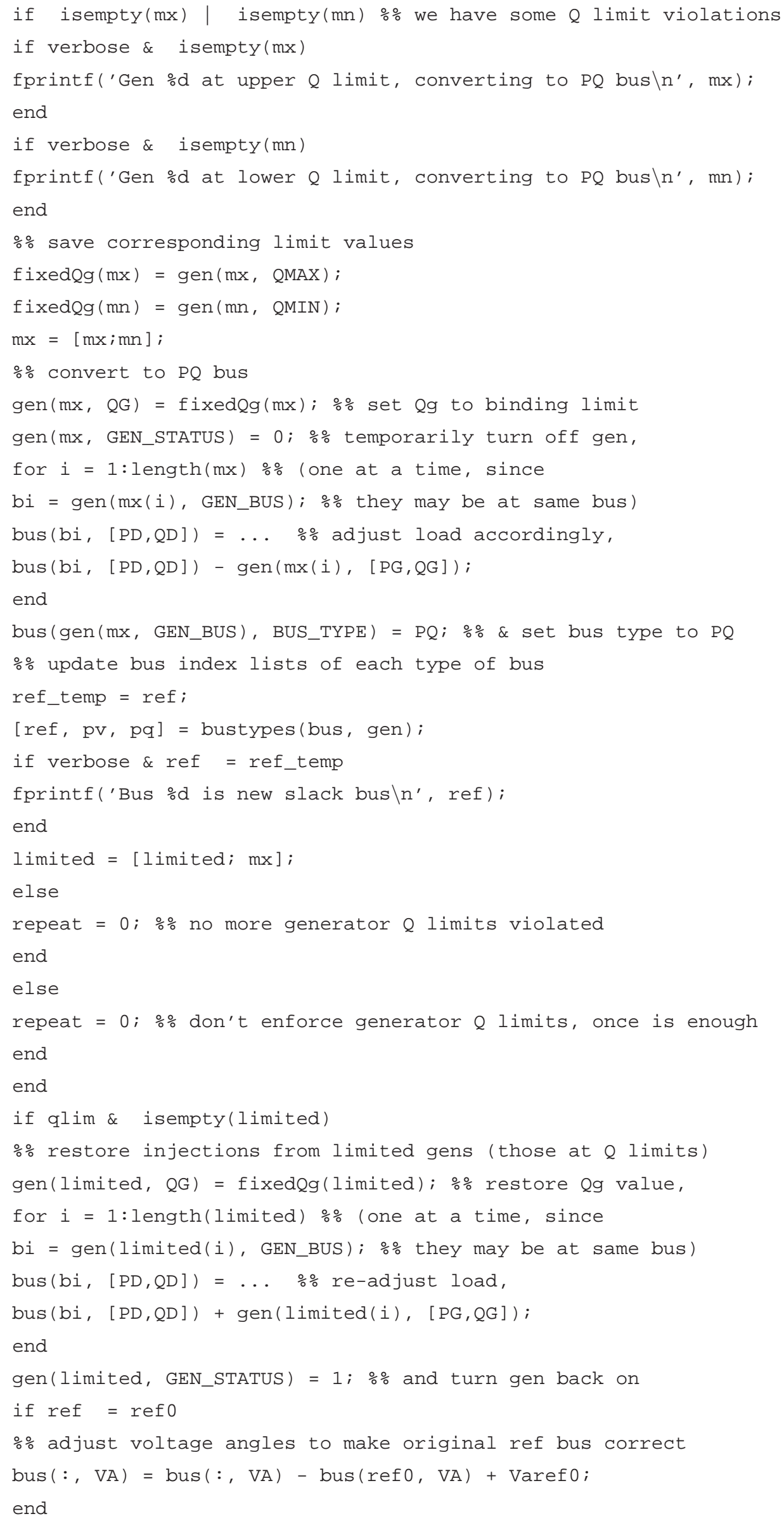




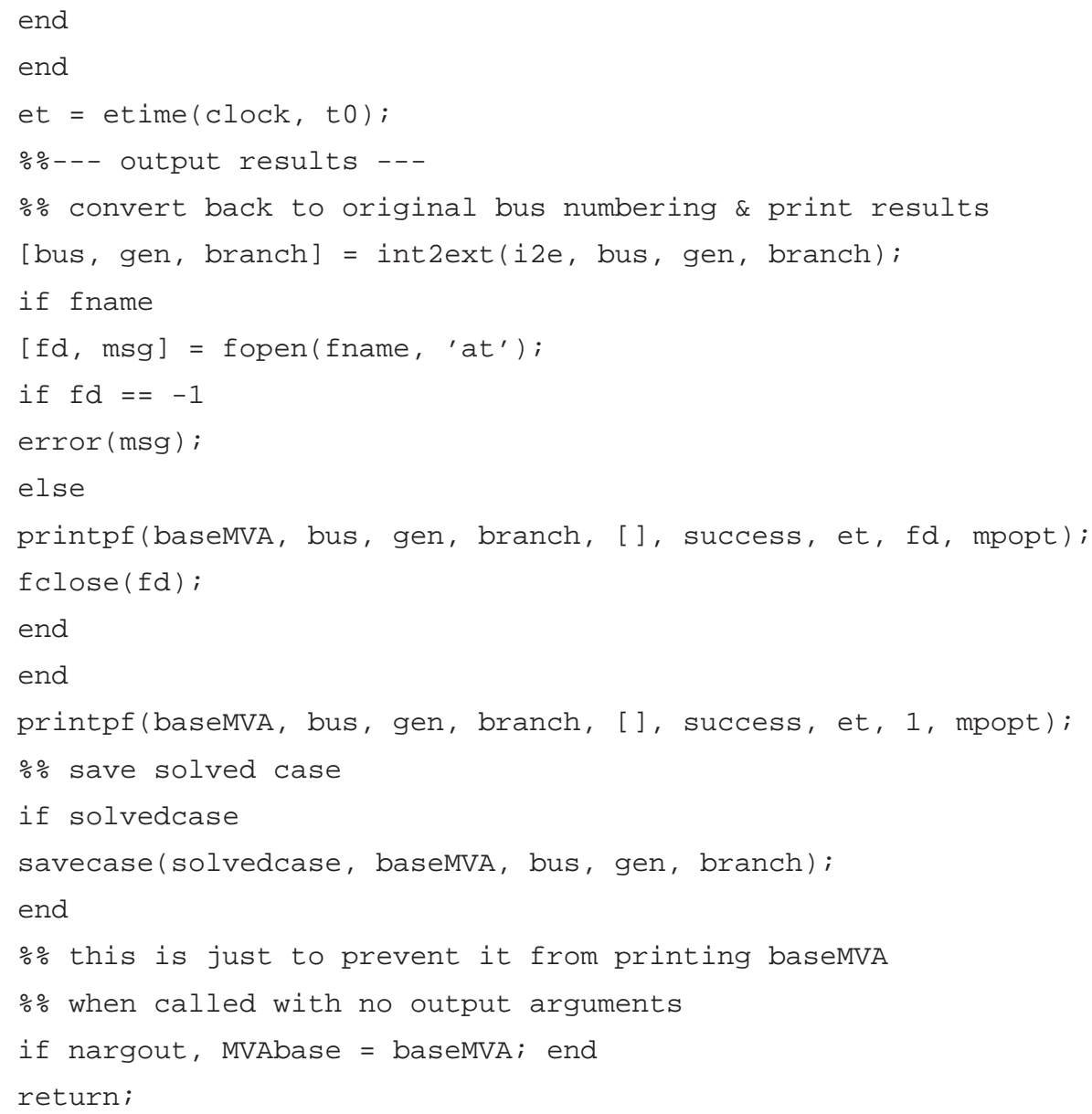

\section{II.2 NEWTONCONTINUADO.M}

function [V, converged, i,SbusF] = NewtonContinuado(Ybus, Sbus, vo, ref, pv, pq, mpopt, sig, gen) oNEWTONPF Solves the power flow using a full Newton's method.

이, converged, i] = newtonpf (Ybus, Sbus, Vo, ref, pv, pq, mpopt)

\% solves for bus voltages given the full system admittance matrix (for

이 buses), the complex bus power injection vector (for all buses),

\% the initial vector of complex bus voltages, and column vectors with

응 the lists of bus indices for the swing bus, PV buses, and PQ buses,

o respectively. The bus voltage vector contains the set point for

\% generator (including ref bus) buses, and the reference angle of the

o swing bus, as well as an initial guess for remaining magnitudes and

o angles. mpopt is a MATPOWER options vector which can be used to

o set the termination tolerance, maximum number of iterations, and

o output options (see 'help mpoption' for details). Uses default

\% options if this parameter is not given. Returns the final complex

o voltages, a flag which indicates whether it converged or not, and

\% the number of iterations performed.

MATPOWER

잉 newtonpf.m,v 1.6 2005/01/14 17:22:23 ray Exp \$

ㅇ by Ray zimmerman, PSERC Cornell 


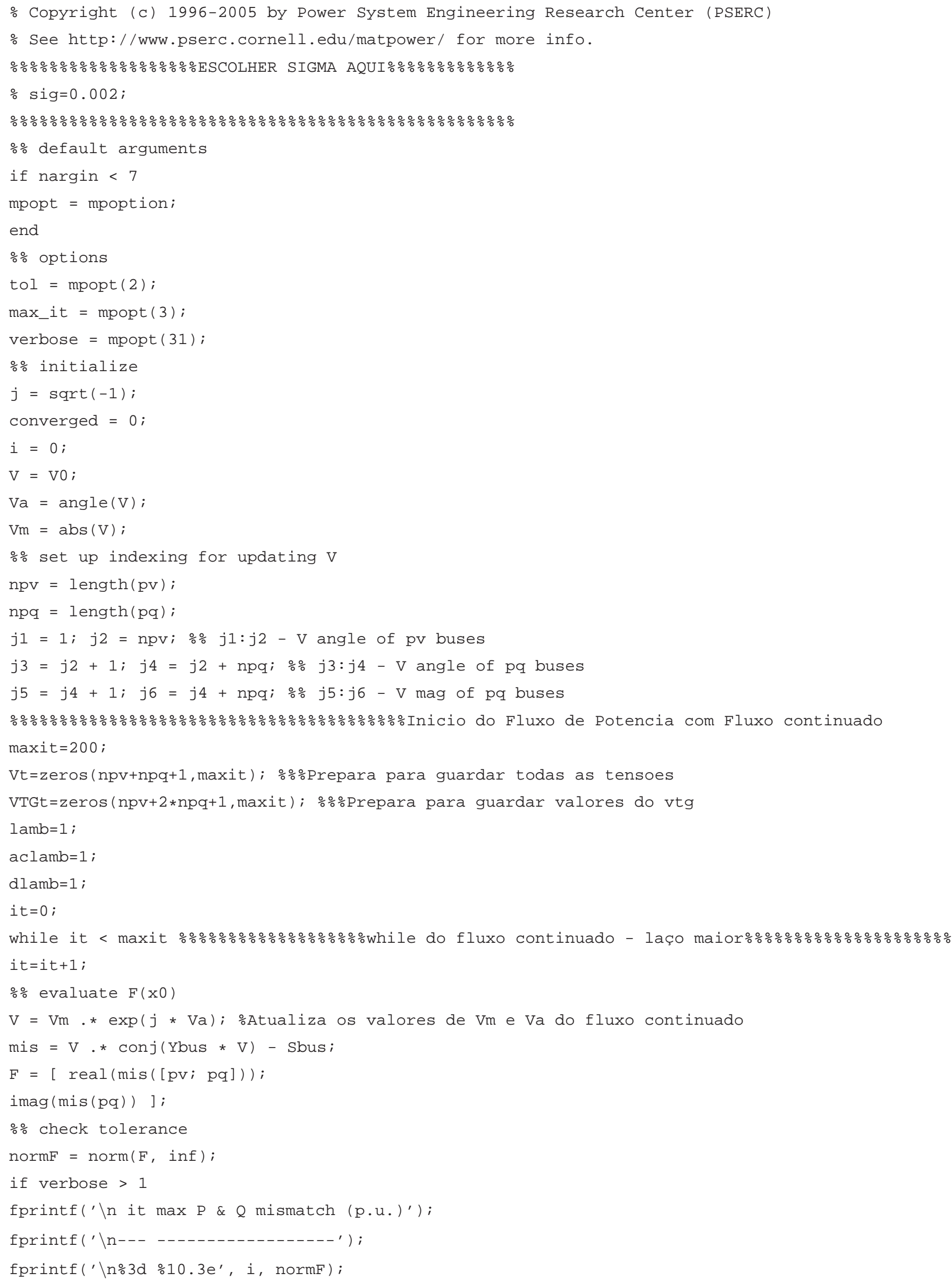




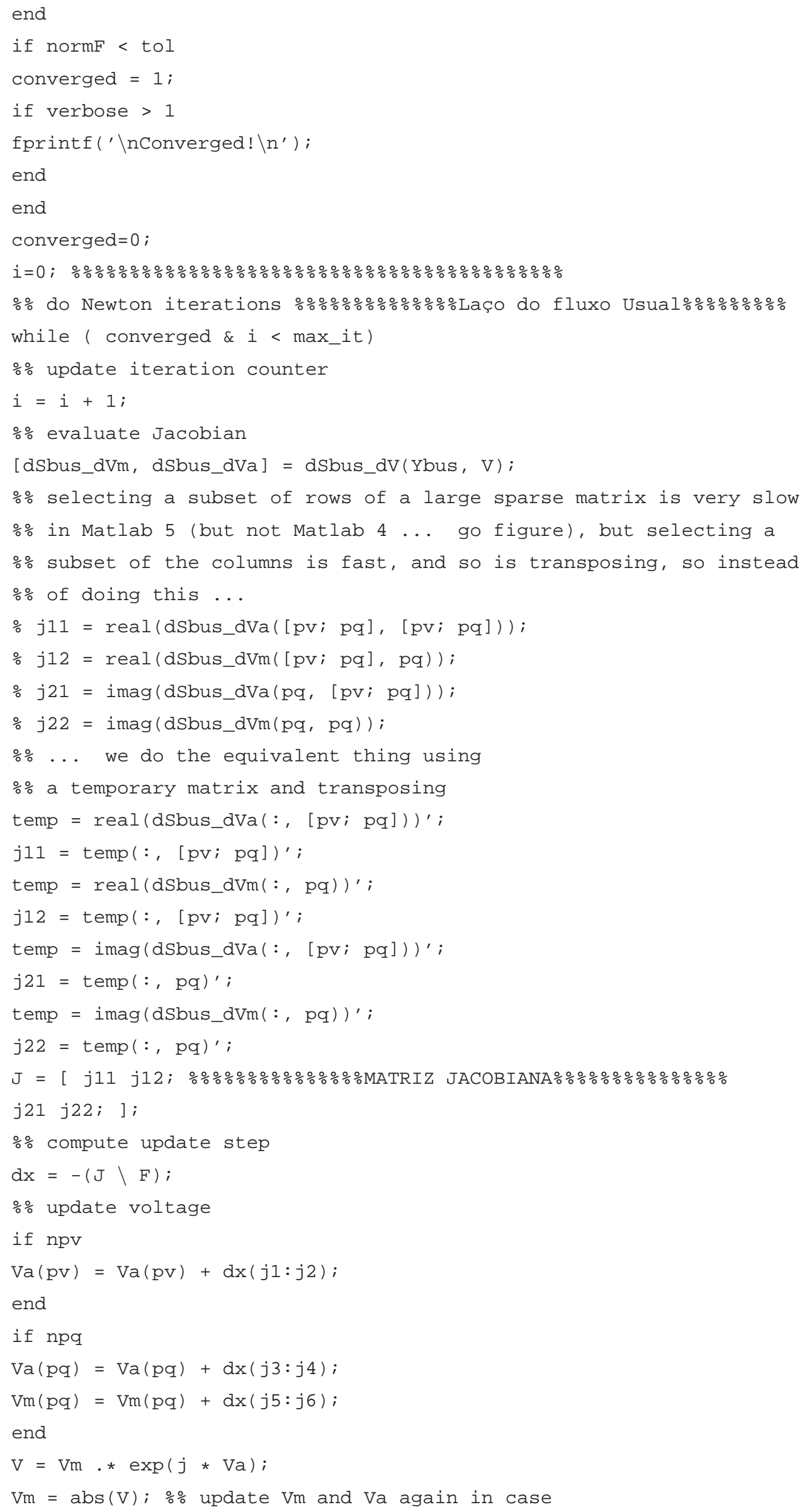




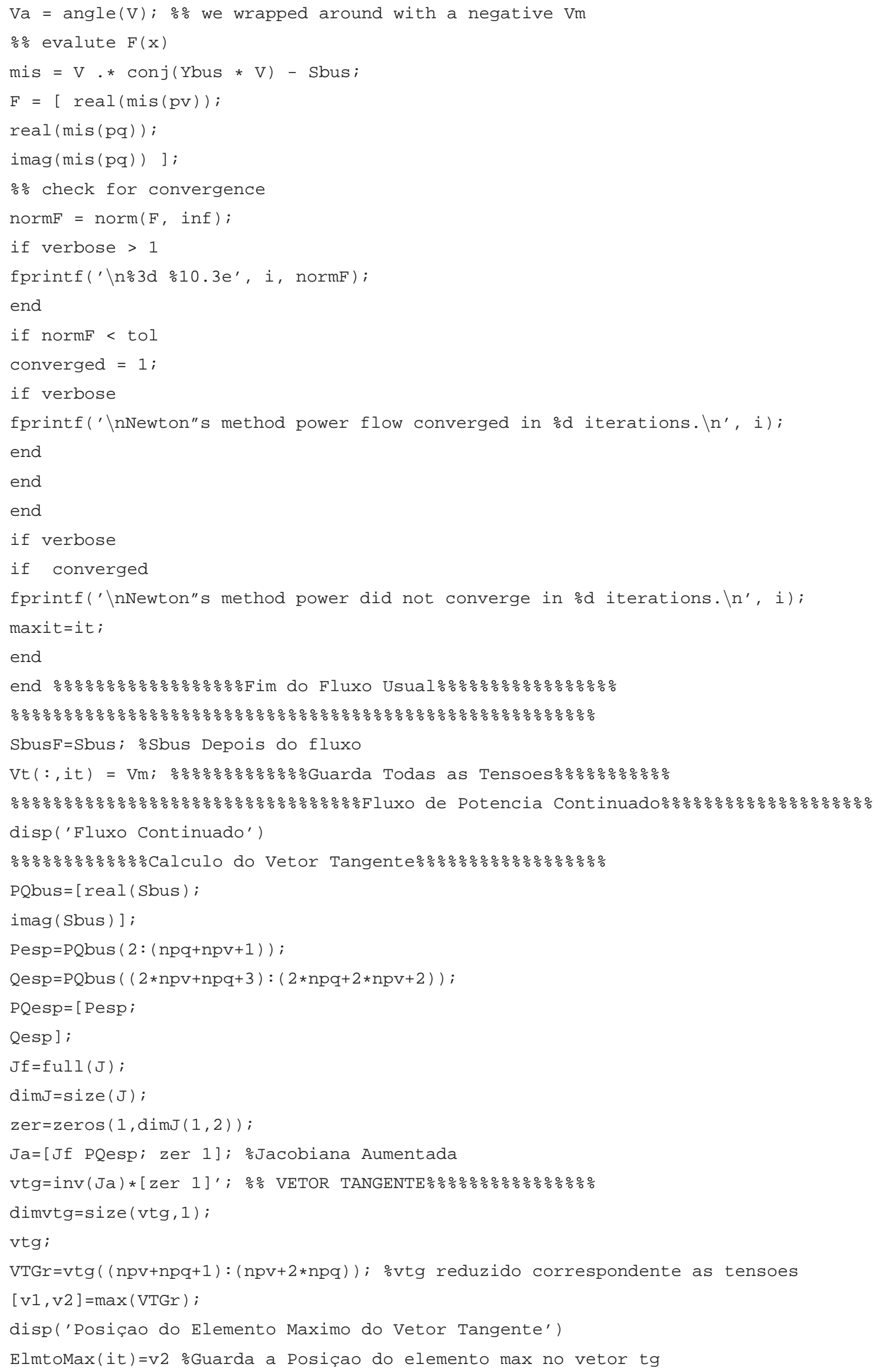




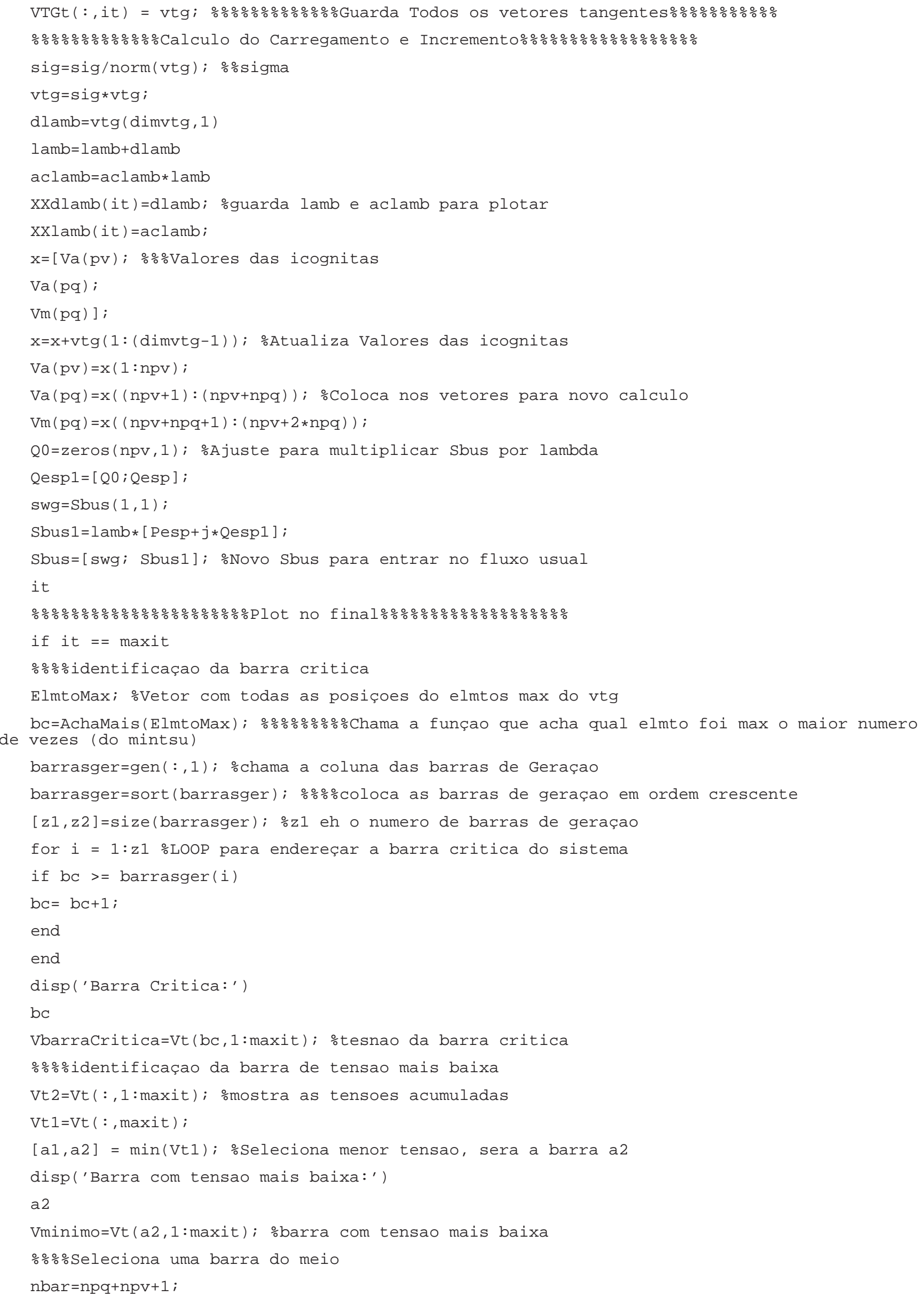




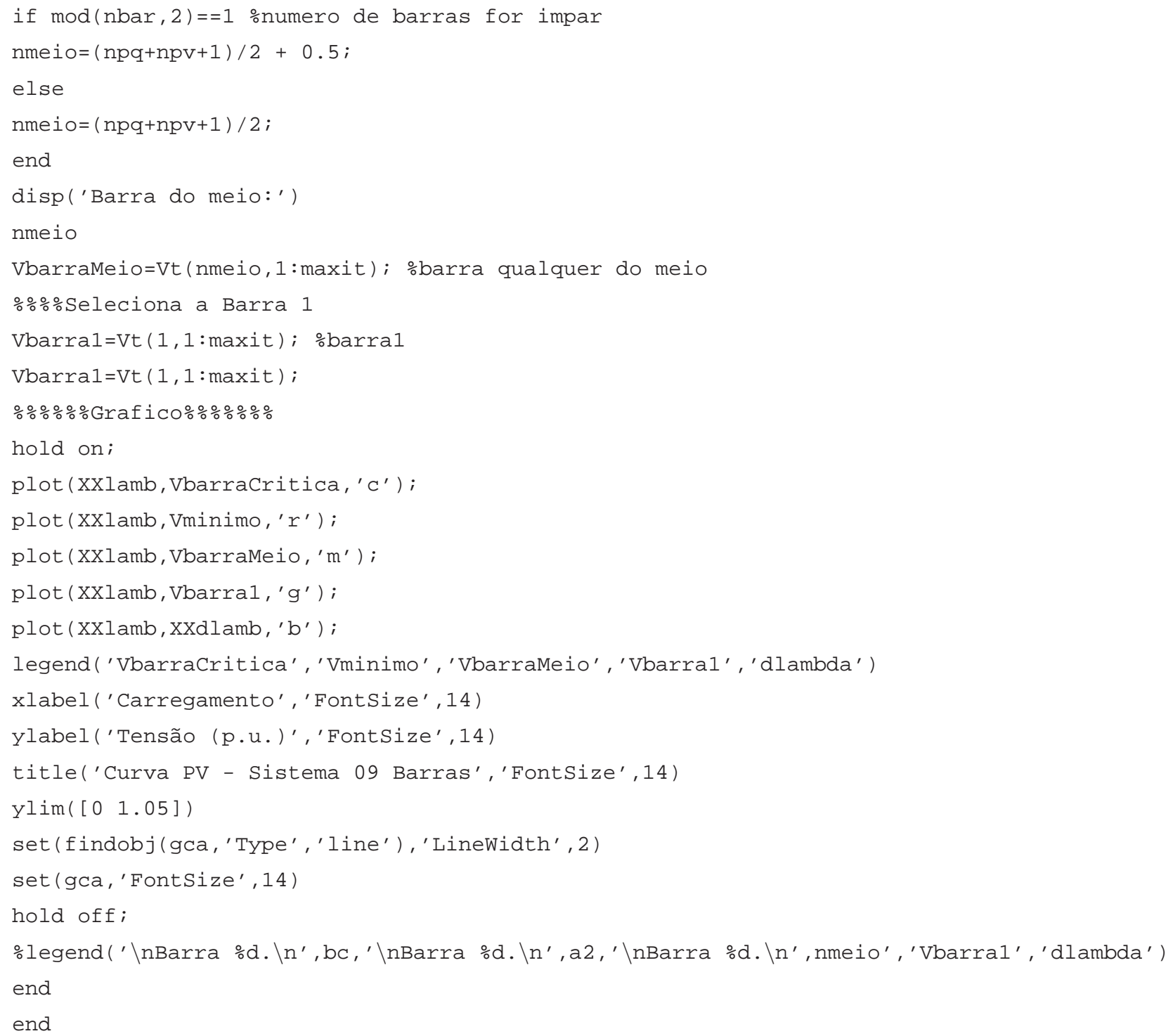

